Universidade de São Paulo - USP
Faculdade de Ciências Farmacêuticas de Ribeirão Preto - FCFRP

Isolamento e caracterização bioquímica e funcional de L-aminoácido oxidase do veneno de Bothrops atrox

Raquel de Melo Alves

Ribeirão Preto

$-2007-$ 


\title{
Isolamento e caracterização bioquímica e funcional de L-aminoácido oxidase do veneno de Bothrops atrox
}

\author{
Dissertação de Mestrado apresentada ao \\ Programa de Pós-Graduação em Toxicologia \\ para obtenção do título de Mestre em \\ Toxicologia, Área de concentração: \\ Toxicologia.
}

Orientada: Raquel de Melo Alves Orientadora: Prof ${ }^{\mathrm{a}} \mathrm{Dr}^{\mathrm{a}}$ Suely Vilela

\section{RIBEIRÃO PRETO}




\section{AUTORIZO A REPRODUÇÃO TOTAL OU PARCIAL DESTE TRABALHO, POR QUALQUER MEIO CONVENCIONAL OU ELETRÔNICO, PARA FINS DE ESTUDO E PESQUISA, DESDE QUE CITADA A FONTE.}

\section{FICHA CATALOGRÁFICA}

Alves, Raquel de Melo

Isolamento e Caracterização bioquímica e funcional de L-aminoácido oxidase do veneno de Bothrops atrox. Ribeirão Preto, 2007

$110 \mathrm{p}$.

Dissertação de Mestrado apresentada à Faculdade de Ciências Farmacêuticas de Ribeirão Preto / USP - Área de Concentração: Toxicologia

Orientadora: Sampaio, Suely Vilela.

1. L-aminoácido oxidase. 2. Bothrops atrox. 3. Atividade citotóxica 4. Apoptose 


\section{FOLHA DE APROVAÇÃO}

Autora: Raquel de Melo Alves

Título: Isolamento e Caracterização bioquímica e funcional de L-aminoácido oxidase do veneno de Bothrops atrox

Dissertação de Mestrado apresentada ao Programa de Pós-Graduação em Toxicologia para obtenção do título de Mestre em Toxicologia, Área de concentração: Toxicologia.

BANCA EXAMINADORA

$\operatorname{Prof}(\mathrm{a}) . \operatorname{Dr}(\mathrm{a})$.

Instituição___ Assinatura

$\operatorname{Prof}(\mathrm{a}) . \operatorname{Dr}(\mathrm{a})$.

Instituição Assinatura

$\operatorname{Prof}(\mathrm{a}) . \operatorname{Dr}(\mathrm{a})$.

Instituição Assinatura

Trabalho defendido e aprovado pela Comissão Julgadora em ................. 


\section{DEDICATÓRIA}


Este trabalho é dedicado exclusivamente a duas pessoas que amo demais, pessoas que me fazem muita falta, que me ensinaram tudo o que hoje sei, que cuidam de mim, mesmo quando estou longe... e que me amam. PAI e MÃE, penso em vocês todos os dias e sinto uma saudade que ninguém pode entender o tamanho. AMO VOCÊS! 
A Deus. Não há palavras para este agradecimento. Minha fonte de vida, meu amparo, meu escudo.

À Profa. Dra. Suely Vilela, pela orientação deste trabalho, oportunidade de aperfeiçoamento, maturidade profissional e pelo exemplo de profissionalismo e determinação.

Aos colegas de laboratório: Lorane, Fábio, Paulinha, Xicrão e agora a Raquelzinha e tantos outros que, de alguma forma, entraram em minha vida. Obrigada a todos vocês pelo carinho e ajuda.

À Gi, que muito me ajudou na finalização da minha dissertação, me dando apoio moral, levantando meu astral e, de certa forma, compreendendo meu estresse.

À Elaine, minha querida "mãe", companheira e amiga. Às vezes Deus coloca pessoas em nossas vidas que não podemos entender no começo, mas, no fỉm, fica tudo muito claro. A Elaine foi uma pessoa de fundamental importância para minha mais nova formação, quem me ajudou a levantar, enxugar as lágrimas quando necessário e a sorrir sem medida. Uma pessoa que lutava pelos meus sonhos como se fosse eu mesma e que acreditava em mim, no meu futuro, no meu trabalho, na pessoa que eu sou. Amo você, de coração!! Simplesmente obrigada!

À Adélia, que tanto me ajudou profissionalmente, me mostrando as melhores vias para finalização deste trabalho. Agüentou a mim todo esse tempo com carinho e com broncas, houve dias que ela não queria me ver pintada de ouro...mas lá estava eu...todos os dias!!! Você sempre foi uma companheira, muito obrigada!

Ao Franco, que esteve sempre disposto a colaborar no desenvolvimento do meu trabalho, ajudando tecnicamente. Uma pessoa que, muitas vezes, ouvia meus sonhos e me mandava torná-los reais. Obrigada, Franco, por seu carinho e dedicação. 
Ao professor Dr. Andreimar Soares e sua equipe de laboratório especialmente Carol e Clayton.

À professora Dra. Eliane Candiani por seu carinho e tempo em me atender quando eu corria e pedia por socorro. Pela colaboração e acréscimo de sugestões ao meu trabalho. À Dani, que me ajudou, me explicou, me deu livros para ler e acima de tudo incentivou todo meu interesse pela pesquisa.

Ao professor Dr. Marcelo Dias Baruffi pelo carinho, atenção, dedicação, por me receber toda semana em seu laboratório. Obrigada professor por ser tão especial. À toda sua equipe: "Ktaldi”, “Chelize”, "Fifi”, Natália, "Ju”, Michele, "Rubinho" e Helder. À vocês, meu agradecimento simplesmente por terem feito parte da minha vida nesse pouco tempo. Aprendemos a conviver tanto dentro quanto fora do laboratório, sem contar nossas sociais semanais, o que nos aproximou bastante.

Ao professor Dr. José César Rosa e outros colaboradores que contribuíram para a conclusão deste trabalho.

À minha avó, super vó, Lourdes, mulher sábia que tem experiências de sobra para compartilhar e ensinar que a vida não se baseia somente nisso ou naquilo, existe sempre coisas mais importantes para se ocupar e preocupar. Às minhas tias Fran e Pas pela amizade, companheirismo, tia Fran por ser minha amiga, por me aconselhar, por perceber o porquê de minhas tristezas e sempre me dar uma idéia diferente.

À minha família que é a base de tudo o que sou hoje. Aos meus pais, que são meu orgulho, pessoas que, após 30 anos de casados são eternos namorados, dando o exemplo do verdadeiro amor, da verdadeira união. Meu pai, um homem inteligente visando sempre ao nosso futuro e, minha mãe, mulher sábia, cheia de emoções e sentimentos por ficarmos tão longe. Pai e mãe: Valeu a pena! Muito obrigada por seus esforços, por me sustentarem aqui, por me apoiarem, por me ouvirem chorar, por simplesmente me abraçarem no momento 
certo e dizerem palavras certas, por acreditarem em mim mesmo quando eu mesma desacreditei. EU AMO VOCÊS.

Aos meus queridos irmãos Rafael e Ricardo e minhas cunhas Déa e Luca. Essas pessoas são motivos de alegria, de luta, de conquista dos meus sonhos. São pessoas maravilhosas, meus amigos, que sempre me incentivam e acima de tudo, me amam de verdade. Obrigada meus queridos pelo apoio, pelos telefonemas, pelo carinho.

Ao Helder, um agradecimento especial por ser meu amigo, meu companheiro, meu namorado, por acreditar em mim ("você não precisa de sorte porque você é muito capaz"), por me fazer sorrir e me incentivar a lutar, ir de encontro com meu maior sonho. Obrigada pelo amor, compreensão, carinho e profissionalismo. Pelos gráficos, leituras de papers, noites de sono perdidas, por todo incentivo. Obrigada por fazer parte dessa nova vitória. Não havia hora mais certa para Deus te colocar em minha vida. TE ADORO MUITO!!Obrigada!

Aos meus amigos de modo geral, de Ribeirão Preto e Campo Grande que não citei os nomes, muito obrigada pela amizade e pelos bons momentos que sempre me proporcionaram, fazendo com que meus dias fossem de muita alegria e tranqüilidade.

Aos funcionários da Faculdade de Ciências Farmacêuticas de Ribeirão Preto, desde as secretárias, os porteiros e seguranças até os responsáveis pela limpeza dos laboratórios, que estavam sempre dispostos e com sorriso no rosto, incentivando-me em vários dias de desânimo.

Às fundações FAPESP, CAPES, CNPq pelo auxílio financeiro, proporcionando a realização do meu trabalho. 
ALVES, R.M. Isolamento e caracterização bioquímica e funcional de L-aminoácido oxidase do veneno de Bothrops atrox. 2007. 110p. Dissertação (Mestrado) - Faculdade de Ciências Farmacêuticas de Ribeirão Preto, Universidade de São Paulo, 2007.

Os venenos de serpentes são ricos em proteínas, enzimas e peptídeos biologicamente ativos. Diversas enzimas tais como fosfolipases $\mathrm{A}_{2} \quad\left(\mathrm{PLA}_{2} \mathrm{~s}\right)$, metaloproteases (MP), L-aminoácido oxidases (LAAOs) são responsáveis pelo quadro clínico do envenenamento ofídico. Atualmente, o isolamento e a caracterização funcional e estrutural destas enzimas têm auxiliado na compreensão do mecanismo de ação destas toxinas e nas formas alternativas de tratamento. Além disso, estas enzimas se tornaram valiosas ferramentas de aplicação biotecnológica, na busca de novos fármacos de interesse na clínica médica. O objetivo deste trabalho foi isolar e caracterizar bioquímica e funcionalmente a L-aminoácido oxidase do veneno de Bothrops atrox. O isolamento da LAAO de B. atrox (LAAOBatrox) envolveu três etapas cromatográficas: a exclusão molecular em Sephadex G-75, troca iônica em ES-502N utilizando CLAE e, por último, a cromatografia de afinidade com uso da Lentil-Lectina, conferindo um alto grau de pureza à proteína confirmado por SDS-PAGE. Após a caracterização bioquímica, a LAAOBatrox demonstrou ser uma glicoproteína com 12\% de açúcar, massa molecular relativa de 67.000 e pI de 4,4 confirmando seu caráter ácido pela composição em aminoácidos, predominando Asx (Ácido aspártico ou asparagina) e Glx (Ácido glutâmico ou glutamina). LAAOBatrox apresentou especificidade de substrato para L-Met e L-Leu. Com o seqüenciamento dos peptídeos trípticos internos e em comparação com as LAAOs de outros venenos, a LAAOBatrox apresentou homologia de $100 \%$ com LAAOs isoladas de B. moojeni e $B$. jararacussu e apresentou sequenciamento N-terminal de ADDN-NPLEE-NIRRDD que é homólogo ao das LAAOs já descritas. A LAAOBatrox apresentou atividade edematogênica moderada quando comparada ao veneno bruto, atividade coagulante baixa sobre o plasma humano citratado, atividade de agregação plaquetária sendo que $25 \mu \mathrm{g} / \mathrm{mL}$ foi capaz de agregar aproximadamente $100 \%$ de plaquetas, onde o efeito obtido pela proteína pode ser devido à liberação de $\mathrm{H}_{2} \mathrm{O}_{2}$, sendo que a catalase foi adicionada ao meio tratado com LAAOBatrox e o efeito de agregação plaquetária obtido foi próximo à 0\%. LAAOBatrox apresentou efeito citotóxico sobre diferentes linhagens tumorais: B16F10 onde as células apresentaram $70 \%$ de morte por apoptose e $\mathrm{PC} 12$ que apresentaram uma viabilidade celular de $20 \%$ após o tratamento com a enzima. LAAOBatrox não apresentou efeito 
citotóxico significativo sobre células normais. Portanto, a LAAOBatrox consiste de uma enzima multifuncional que poderá servir como ferramenta para investigação dos processos celulares que estão envolvidos no envenenamento.

Palavras-chave: L-aminoácido oxidase, Bothrops atrox, atividade citotóxica, apoptose. 
ABSTRACT 
ALVES, R.M. Isolation and characterization of an L-amino acid oxidase from Bothrops atrox snake venom. 2007. 110p. Dissertation (Master) - Faculdade de Ciências Farmacêuticas de Ribeirão Preto, Universidade de São Paulo, 2007.

Snake venoms are rich in proteins, enzymes and biological active peptides. Many enzymes, like phospholipases A2, metalloproteinases, L-amino acid oxidases are responsible by clinical aspects of ophidian poisoning. Nowadays, isolation and the functional and structural characterizations of these enzymes have been useful to elucidate their mechanisms of action. Besides, these enzymes have great value for biotechnology on searching of new molecules for medicine development. The aim of this work was isolate Lamino acid oxidase from $B$. atrox venom (LAAOBatrox) and characterize biochemical and functionally $L A A O B$ atrox. The isolation consisted of 3 chromatographic steps: molecular exclusion using a G-75 Sephadex column, ion exchange using ES-502N column in HPLC and affinity chromatography with Lentil-Lectin column. Afterward, LAAOBatrox was analyzed by SDS-PAGE to confirm an expected high purity level. Biochemical characterization showed LAAOBatrox is a glycoprotein of $12 \%$ sugar-containing with relative molecular weight of 67000 , pI estimated in 4,4 pointing to acid character due to its amino acids composition, rich for Asx and Glx residues. LAAOBatrox displays high specificity to hydrophobic L-amino acids (best substrates: L-Met and L-Leu). The Nterminal amino acid sequence (ADDN-NPLEE-NIRRDD) and the internal peptide sequences showed close structural homology to other snake venom L-amino acid oxidades, presenting $100 \%$ homology to LAAO from B. moojeni and B. jararacussu. This enzyme induces moderate edema compared to crude venom, low coagulating activity in human plasma and $100 \%$ of in vitro platelet aggregation induction with $25 \mu \mathrm{g} / \mathrm{mL}$, but this can be due to $\mathrm{H}_{2} \mathrm{O}_{2}$ production by LAAOs once added catalase has inhibited aggregation induced by LAAOBatrox and the effect was close to 0\%. LAAOBatrox presents citotoxicity effect for tumor cell lines: $70 \%$ of death by apoptosis in B16F10 and 20\% cellular viability for PC12, after LAAOBatrox treatment. LAAOBatrox did not display citotoxicity effect in normal cells (peripheral blood mononuclear cells). Thus, LAAOBatrox is a multifunctional enzyme of huge potential for investigation of cellular processes involved on poisoning and also for developing new medicines.

Key words: L-amino acid oxidase, Bothrops atrox, cytotoxic activity, apoptosis. 


\section{LISTA DE FIGURAS}

Figura 1 Distribuição dos acidentes ofídicos no Brasil 22

$\begin{array}{ll}\text { Figura } 2 \text { Foto da serpente Bothrops atrox } & 23\end{array}$

Figura 3 Acidente botrópico - Ação proteolítica

Figura 4 Deaminação estereoespecífica oxidativa de um substrato L-aminoácido catalisado 28 por uma LAAO

Figura 5 Filtração em Sephadex G-75 Veneno Bruto de B.atrox 54

Figura 6 Cromatografia Líquida de Alta Eficiência (CLAE) da fração BaPI do veneno de B. 55 atrox obtida da filtração em gel de Sephadex G-75

Figura 7 Cromatografia em Lentil Lectina da fração ativa ES-III obtida da CLAE (troca 56 iônica)

Figura 8 Ensaio de Atividade Específica da LAAO

$\begin{array}{lr}\text { Figura } 9 \text { Eletroforese SDS-PAGE } & 59\end{array}$

$\begin{array}{lr}\text { Figura } 10 \text { Eletroforese SDS-PAGE } & 60\end{array}$

Figura 11 Determinação da Massa Molecular

Figura 12 Determinação da Massa Molecular

$\begin{array}{lr}\text { Figura 13 Determinação do Ponto Isoelétrico } & 63\end{array}$

Figura 14 Deglicosilação

Figura 15 Seqüenciamento de LAAO de B. atrox em comparação com outras LAAOs de 67 venenos de serpentes

Figura 16 Espectro de massa dos íons 569,6 $\left[\mathrm{M}+2 \mathrm{H}^{+}\right]$

Figura 17 Ensaio de Especificidade de substrato $\quad 71$

Figura 18 (A) Indução de Edema

Figura 18 (B) Indução de Edema

Figura 19 Atividade Hemorrágica $\quad 74$

$\begin{array}{ll}\text { Figura } 20 \text { Atividade Hemorrágica } & 75\end{array}$

$\begin{array}{ll}\text { Figura } 21 \text { Atividade de Agregação Plaquetária } & 76\end{array}$

$\begin{array}{ll}\text { Figura } 22 \text { Atividade de Agregação Plaquetária com catalase } & 77\end{array}$ 
Figura 23 Atividade Anti-tumoral (JURKAT)

Figura 24 Atividade Anti-tumoral (B16F10) $\quad 80$

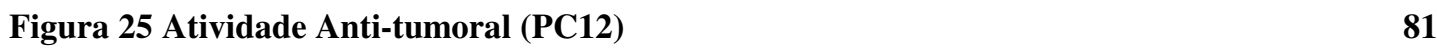

Figura 26 Atividade Anti-tumoral (Células mononucleares de sangue periférico) 82

Figura 27 Análise do índice apoptótico por microscopia de fluorescência 83

Figura 28 Análise de núcleos apoptóticos por microscopia de fluorescência 83

Figura 29 Análise do efeito apoptótico por citometria de fluxo (JURKAT)

Figura 30 Análise do efeito apoptótico por citometria de fluxo (B16F10) 85

Figura 31 Análise do efeito apoptótico por citometria de fluxo (PC12) 86

Figura 32 Análise do efeito apoptótico por citometria de fluxo (Células mononucleares de 87 sangue periférico)

Figura 33 Análise comparativa da indução de apoptose por citometria de fluxo nas 88 diferentes linhagens celulares expostas ao tratamento com LAAOBatrox 


\section{LISTA DE TABELAS}

Tabela 1 Avaliação da indução do edema pela enzima LAAO

Tabela 2 Análise comparativa da indução do edema pela enzima LAAO e veneno bruto

Tabela 3 Avaliação da indução da hemorragia pela enzima LAAO

Tabela 4 Análise Quantitativa das Etapas de Purificação da LAAO do veneno de B.atrox

Tabela 5 Composição em aminoácidos da LAAO de B. atrox

Tabela 6 Alinhamento das sequiências parciais determinadas de fragmentos peptídicos

trípticos de LAAO B. atrox

Tabela 7 Alinhamento da região N-terminal da LAAO de B. atrox com seqüência de outras 70

LAAOs obtidas de venenos de serpentes

Tabela 8 Atividade L-Aminoácido Oxidase de Venenos de Serpentes 


\section{LISTA DE ABREVIATURAS}

\begin{tabular}{|c|c|}
\hline AMBIC & Bicarbonato de Amônio \\
\hline ATCC & Coleção Americana de Cultura de Células \\
\hline B. & Gênero Bothrops \\
\hline C. & Gênero Crotalus \\
\hline CLAE & Cromatografia Líquida de Alta Eficiência \\
\hline CID & Dissociação induzida por colisão \\
\hline DAPI & Diacetato de Iodeto de Propídeo \\
\hline DCM & Dose Coagulante Mínima \\
\hline DHM & Dose Hemorrágica Mínima \\
\hline DMSO & Dimetilsulfóxido \\
\hline DTT & Ditiotreitol \\
\hline FITC & Isotiocianato de Fluoresceína \\
\hline I.D. & Intra-dérmica \\
\hline LAAOs & L-aminoácido oxidases \\
\hline MS/MS & Espectro de Massa \\
\hline MPs & Metaloproteases \\
\hline MTT & 3-(4,5-Dimetil tiazol 2-il)2,5-Difenil Brometo de Tetrazolium \\
\hline PBS & Tampão Salina Fosfato \\
\hline PEG & Polietilenoglicol \\
\hline pI & Ponto Isoelétrico \\
\hline PITC & Fenilisotiocianato \\
\hline $\mathbf{P L A}_{2}$ & Fosfolipases $\mathrm{A}_{2}$ \\
\hline PTC & Feniltiocarbamil aminoácidos \\
\hline RPMI & Roswell Park Memorial Institute \\
\hline SDS & Dodecil Sulfato de Sódio \\
\hline SDS-PAGE & Eletroforese em gel de poliacrilamida contendo SDS \\
\hline TC & Tempo de Coagulação \\
\hline TEMED & $\mathrm{N}, \mathrm{N}, \mathrm{N}^{\prime}, \mathrm{N}^{\prime}-$ Tetrametiletilenodiamina \\
\hline
\end{tabular}




\section{SUMÁRIO}

1. INTRODUÇÃO.

1.1. Aspectos gerais sobre as serpentes no Brasil.

1.2. O veneno das serpentes do gênero Bothrops.

1.3. A L-aminoácido oxidases. $\quad 28$

2. OBJETIVOS. 32

2.1. Objetivos Gerais $\quad 33$

2.2. Objetivos Específicos.

3. MATERIAL E MÉTODOS.

$\begin{array}{ll}\text { 3.1. Material } & 35\end{array}$

3.1.1. Veneno. $\quad 35$

$\begin{array}{ll}\text { 3.1.2. Plasma. } & 35\end{array}$

3.1.3. Animais.

3.1.4 Aspectos Éticos.

3.1.5. Outros Reagentes.

3.2. Métodos. $\quad 36$

3.2.1. Purificação da LAAO do veneno de B. atrox.

3.2.1.1. Filtração em Sephadex G-75.

3.2.1.2. Cromatografia Líquida de Alta Eficiência. 36

3.2.1.3. Cromatografia de Afinidade em Lentil Lectina. $\quad 37$

3.2.2. Ensaio de Atividade Específica de L-aminoácido oxidase. $\quad 37$

3.2.3. Caracterização Bioquímica. $\quad \mathbf{3 8}$

$\begin{array}{ll}\text { 3.2.3.1. Eletroforese SDS-PAGE. } & \mathbf{3 8}\end{array}$

3.2.3.2. Massa Molecular. $\quad \mathbf{3 8}$

3.2.3.3. Determinação do Ponto Isoelétrico (pI). 39

3.2.3.3.1. Aplicação das amostras e focalização isoelétrica. 39

3.2.3.3.2. Detecção e determinação do gradiente de pH. 
3.2.7.3. Atividade Coagulante. $\quad 46$

3.2.7.4 Agregação Plaquetária $\quad 46$

$\begin{array}{ll}\text { 3.2.7.5. Atividade Anti-Tumoral. } & 47\end{array}$

3.2.7.1. Linhagens Humanas. $\quad 47$

3.2.7.5.1. Meios de Cultura Celular. $\quad 47$

3.2.7.5.2. Linhagens Tumorais Animais. $\quad 48$

3.2.7.5.2.1 Manutenção da Linhagem celular. $\quad 48$

3.2.7.5.3 Tratamento das Células com LAAOBatrox $\quad 48$

3.2.7.5.4 Análise da atividade anti-tumoral. $\quad 48$

3.2.7.5.5 Determinação do Índice apoptótico com Diferentes Corantes. $\quad 50$

3.2.7.5.6 Análise de efeitos apoptótico e necrótico por citometria de fluxo. $\quad 5$

$\begin{array}{ll}\text { 3.2.7.6 Análise Estatística. } & \mathbf{5 1}\end{array}$ 
4.1. Isolamento de LAAOBatrox.

4.1.1. Filtração em Sephadex G-75 do veneno bruto de B. atrox.

4.1.2. Cromatográfica Líquida de Alta Eficiência (CLAE) da fração BaPI do $\mathbf{5 5}$

veneno de B. atrox obtida da filtração em gel de Sephadex G-75.

4.1.3. Cromatografia em Lentil Lectina da fração ativa ES-III obtida da CLAE $\mathbf{5 6}$

(troca iônica).

4.2. Ensaio de Atividade Específica da LAAO.

4.3. Caracterização Bioquímica.

4.3.1. Eletroforese SDS-PAGE. $\quad \mathbf{5 9}$

4.3.2. Determinação de Massa Molecular Relativa.

4.3.3. Determinação do Ponto Isoelétrico.

4.3.4. Composição em Aminoácido. $\quad 64$

4.3.5. Deglicosilação. $\quad \mathbf{6 5}$

4.3.6. Sequenciamento de LAAOBatrox em comparação com outras LAAOs $\mathbf{6 6}$

de venenos de serpentes.

4.3.7. Ensaio de Especificidade de Substrato. $\quad 71$

4.4. Caracterização Funcional.

4.4.1. Indução de Edema.

4.4.2. Atividade Hemorrágica. $\quad \mathbf{7 4}$

4.4.3. Atividade Coagulante. $\quad \mathbf{7 5}$

4.4.4. Atividade de Agregação Plaquetária. $\quad 76$

$\begin{array}{lr}\text { 4.4.5. Atividade anti-tumoral. } & \mathbf{7 8}\end{array}$

$\begin{array}{ll}\text { 4.5.1 Ensaio de atividade antitumoral. } & \mathbf{7 8}\end{array}$

$\begin{array}{ll}\text { 4.4.5.2 Análise do efeito apoptótico por citometria de fluxo. } & \mathbf{8 4}\end{array}$

$\begin{array}{ll}\text { 4.4.5.2.1 Nível de apoptose induzido pela LAAO. } & \mathbf{8 4}\end{array}$

$\begin{array}{ll}\text { 5. DISCUSSÃO. } & 89\end{array}$

6. CONCLUSÕES.

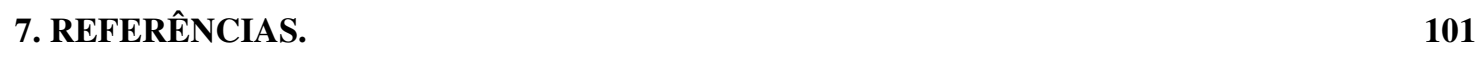




\subsection{Aspectos Gerais sobre as serpentes no Brasil.}

A gravidade e a grande frequiência dos acidentes ofídicos que ocorrem no país acarretam sérios problemas à saúde humana, exigindo notificação obrigatória ao Ministério e às Secretarias Estaduais de Saúde.

O Brasil possui uma riquíssima fauna de serpentes, aproximadamente 265 espécies, classificadas dentro de 73 gêneros, reunidas em 9 famílias. Apenas duas dessas famílias são conhecidas como peçonhentas (Viperidae e Elapidae), isto é, aquelas que produzem toxinas em glândulas especializadas e têm aparelhos apropriados para inoculá-las, ocasionando intoxicações sérias no homem e em outras espécies animais. A família Elapidae é composta por serpentes encontradas principalmente na Ásia, África e Austrália. Nas Américas, a família está representada pelas chamadas cobras corais, pertencentes ao gênero Micrurus. A família Viperidae com serpentes distribuídas por todo mundo, sem dúvida representa o mais importante grupo de serpentes para a saúde pública, pois são responsáveis pela maioria e pelos mais graves acidentes ofídicos registrados, não só no Brasil, mas também em outros países das Américas (Figura 1).

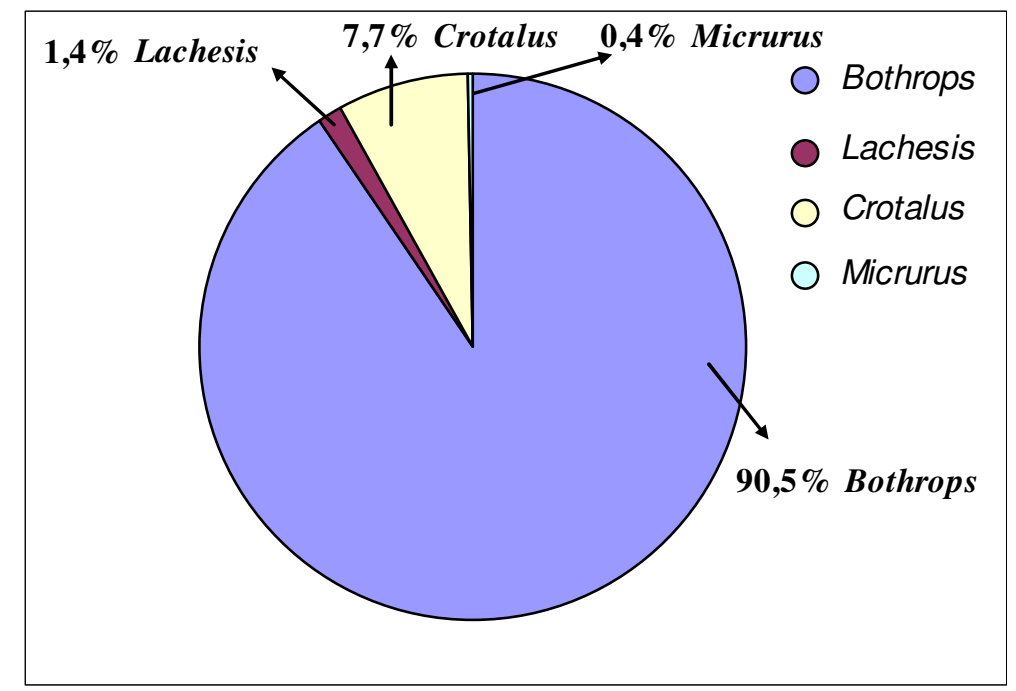

Figura 1. Distribuição dos acidentes ofídicos no Brasil, segundo o gênero da serpente causadora do acidente.

Fonte: Fundação Nacional de Saúde, 1998

http://www.butantan.gov.br/info_uteis.htm 
A fauna brasileira inclui 5 gêneros que somam aproximadamente 30 espécies e, incluindo as subespécies o número chega a 36. Os principais gêneros são Bothrops, representado pelas jararacas, como são popularmente conhecidas; Crotalus, representado pelas cascavéis e Lachesis, cujas serpentes são conhecidas como surucucus.

O gênero Bothrops destaca-se como o responsável por cerca de 85 a $90 \%$ do total de acidentes ofídicos ocorridos no país (Rosenfeld, 1971; Ferreira et al., 1992; Ribeiro et al., 1993).

Segundo Guércio et al. (2006), muitos fatores influenciam na composição do veneno dessas serpentes, dentre eles, a idade do animal.

\subsection{O veneno das serpentes do gênero Bothrops.}

A espécie B. atrox (Figura 2) é responsável pela maioria dos acidentes ofídicos na região da Amazônia Brasileira. Em humanos, o envenenamento por B. atrox causa efeitos locais como inchaço, hemorragia local e necrose além de efeitos sistêmicos, incluindo alterações na coagulação sanguínea e vários pontos hemorrágicos ao longo da mordida (Guércio et al., 2006).

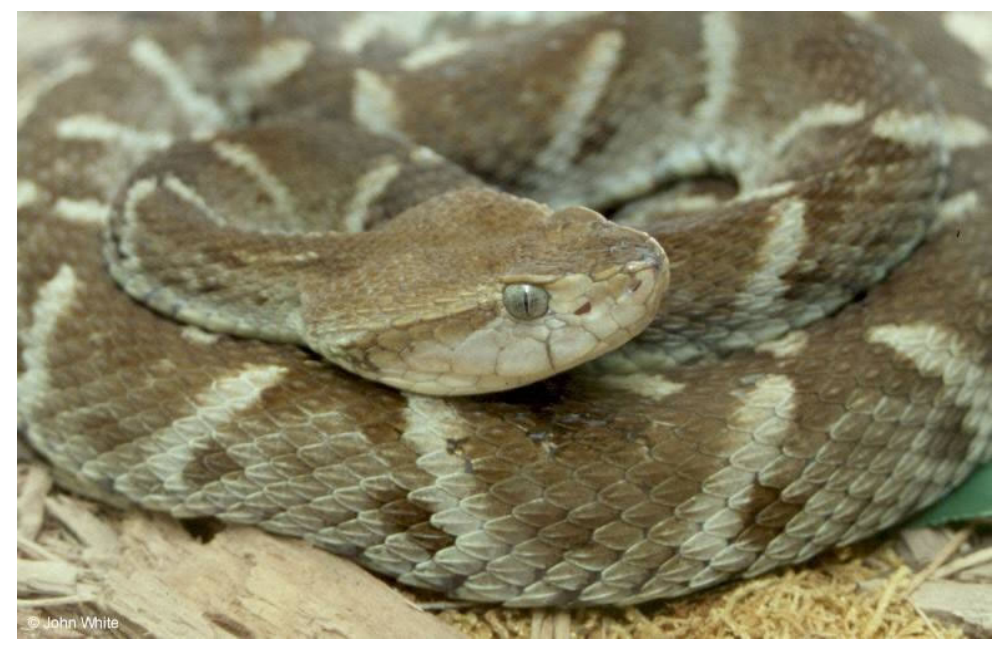

Figura 2. Foto da serpente Bothrops atrox. Fonte:http://animalpicturesarchive.com/animal/a7/Fer-deLance_Bothrops_atrox_Caissaca_Lancehead_Snakeby_John_White.jpg 
Cerca de $90 \%$ do peso seco do veneno é constituído por proteínas, compreendendo grande variedade de enzimas como fosfolipases $\mathrm{A}_{2}$, proteases, L-aminoácido oxidase, hialuronidases, entre outras, toxinas não-enzimáticas e proteínas não-tóxicas. As frações não-protéicas são representadas por carboidratos, lipídeos, metais, aminas biogênicas, nucleotídeos e aminoácidos livres (Cardoso et al., 2003).

O veneno botrópico possui três atividades fisiopatológicas: proteolítica (Figura 3 A e B), também definida como inflamatória aguda, coagulante e hemorrágica. Os sintomas da vítima são: dor, edema, rubor, equimose e necrose (Cardoso et al., 2003).

As Metaloproteinases de venenos de serpentes são responsáveis pelos efeitos locais e sistêmicos observados durante o envenenamento por serpentes da família Viperidae: hemorragias, mionecroses, lesões de pele, inflamação, ativação do complemento e ativação da matriz endógena de metaloproteinase. Fatores severos afetam a adesão e migração celular, incluindo a concentração de moléculas de adesão da matriz extracelular, o número e afinidade de integrinas e interação entre esses receptores e o citoesqueleto (Costa; Santos, 2004).

A hemorragia é causada pela ação de metaloproteinases que provavelmente degradam colágeno e outros componentes da lâmina basal dos vasos capilares. Como conseqüência os capilares são rompidos, promovendo equimoses e sangramentos. O veneno possui uma ação sobre os fatores de coagulação, alterando o tempo de coagulação (TC). Os venenos das serpentes do gênero Bothrops diminuem o tempo de coagulação, por atuarem sobre fatores da cascata de coagulação e sobre a trombina (Gutierrez; Chaves, 1980; Queiroz; Petta, 1984).

A hemorragia, uma das mais evidentes atividades biológicas dos venenos da família Viperidae, é a mais relevante patofisiologia do envenenamento (Bjarnasson; Fox, 1994). A medição do halo hemorrágico obtido após a injeção intra-dérmica dorsal do veneno (Kondo et al., 1960) é específico, rápido e reprodutível.

Os danos hemorrágicos locais são rápidos, a patogênese do veneno é complexa, envolvendo ação combinada de metaloproteinases e outros componentes existentes no veneno bruto (Gutierrez et al., 1995). 
O edema local é outra típica manifestação de envenenamento botrópico, independente da via de inoculação. O edema é acompanhado de dor, que pode variar de discreta a intensa. Isto é causado, provavelmente, pela combinação de elementos tais como: efeito direto do veneno sobre os vasos e liberação de mediadores endógenos como histamina, cininas e prostaglandinas devido a ação dos componentes dos venenos sobre os mastócitos, cininogênios e fosfolipídeos, respectivamente. Em alguns casos, o edema é responsável pela elevação da pressão intersticial hidrostática nos compartimentos musculares. Além da sua ação sobre células musculares e microvasculatura, o veneno botrópico também afeta artérias, causando trombose e lesão das paredes arteriais. Lesão arterial causa isquemia e necrose futura. Em adição, este veneno afeta nervos intramusculares (Barravieira, 1994).
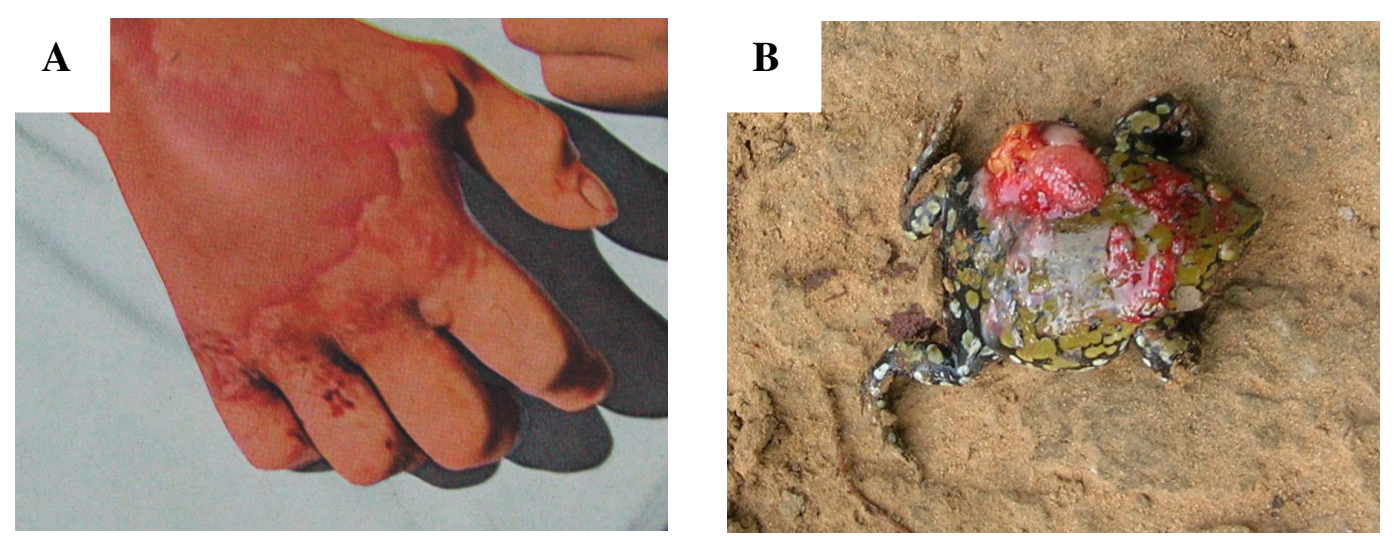

Figura 3 A e B: Acidente botrópico - Ação proteolítica. Fonte: A) http://www.gifte.de/Gifttiere/biss_bothrops_atrox_bild02.htm ; B) Obtida "in loco" pela mestranda Raquel de Melo Alves em 31/12/2005 na zona rural do município de Rochedo - MS.

A hipotensão e o choque periférico são observados em acidentes graves e são devidos à liberação de mediadores vasoativos. Ocorre aumento do tempo de coagulação sanguínea. A vítima pode ir a óbito por insuficiência renal aguda e/ou poderá ter infecção secundária por bactérias que são encontradas na microbiota bucal da serpente. (Amaral, 1977). 
A mortalidade causada pelas espécies botrópicas, foi estimada em 2,4\% podendo atingir 8\% quando não tratadas devidamente (World Health Organization, 1981). Nestes casos o edema, a hemorragia e a necrose muscular são as mais sérias manifestações clínicas locais, causando incapacidade prolongada ou permanente do membro atingido. Alguns componentes isolados dos venenos do gênero Bothrops, são enzimas que provocam distúrbios da coagulação sangüínea (Assakura et al., 1985; Hofmann; Bon, 1987), e miotoxinas (Lomonte; Gutierrez, 1989; Homsi-Brandeburgo et al., 1988) responsáveis pelos sintomas clínicos do envenenamento botrópico.

O estudo dos venenos de serpentes tem propiciado a elucidação de diversos mecanismos farmacológicos e auxiliado muito na indústria farmacêutica em busca de novos fármacos, como por exemplo, a elaboração da molécula de um dos medicamentos mais vendidos para controle da pressão arterial, o Captopril. Este medicamento foi obtido a partir de um peptídeo isolado do veneno da serpente Bothrops jararaca por Rocha e Silva et al. (1949). Esse estudo demonstrou a eficiência do peptídeo em inibir a conversão de angiotensina (Ferreira, 2000).

Esses estudos e descobertas têm propiciado maiores interesses dos pesquisadores em elucidar os princípios e mecanismos dos componentes presentes nos venenos de serpentes como enzimas (fosfolipases, proteases, L-aminoácido oxidases), proteínas não tóxicas e toxinas não enzimáticas.

As enzimas fosfolipases $\mathrm{A}_{2}\left(\mathrm{PLA}_{2}\right)$, diferentes das enzimas de mamíferos, induzem grande variedade de efeitos farmacológicos pela interferência severa das funções fisiológicas, incluindo trombose e hemostasia. São também importantes nas funções celulares como na transdução de sinal, via biossíntese de prostraglandinas e leucotrienos, e hemostasia membranar, incluindo a manutenção da quantidade de fosfolipídeos celulares e reparo na membrana através de desacilação e reacilação (Kini; Evans, 1990; Kini, 2003). Estão envolvidas em mecanismos como proliferação celular, quimioatração, contração do músculo liso e atividades microbiológicas, estando também associadas a eicosanóides e hemostasia de membrana (Mora et al., 2005). Algumas das fosfolipases iniciam agregação plaquetária, enquanto que outras inibem severamente esta atividade (Kini; Evans, 1990; Kini, 2003). 
$\mathrm{PLA}_{2} \mathrm{~S}$ são abundantes em vários fluidos biológicos e secreções como exsudato inflamatório, secreção pancreática e outros fluidos e células, bem como nos venenos de moluscos, artrópodes e serpentes (Mora et al., 2005).

As serinoproteases são encontradas em microorganismos, plantas e diversos animais. São muito abundantes nos venenos de serpentes principalmente na família Viperidae, onde constituem aproximadamente $20 \%$ do total de proteínas contidas no veneno. Estas enzimas têm propriedades bioquímicas e estruturais, como a tríade catalítica que é altamente conservada ( $\mathrm{Ser}_{195}, \mathrm{His}_{57}$ e $\mathrm{Asp}_{102}$ ), que as classificam como serinoproteases. Apresentam diversas funções biológicas e podem estar envolvidas na digestão, ativação do sistema complemento, diferenciação celular, hemostasia, etc. Estas enzimas sozinhas não são letais, mas contribuem para o efeito tóxico quando associadas com outras proteínas do veneno. As serinoproteases afetam muitos passos na cascata de coagulação, muitas vezes não especificamente através da degradação proteolítica, ou seletivamente através da ativação ou inativação de fatores da coagulação, envolvidos na agregação plaquetária, coagulação e fibrinólise (Braud; Bom; Wisner, 2000).

Do veneno de Bothrops atrox podemos destacar algumas proteínas e enzimas já isoladas como a trombolectina (lectina) (Gartner; Stocker; Williams, 1980). Atroxin, uma enzima proteolítica isolada que produz hemorragia e necrose após 24 horas da injeção e possui sua atividade aumentada na presença de caseína (Pantigoso et al., 1996). Uma enzima coagulante denominada Batroxobin (Stocker; Barlow, 1976) e uma glicoproteína denominada Trombocetina, com massa molecular relativa de 36.000 e contém 5,6\% de carboidrato. Promove agregação plaquetária e ativa o fator XIII da cascata de coagulação. Está caracterizada como uma serinoprotease clássica (Kirby et al., 1979).

Dentre outras enzimas isoladas como fofodiesterases (Frischauf; Eckstein, 1973) e hemorraginas (Rodrigues et al., 2004) podemos destacar também 2 fosfolipases $\mathrm{A}_{2}$ denominadas BaPLA(2)I e BaPLA(2)III com massa molecular estimada em 15kDa, sendo que a primeira trata-se de uma fosfolipase básica com pI de 9,1 e a BaPLA(2)III uma fosfolipase neutra, com pI de 6,9 demonstrando maior atividade catalítica que a BaPLA(2)I para substratos sintéticos (Kanashiro et al., 2002). 


\subsection{As L-aminoácido oxidades - LAAOs.}

As L-aminoácido oxidases (LAAOs) são flavoenzimas, que catalisam a deaminação oxidativa estereoespecífica de um substrato L-aminoácido para um $\alpha$-cetoácido com a produção de amônia e peróxido de hidrogênio (Figura 4) (Curti; Ronchi; Simoneta, 1992; Ahn; Lee; Kim, 1997; Zhang, et al., 2003; Kommoju et al., 2007). São amplamente distribuídas em muitos organismos diferentes como as bactérias, fungos, algas verdes e venenos de serpentes e são envolvidas na utilização de fontes de nitrogênio (Stábeli et al., 2004).
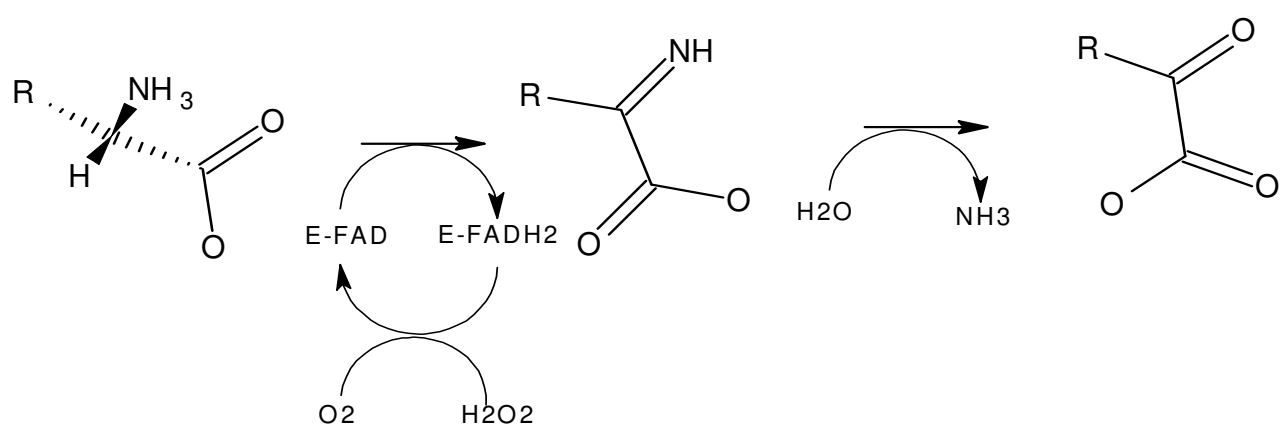

Figura 4. Deaminação estereoespecífica oxidativa de um substrato L-aminoácido catalisado por uma LAAO.

As LAAOs exibem uma preferência para aminoácidos hidrofóbicos incluindo, fenilalanina, triptofano, tirosina e leucina. No entanto, o mecanismo de toxicidade induzido pelas LAAOs de venenos ainda é pouco conhecido. Tem-se demonstrado que estas enzimas isoladas de Crotalus adamanteus e C. atrox podem se associar especificamente com células endoteliais de mamíferos que pode ser devido ao aumento na produção de peróxido de hidrogênio (Surh; Kim, 1999; Du; Clemetson, 2002).

A LAAO apresenta peculiaridades para cada veneno de serpente, por exemplo, esta enzima purificada do veneno de C. adamanteus apresenta inativação reversível, quando congelada $\left(-20^{\circ} \mathrm{C}\right)$ (Curti; Massey; Zmudka, 1968, Coles; Edmondson; Singer, 1977) e, 
quando reaquecida novamente $\left(37^{\circ} \mathrm{C}\right)$ em $\mathrm{pH} 5$ ela é renaturada e volta a ter atividade (Coles; Edmondson; Singer, 1977).

É amplamente aceito que a reatividade ligada ao sistema imunológico é mediada por anticorpos de venenos de serpentes que reconhecem componentes relacionados a sequiência homóloga de aminoácido ou funções biológicas similares. Entretanto, Stábeli et al. (2005) demonstraram que o antiveneno poliespecífico de Bothrops é uma fonte de anticorpos de reação cruzada que interagem com proteínas do veneno ou estruturas primárias distintas e funções biológicas.

Recentemente, as L-aminoácido oxidases de venenos de serpentes foram objeto de estudo interessante para a farmacologia, bem como seus estudos em biologia estrutural e molecular (Stábeli et al., 2004).

A primeira função da LAAO é provavelmente a de promover hipotensão à vítima pela ativação de guanilato ciclase solúvel na presença de superóxido dismutase (Aird, 2002).

LAAOs têm sido caracterizadas com funções distintas como preferência de substrato, indução de apoptose, citotoxicidade, hemólise, agregação plaquetária, indução de hemorragia, edema e atividades bactericidas (Du; Clemetson, 2002; Cooper; Pinto, 2005; Ali et al., 2000) e atividade anti-HIV (Kommojua, et al., 2007). As LAAOs dos venenos de serpentes produzem peróxido de hidrogênio que são responsáveis pela ativação das plaquetas por meio da via sinalizadora (Lu et al., 2005).

Os efeitos citotóxicos de LAAO de venenos de serpentes, bem como indução de apoptose/necrose têm sido demonstrados em diversas linhagens celulares. Recentemente foi demonstrado que LAAO do veneno de Crotalus adamanteus induziu apoptose em células endoteliais de cordão umbilical humano, bem como em alguns tipos de células tumorais. Apoptose tem sido definida como morte celular programada, caracterizada pelo ilustre exemplo de eventos celulares morfológicos e bioquímicos (Souza et al., 1999).

Araki et al. (1993) demonstraram que venenos de serpentes com atividade hemorrágica induzem apoptose em células endoteliais vasculares. Muitos outros estudos relatam a indução de apoptose por LAAO de vários venenos de serpentes, incluindo víboras, em diferentes linhagens celulares como células embrionárias de rim humanas (293T) (Torii et al., 2000), células de leucemia humana promielocítica (HL-60) (Torii et al., 
1997), células de leucemia T humanas (MOLT-4) (Suhr and Kim, 1996), células monocíticas humanas (MM6) com confirmação da apoptose pela fragmentação do DNA das células tratadas com LAAO (Ali et al., 2000).

Efeitos citotóxicos da LAAO de Bothrops pirajai (BpirLAAO-I) foram observados em tumores S180, SKBR-3, Jurkat e EAT. A morte celular para células normais (macrófagos) foi insignificante. Além disso, BpirLAAO-I foi capaz de induzir a fragmentação de DNA após a incubação a $37^{\circ} \mathrm{C}$ por $24 \mathrm{~h}$ (Izidoro et al., 2006).

Alguns estudos mostram a indução de apoptose por LAAO envolvida nas vias das caspases, no entanto, muitos dos efeitos biológicos de LAAO são devidos ao efeito secundário de $\mathrm{H}_{2} \mathrm{O}_{2}$ que é produzido durante a reação enzimática. Durante o estresse oxidativo, $\mathrm{H}_{2} \mathrm{O}_{2}$ em níveis baixos tem uma função de ativação e transcrição de alguns genes que poderiam prevenir a morte celular. Entretanto, um aumento na concentração de $\mathrm{H}_{2} \mathrm{O}_{2}$ induz um atraso no crescimento e morte celular por apoptose (SOUZA et al., 1999, Du; Clemetson, 2002). Araki et al. (1993) mostraram que substâncias citotóxicas em venenos de Crotalus atrox, Trimeresurus flavoviridis, Gloydius halys blomhoffii, Vipera ammodytes e Bitis arietnas causam apoptose em célula endotelial vascular em pulmão humano, mas não em ratos ou células de músculo liso de bovinos, ou fibroblastos embrionários de humanos (Aird, 2002).

Em 1980, Gewitz et al. (1980) demonstraram que LAAO libera HCN (ácido cianídrico) sobre a oxidação de histidina. Nathan et al. (1982) reportaram que LAAO, de venenos de Echis coloratus inibe agregação plaquetária via liberação de $\mathrm{H}_{2} \mathrm{O}_{2}$, sugerindo uma função anticoagulante.

As LAAOs purificadas de venenos são geralmente glicoproteínas (aproximadamente 3-4\%) homodiméricas ácidas ou básicas, com ponto isoelétrico entre 4,4 - 8,5, tendo FMN e FAD como co-fatores (aproximadamente $2 \mathrm{~mol} / \mathrm{mol}$ ), com massa molecular de 120 - $150 \mathrm{kDa}$ na forma nativa e 55 - $66 \mathrm{kDa}$ em suas formas monoméricas (Souza et al., 1999; Ponnudurai; Chung; Tan, 1994; Tan; Swaminathan, 1992; Tan; Saifuddin, 1989; Torii; Naito; Tsuruo, 1997; Abe et al., 1998; Du; Clemetson, 2002; Ali et al., 2000; Toyama et al., 2006; Samel, et al., 2006). 
A purificação de LAAOs de venenos de serpentes tem sido descrita por vários grupos de pesquisadores, sendo que, enzimas de diferentes origens exibem diferentes especificidades, estabilidades e diversas atividades biológicas e tóxicas.

Até o momento, apenas três LAAOs foram isoladas do gênero Bothrops, das espécies Bothrops moojeni (Tempone et al., 2001), B. alternatus (Stábeli et al., 2004) e Bothrops pirajai (Izidoro et al., 2006). Ticli et al. (2006) isolaram e caracterizaram funcionalmente e estruturalmente a LAAO de Bothrops jararacussu onde esta demonstrou resultados significativos na atividade bactericida, leishmanicida e anti-tumoral, permitindo novos estudos de estrutura molecular para a determinação dos possíveis mecanismos de ação da proteína. De forma geral, apenas a LAAO do veneno de Calosellasma rodhostoma foi amplamente caracterizada e sua estrutura tridimensional determinada. Kommoju et al. (2007) publicaram, com sucesso, a expressão do recombinante ativo de LAAO de Calosellasma rhodostoma em levedura Pichia pastoris.

Desta forma observa-se que estudos de caracterização funcional e estrutural bem como seqüência de estudos mais aprofundados desta classe de enzimas são muito importantes para compreensão do seu mecanismo de ação e quanto a aplicação biotecnológica na clínica farmacêutica. 


\subsection{Objetivos Gerais:}

2.1.1 Isolar e caracterizar bioquímica e funcionalmente a L-aminoácido oxidase do veneno de Bothrops atrox.

\subsection{Objetivos Específicos:}

2.2.1 Padronizar a metodologia da L-aminoácido oxidase do veneno de B. atrox.

2.2.2 Caracterizar bioquimicamente a LAAOBatrox por meio da determinação do pI, massa molecular, composição em aminoácidos e seqüenciamento amino terminal, conteúdo de açúcar e quanto à especificidade de substrato.

2.2.3 Caracterizar funcionalmente a LAAOBatrox por meio das seguintes atividades: indução de edema, atividade hemorrágica, atividade coagulante, agregação plaquetária, atividade anti-tumoral e atividade pró-apoptótica. 


\subsection{Material}

\subsection{1 - Veneno.}

Veneno bruto de B. atrox adquirido do Serpentário SANMARU, Taquaral, SP e do Instituto Butantã de São Paulo.

\subsection{2 - Plasma.}

Plasma humano de indivíduos saudáveis recém colhido, procedente do Hemocentro da cidade de Ribeirão Preto - SP.

\subsection{3 - Animais.}

Camundongos machos de linhagem suíça, pesando de 18 a 20g, adquiridos do Biotério Central da Universidade de São Paulo - Ribeirão Preto.

\subsection{4 - Aspectos éticos.}

O projeto de pesquisa foi aprovado pelo CEUA - Comissão de Ética no Uso de Animais - (Protocolo $\mathrm{n}^{\mathrm{o}}$ 05.1.821.53.1) e também pelo Comitê Nacional de Ética em Pesquisa para utilização de plasma humano fornecido pelo Centro Regional de Hemoterapia de Ribeirão Preto.

\subsection{5 - Outros reagentes.}

Foram utilizados reagentes de grau analítico. 


\subsection{Métodos}

\subsubsection{Purificação da LAAO do veneno de B. atrox.}

\subsubsection{Filtração em Sephadex G-75.}

Aproximadamente 500mg de veneno bruto de $B$. atrox foram suspensos em $5 \mathrm{~mL}$ de tampão bicarbonato de amônio (AMBIC) 0,05M, pH 8,0, centrifugado a 12.000 x g por 10 minutos e o sobrenadante obtido aplicado à coluna contendo gel de Sephadex G-75 (4,0 x $90 \mathrm{~cm}$ ). A coluna foi previamente equilibrada com a mesma solução tampão com um fluxo de $30 \mathrm{~mL} / \mathrm{h}$ e foram coletadas frações de $5 \mathrm{~mL} /$ tubo em coletor LKB Bromma 2070 ULTRORAC® II. A absorbância das frações coletadas foram determinadas em 280nm, em espectrofotômetro Beckman DU® 640. Os picos obtidos foram reunidos e concentrados em sistema de ultrafiltração AMICON utilizando membrana de 10.000 Da e avaliada a atividade específica da LAAO. O pico ativo foi submetido à próxima etapa de purificação.

\subsubsection{2 - Cromatografia Líquida de Alta Eficiência.}

A fração BaPI obtida da filtração em gel Sephadex G-75 (item 3.2.1.1) e concentrada por ultrafiltração foi submetida à cromatografia líquida de alta eficiência (SHIMADZU) utilizando coluna de troca iônica Shodex ES-502N 7C (7,6 mm/10 cm).

A fase móvel constituiu-se de bicarbonato de amônio 0,05 M, pH 8,0 (eluente A) e bicarbonato de amônio 0,5 M, pH 8,0 (eluente B). A amostra foi suspensa no eluente A, centrifugada a $3.500 \mathrm{x}$ g por 5 minutos e aplicada com o mesmo tampão por 40 minutos, iniciando o gradiente linear de concentração de 0 a 100\% de B em 220 minutos, permanecendo por 20 minutos e voltando ao tampão inicial em 20 minutos, completando o tempo total de corrida em 300 minutos, em um fluxo de 0,4mL/min.

As amostras foram solubilizadas em tampão bicarbonato de amônio 0,05M, pH 8,0 sendo aplicados $600 \mu \mathrm{L}$ em cada ciclo. A detecção foi feita pelo detector SPD-10AV em $280 \mathrm{~nm}$.

O ensaio de atividade específica da LAAO foi realizado em cada pico coletado. 


\subsubsection{Cromatografia de Afinidade em Lentil Lectina.}

A fração ES-III obtida da cromatografia líquida de alta eficiência em coluna de troca iônica foi concentrada em aparelho de ultrafiltração Y-M de $10 \mathrm{~mL}$ (AMICON) até 2,0mL e aplicada à coluna de afinidade Lentil Lectina $(1,0 \times 26 \mathrm{~cm})$, com fluxo de $20 \mathrm{~mL}$ por hora, sendo coletados $3 \mathrm{~mL}$ por tubo. A coluna foi previamente equilibrada com tampão de ligação correspondente a Tris- $\mathrm{HCl} 20 \mathrm{mM}, \mathrm{NaCl} 0,5 \mathrm{M}, \mathrm{MgCl}_{2} 1 \mathrm{mM}$ e $\mathrm{CaCl}_{2} 1 \mathrm{mM}, \mathrm{pH}$ 7,4. Os tubos foram lidos em comprimento de onda de $280 \mathrm{~nm}$ em espectrofotômetro Beckman DU® 640 e após a saída do primeiro pico, o material adsorvido foi eluído com tampão de eluição, correspondente a 0,1 a $0,5 \mathrm{M}$ de glicose em Tris- $\mathrm{HCl} 20 \mathrm{mM}$ e $0,5 \mathrm{M}$ de $\mathrm{NaCl}, \mathrm{pH} 7,4$. Os tubos seguintes também foram monitorados em comprimento de onda de 280nm em espectrofotômetro Beckman DUß 640 e para cada pico foi realizado o ensaio de atividade de LAAO.

\subsubsection{Ensaio de Atividade Específica de L-aminoácido oxidase.}

A atividade da LAAO e dos venenos de serpentes foram determinados em (5 a $10 \mathrm{~mL}$ ) tampão Tris-HCl $0,1 \mathrm{M}, \mathrm{pH} \mathrm{7,2}$ à $25^{\circ} \mathrm{C}$ utilizando uma enzima conjugada no ensaio. Este ensaio gerou peróxido de hidrogênio pela deaminação oxidativa da L-leucina pela LAAO. Foi usado peróxido de rabanete para oxidar a o-fenilenediamina, o radical cátion que foi espectrofotometricamente monitorado no comprimento de onda de $490 \mathrm{~nm}$, utilizando para a reação $10 \mathrm{~mL}$ de L-Leucina $0,1 \%$ em Tris-HCl 0,1M (5 a $10 \mathrm{~mL}), \mathrm{pH}$ 7,2; $10 \mu \mathrm{L}$ de peróxido de rabanete $(1 \mathrm{mg} / \mathrm{mL}), 100 \mu \mathrm{L}$ de uma solução de o-fenilenediamina $(10 \mathrm{mg} / \mathrm{mL}$ em metanol). A reação foi realizada com $0,5 \mathrm{~mL}$ da solução ensaio, $10 \mu \mathrm{L}$ de LAAO e após 30 minutos a reação foi interrompida pela adição de $0,5 \mathrm{~mL}$ de ácido cítrico $10 \%$ (m/v) (PESSATTI et al., 1995) e a absorbância determinada em 490nm.

Uma curva padrão foi determinada a partir de diferentes concentrações de peróxido de hidrogênio. Os dados da regressão linear foram calculados utilizando o Aplicativo Excel (MICROSOFT OFFICE) e a atividade de LAAO foi expressa em nmoles $\mathrm{H}_{2} \mathrm{O}_{2} /$ min.

Peróxido de hidrogênio em diferentes concentrações $(3,75 ; 7,5 ; 15 ; 30 ; 60 ; 120$ e 240nM). As concentrações de peróxido de hidrogênio foram obtidas após diluição em Tris- 
$\mathrm{HCl}, 0,1 \mathrm{M} \mathrm{pH} \mathrm{7,2}$ contendo $5 \mu \mathrm{L}$ de ODP $(10 \mathrm{mg} / \mathrm{mL}$ de metanol), $1 \mu \mathrm{L}$ de peroxidase $(1 \mathrm{mg} / \mathrm{mL})$ e incubado por 30 minutos a $25^{\circ} \mathrm{C}$. A reação foi parada pela adição de $500 \mu \mathrm{L}$ de ácido cítrico $10 \%(\mathrm{~m} / \mathrm{v})$ e a absorbância determinada em 490nm.

\subsubsection{Caracterização Bioquímica.}

\subsubsection{Eletroforese SDS-PAGE.}

A pureza da fração obtida foi analisada eletroforeticamente por SDS-PAGE utilizando gel de poliacrilamida a $12 \%$ em condições desnaturantes (Laemmli, 1970). A coloração foi realizada com Azul Coomassie G-250 0,2\% em $\mathrm{H}_{2} \mathrm{O} / \mathrm{MeOH}$ 1:1 (v/v) durante 15 min. O descoramento foi obtido com trocas sucessivas de solução de ácido acético glacial à $10 \%$ (v/v) e, para a identificação com prata foi utilizado o kit de coloração com nitrato de prata (GE Healthcare Bio-Sciences AB).

\subsubsection{Massa Molecular.}

A eletroforese para determinação da massa molecular foi realizada em condições desnaturantes, segundo metodologia descrita por Laemmli (1970). O gel de resolução a 13,5\% (m/v) em acrilamida (bis acrilamida/acrilamida 0,8:30) foi preparado em tampão Tris- $\mathrm{HCl}$ 2,0M, pH 8,0 e SDS 0,1\%. O gel de concentração a 3\% em acrilamida foi preparado em tampão Tris-HCl 0,05M, pH 6,8 e SDS 0,1\%.

Amostras contendo 5 a $50 \mu \mathrm{g}$ de proteínas foram dissolvidas em tampão Tris- $\mathrm{HCl}$ 0,0625M, pH 6,8, DTT a 10\% (ditiotreitol-Pierce), glicerol a 10\%, SDS a $2 \%$ e azul de bromofenol a $0,001 \%$ como corante. As proteínas foram completamente dissociadas por imersão das amostras por 1 a 5 minutos em água fervente. Foram aplicados no gel cerca de 5 a $30 \mu \mathrm{L}$ da amostra, sendo também aplicados padrões de peso molecular dissolvidos no mesmo tampão.

O tampão de eletrodo foi Tris 0,225M, glicina 0,192M e SDS a 0,1\%, pH 8,3. 
A eletroforese foi realizada com uma corrente de $5 \mathrm{~mA}$ até o indicador azul de bromofenol alcançar o final do gel. Decorrido o tempo adequado, o gel foi retirado e corado por 30 minutos em Coomassie Blue G-250 0,1\% (m/v) dissolvido em água/metanol (1:1) e descorado numa solução de ácido acético a $70 \%$ (v/v). A distância de migração de cada padrão foi determinada em centímetros e traçada uma curva padrão para determinação de massa molecular que relacionava logaritmos dos valores de massa molecular dos padrões de proteína com as distâncias de migração.

\subsubsection{Determinação do Ponto Isoelétrico (pI).}

O ponto isoelétrico da enzima LAAO foi determinado por focalização isoelétrica segundo método descrito por Vesterberg (1972), modificado como descrito a seguir. O gel foi preparado a $5 \%$ em acrilamida, contendo $10 \%(\mathrm{~m} / \mathrm{v})$ de sacarose, $1 \%(\mathrm{v} / \mathrm{v})$ de anfólitos pH 3,0 a 14,0; 0,17\% (v/v) de TEMED e 0,075\% (m/v) de persulfato de amônio.

\subsection{Aplicação das amostras e focalização isoelétrica.}

O gel foi colocado sobre uma placa refrigerada ligada a um banho termostatizado a $8^{\circ} \mathrm{C}$. Cinco tiras de papel whatman $\mathrm{n}^{\circ} 3$ sobrepostas foram utilizadas para contactar o gel e os eletrodos, sendo o cátodo embebido em uma solução de $\mathrm{NaOH} 1 \mathrm{M}$ e o ânodo em ácido fosfórico $1 \mathrm{M}$.

A fonte de alta voltagem foi ajustada para valores máximos de $1500 \mathrm{~V}, 30 \mathrm{~mA}$ e 10W e então realizada uma pré-focalização por 30 minutos.

Pedaços de papel da LKB de 1,0 x $0,5 \mathrm{~cm}$ foram embebidos nas amostras e colocados sobre o gel sendo retiradas após 30 minutos de focalização, a qual continuou por mais 4 horas. 


\subsection{Detecção e determinação do gradiente de $\mathbf{p H}$.}

Após a focalização isoelétrica, foram desprezadas $0,5 \mathrm{~cm}$ das laterais do gel, sendo então, seccionadas tiras de 1,0 x 2,0cm do mesmo e colocadas em tubos de ensaio contendo 0,2 $\mathrm{ml}$ de água millipore, para leitura do $\mathrm{pH}$ após 2 horas em repouso. Estas tiras foram cortadas nas duas laterais do gel intercaladamente, de forma a obter valores médios de $\mathrm{pH}$ para cada $0,5 \mathrm{~cm}$ do gel. $\mathrm{O}$ restante do gel contendo amostra foi então colocado em uma solução de ácido tricloroacético a $10 \%(\mathrm{~m} / \mathrm{v})$ e ácido sulfosalicílico a $2 \%(\mathrm{~m} / \mathrm{v})$ por 15 minutos, lavado com água destilada e corado por 2 horas em uma solução de Coomassie brilliant blue G-250 0,2\% em água/metanol, 1:1 (v:v). O descoramento foi feito com uma solução de metanol/ácido acético/água, 3:1:9 (v/v).

\subsubsection{Composição em aminoácidos.}

\subsection{Hidrólise ácida.}

Amostras de cada proteína $(0,5-10 \mu \mathrm{g})$ foram transferidas para tubos de borosilicato $(6 \times 50 \mathrm{~mm})$, os quais foram pirolisados a $500^{\circ} \mathrm{C}$ por 12 horas e então lavadas por métodos usuais .

Cada tubo foi então transferido para uma câmara de reação e 200 a $300 \mu 1$ de $\mathrm{HCl}$ $6 \mathrm{~N}$ contendo fenol $(0,1 \mathrm{a} 0,5 \%)$ foi adicionado no interior da câmara.

A câmara foi selada à vácuo após fluxar $\mathrm{N}_{2}$ e hidrolisada por 24 horas a $100^{\circ} \mathrm{C}$, onde a câmara de reação foi completamente aquecida.

Após hidrólise, a câmara de reação foi aberta e os tubos contendo o hidrolisado foi transferido para o sistema Speed Vac, para remoção do excesso de $\mathrm{HCl}$ por 15 minutos a $50^{\circ} \mathrm{C}$. 


\subsection{Derivatização.}

Após remoção do excesso de $\mathrm{HCl}$, foi adicionado a cada tubo $20 \mu 1$ do seguinte reagente: metanol/ $\mathrm{H}_{2} 0 /$ trietilamina (2:2:1), agitados vigorosamente e secos em Speed Vac por 15 minutos a $50^{\circ} \mathrm{C}$. Em seguida, foram adicionados $20 \mu$ l do reagente de derivatização a cada tubo: metanol/ $\mathrm{H}_{2} 0 /$ trietilamina/PITC $(7: 1: 1: 1)$ e deixados reagir por 20 minutos em temperatura ambiente.

Sequencialmente, foi removido o excesso de reagente em Speed vac durante 1h e 30 minutos em temperatura ambiente e as amostras foram suspensas em $500 \mu 1$ de acetato de sódio $0,14 \mathrm{M} \mathrm{pH} \mathrm{7,5} \mathrm{contendo} \mathrm{5 \%} \mathrm{de} \mathrm{acetonitrila.}$

Todos esses procedimentos foram realizados simultaneamente com os padrões de aminoácidos da Pierce (solução estoque 2,5 $\mu \mathrm{mol} / \mathrm{ml}$ ).

Após derivatização o padrão de aminoácidos foi suspenso em $500 \mu 1$ de diluente de amostra e injetado $20 \mu 1$ (correspondendo a 100 picomol) na coluna.

\subsection{Sistema de separação das PTC.}

As análises foram realizadas através de um aparelho CLAE (modelo MP-3000EMilton Roy Co.) constituído por um espectromonitor D, com comprimento de onda fixado em $254 \mathrm{~nm}$ e um controlador integrador MP-3000 E, equipado com coluna: PICOTAG (150 $\mathrm{mm} \times 3,9 \mathrm{~mm}$ ) da Waters, mantida em uma estufa a $38^{\circ} \mathrm{C}$; com fluxo de $1,0 \mathrm{ml} / \mathrm{minuto}$, utilizando um gradiente constituído de duas fases móveis: solvente A-0,14M de acetato de sódio $0,05 \%$, pH 5,6 e solvente B acetonitrila e água (60:40 v/v).

A eluição dos PTC-aminoácidos foi realizada em um gradiente de $10 \%$ a $54 \%$ de B em 10 minutos e então elevado a 100\% de B para lavagem da coluna, retornando a 10\% B em um intervalo de tempo de 8 minutos e permanecendo por 10 minutos para equilíbrio da coluna, somando-se 28 minutos para uma análise completa de PTC- aminoácidos. 


\subsubsection{Deglicosilação da LAAO.}

Aproximadamente $20 \mu \mathrm{L}$ de LAAO foram dissolvidos em $5 \mu \mathrm{L}$ do tampão de desnaturação contendo SDS a $0,5 \%$ e DTT (ditiotreitol) $0,4 \mathrm{M}(\mathrm{m} / \mathrm{v})$ e $45 \mu \mathrm{L}$ de água e foram aquecidos a $100^{\circ} \mathrm{C}$ por 5 minutos. A seguir a mistura recebeu $10 \mu \mathrm{L}$ do tampão de

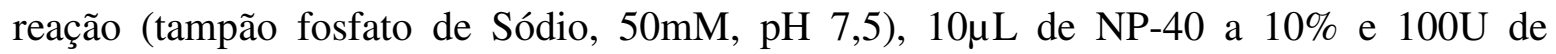
PGNase $\mathrm{F}$ e incubada por $4 \mathrm{~h}$ a $37^{\circ} \mathrm{C}$. A reação foi terminada por adição do tampão de amostra da SDS-PAGE (Tris-HCl, 0,0625M, SDS 2\%, glicerol 10\%, $\beta$-mercaptoetanol 5\%, azul de bromofenol 0,001\%, $\mathrm{pH} 6,8$ ) e aquecimento em banho-maria por 5 minutos. A massa molecular da LAAO com e sem deglicosilação foi analisada por SDS-PAGE a12\%.

\subsubsection{Seqüenciamento da LAAO de B.atrox.}

O seqüenciamento foi feito por meio de um seqüenciador modelo Procise 419 (Perkin-Elmer-Applied Biosystem Division, Foster City, California). A proteína foi eletrotransferida de SDS-PAGE a 12\% para uma membrana de "polyvinylidene difluoride" (Immobilon-P/Millipore) pelo método de "Western Blotting". Os aminoácidos foram identificados em CLAE (Cromatografia Líquida de Alta Eficiência) de fase-reversa. O seqüenciamento de aminoácidos da região N-terminal da LAAOBatrox foi identificado por meio da reação de Edman automatizada.

\subsubsection{Eletroforese em gel de poliacrilamida na presença de SDS (SDS-PAGE).}

A eletroforese foi realizada com agente desnaturante (SDS) segundo a técnica descrita por Laemmeli (1970). Para a preparação do gel foi utilizado acrilamida/bisacrilamida na proporção de 30:0,8\% e preparado um gel de empilhamento a 5\% pH 6,8, contendo $0,125 \mathrm{M}$ de Tris- $\mathrm{HCl}(\mathrm{pH} 6,8)$ e $0,1 \%$ de SDS e um gel de separação a 13,5\% pH 8,8 e $0,1 \%$ de SDS.

O tempo de corrida foi de 4 horas ou até que as amostras atingissem $1,5 \mathrm{~cm}$ do final do gel em 10mA e 100V. A coloração dos géis foi feita com Coomassie Brilliant Blue G 250 por 30min e a descoloração com ácido acético a 7\% (v/v). 


\subsubsection{Eletrotransferência da LAAOBatrox para membrana de PVDF} (“WESTERN BLOTTING").

A proteína do gel foi eletrotransferida para uma membrana de PVDF "polyvinylidene difluoride" (Immobilon-P/Millipore) usando o sistema Mini V-8.10 Blot System (Gibco BRL), por 1,5h a 150V constantes em tampão Tris-Glicina em solução $10 \%$ de metanol. Após a eletrotransferência, a membrana foi corada com Azul de Bromofenol e a banda de 67.000 foi retirada e submetida a reação de Edman (1950) automatizada para a determinação da sequiência de aminoácidos da região N-terminal da LAAOBatrox.

\subsubsection{Digestão in situ do gel por tripsina e análise por espectrometria de massa.}

A proteína isolada por SDS-PAGE foi submetida a uma digestão in situ por tripsina

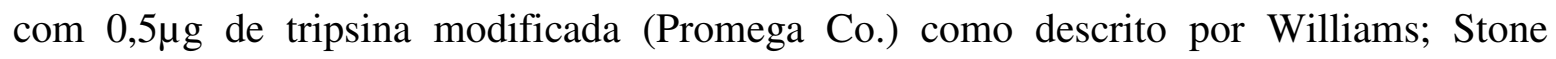
(1997). Para a análise por espectrometria de massa os peptídeos trípticos foram dessalinizados em micro Tip Vydac C18 e eluídos em metanol 70\% e ácido fórmico 0,2\%. A análise dos peptídeos trípticos foi realizada em espectrofotômetro de massa Quatro II (Micromass, Manchester, UK) "eletrospray" triplo-quádruplo por infusão direta (300nL/min) sob as seguintes condições: tensão capilar mantida a $2,8 \mathrm{kV}$, tensão do cone $40 \mathrm{~V}$, temperatura do cone ajustada a $100^{\circ} \mathrm{C}$. Os parâmetros para a exploração do íon MS1 e íon-filho foi otimizado com o peptídeo sintético para o sinal mais elevado em relação ao ruído e foram calibrados com PEG (50-2000 amu). Na modalidade de exploração do íonfilho, a energia de colisão foi ajustada a eV 25-35, e o argônio foi utilizado como gás de colisão com uma pressão parcial de $3,0 \times 10^{-3}$ mTorr. O espectro foi coletado como uma média de 20-50 scans (2-5 s/scan) e processado usando um software v.3.3 de MassLynx (Micromass). A sequiência de peptídeos trípticos foi deduzida da série de fragmentos de íons $b$ e $y$ produzidos pela espectrometria de massa por dissociação induzida por colisão(CID-MS/MS). 


\subsubsection{Caracterização Enzimática.}

\subsubsection{Ensaio de especificidade de substrato da enzima LAAO.}

2mMol dos aminoácidos leucina, isoleucina, metionina, cistina, cisteína, valina, tirosina, triptofano, glutamina, treonina, serina, lisina, arginina, fenilalanina e histidina foram dissolvidos em $500 \mu \mathrm{L}$ de tampão Tris- $\mathrm{HCl} 0,1 \mathrm{M} \mathrm{pH} \mathrm{7,2} \mathrm{contendo} 5 \mu \mathrm{L}$ da solução de o-fenilenediamina $(10 \mathrm{mg} / \mathrm{mL}$ de metanol) e $1 \mu \mathrm{l}$ de peroxidase $(1 \mathrm{mg} / \mathrm{mL})$. A solução foi incubada com $2 \mu \mathrm{g}$ de enzima por 30 minutos a $25^{\circ} \mathrm{C}$. A reação foi bloqueada com $500 \mu \mathrm{L}$ de ácido cítrico10\% (m/v) e a absorbância determinada em 490nm, utilizando um espectrofotômetro BECKMAN DU 640.

\subsubsection{Determinação da Atividade Biológica.}

\subsubsection{Indução de edema.}

O efeito edematogênico da LAAOBatrox foi realizado segundo Levy (1969). Desta forma, camundongos da linhagem suíça, machos, pesando de 18 a 22g, receberam uma injeção intra-dérmica na região sub-plantar na pata posterior direita de LAAO na

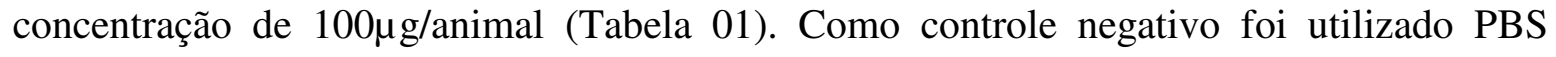
$(50 \mu \mathrm{L} /$ pata) e como controle positivo utilizamos o veneno bruto (VB) de B. atrox. A progressão do edema foi avaliada com um paquímetro de baixa pressão (Mitutoyo, Japão) nos intervalos de $0,0,5 ; 1 ; 2 ; 4 ; 24 ; 48$ e 72h após a injeção. Os valores obtidos no tempo zero foram então subtraídos e as diferenças expressas em porcentagem de edema induzido. 
Tabela 1. Avaliação da indução do edema pela enzima LAAO

\begin{tabular}{|c|c|}
\hline GRUPOS & LAAO ( $\mu \mathrm{g} /$ animal) \\
\hline 1 & 5 \\
\hline 2 & 10 \\
\hline 3 & 25 \\
\hline 4 & 50 \\
\hline 5 & 100 \\
\hline *PBS & - \\
\hline
\end{tabular}

Tabela 2. Análise comparativa da indução do edema pela enzima LAAO e veneno bruto.

\begin{tabular}{cc}
\hline \hline GRUPOS & LAAO $(\boldsymbol{\mu g} /$ animal $)$ \\
\hline *PBS & - \\
LAAO & 100 \\
$* \mathrm{VB}$ & - \\
\hline
\end{tabular}

*50 $\mu \mathrm{L} ; \mathrm{n}=5$

\subsubsection{Atividade hemorrágica.}

Os camundongos foram distribuídos aleatoriamente em grupos de 5 animais, que permaneceram em repouso para adaptação por $24 \mathrm{~h}$. Cada grupo recebeu um tratamento diferente (Tabela 2). A hemorragia foi induzida através de injeção intra-dérmica na região dorsal, sendo a pele retirada 3 horas após a injeção.

A atividade hemorrágica foi avaliada medindo-se os diâmetros dos halos hemorrágicos formados com o auxílio de um escalímetro, segundo método descrito por Kondo et al. (1960). 
Tabela 3. Avaliação da indução da hemorragia pela enzima LAAO.

\begin{tabular}{cc}
\hline \hline GRUPOS & LAAO $(\boldsymbol{\mu g} / \mathbf{a n i m a l})$ \\
\hline *PBS & 50 \\
VB & 20 \\
BaPI & 20 \\
LAAO & 50 \\
\hline \hline $50 \mu \mathrm{L} ;$ VB: Veneno Bruto; $\mathrm{n}=5$ &
\end{tabular}

\subsubsection{Atividade Coagulante.}

A atividade coagulante foi realizada utilizando plasma humano $(200 \mu \mathrm{L})$ e LAAO

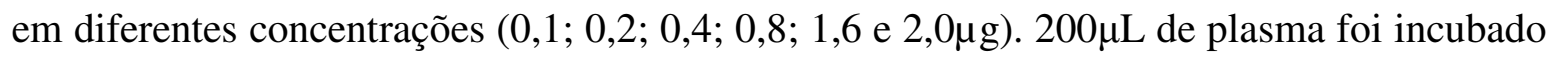
em banho-maria à $37^{\circ} \mathrm{C}$ por $5 \mathrm{~min}$. Após este intervalo de tempo foi adicionada a LAAO, cronometrando o tempo de formação de rede de fibrina. Como controle utilizamos plasma $(200 \mu \mathrm{L})$ e no lugar da LAAO utilizamos $25 \mu \mathrm{L}$ de $\mathrm{CaCl}_{2}$ a $0,25 \mathrm{mM}$, onde a coagulação ocorreu em 3minutos. A dose coagulante mínima (DCM) foi definida com a quantidade mínima de enzima que coagula o plasma no tempo de 1 minuto (Selistre; Giglio; HomsiBrandeburgo, 1990).

\subsubsection{Agregação Plaquetária.}

Amostras de sangue foram obtidas de coelhos normais, sem tratamento ou uso de medicação. Após a coleta, as amostras foram imediatamente transferidas para tubos de propileno contendo citrato de sódio (3,8\%). Plasma Rico em Plaquetas (PRP) foi preparado pela centrifugação do sangue citratado a 200 x g por 10 minutos e o Plasma Pobre em Plaquetas (PPP) foi obtido do resíduo do sangue citratado por centrifugação a 1500 x g por 20 minutos. As plaquetas foram deixadas por 1 hora em temperatura ambiente para retomar a sensibilidade aos agentes agregantes. A contagem de plaquetas foi feita por microscopia de fase contrastante. 
Os experimentos foram realizados em triplicata e foram utilizadas várias concentrações de LAAOBatrox bem como LAAOBatrox na presença de catalase, que foi previamente incubada na presença de plaquetas antes da adição da proteína, este tempo de incubação foi de aproximadamente 15 minutos.

\subsubsection{Atividade Anti-Tumoral.}

\subsection{Linhagens humanas.}

Foram utilizadas linhagens humanas JURKAT (leucemia T - tumoral) e células mononucleares do sangue periférico (normais). As linhagens tumorais foram obtidas da Coleção Americana de Cultura de Células (ATCC, "American Type Culture Collection”, Rockville, MD, USA). As células normais foram obtidas de indivíduos sadios e centrifugadas em Ficoll-Paque ${ }^{\mathrm{TM}}$ PLUS (GE Healthcare), lavadas 3 vezes com solução salina de Hank's (HBSS) (Sigma Chemical Company, St. Louis). Estas linhagens são mantidas em criopreservação em nitrogênio líquido a $-195^{\circ} \mathrm{C}$ em solução de congelamento que consiste em: meio RPMI 1640, suplementado com 10\% de Dimetilsulfóxido (DMSO) e $90 \%$ de soro bovino fetal.

Para fazer os ensaios de atividade citotóxica da LAAOBatrox, essas células foram descongeladas e expandidas em frascos de cultura celular, à temperatura de $37^{\circ} \mathrm{C}$, em estufa incubadora umidificada contendo $95 \%$ de ar e $5 \%$ de $\mathrm{CO}_{2}$.

\subsection{Meios de Cultura Celular.}

Para a manutenção das linhagens humanas, dissolução da LAAOBatrox e realização dos ensaios de atividade antitumoral, utilizamos o meio RPMI 1640 suplementado com $10 \%$ de soro bovino fetal, $20 \mathrm{mM}$ de L-glutamina, 7,5\% de bicarbonato de sódio e $10 \mu \mathrm{g} / \mathrm{mL}$ de gentamicina (meio RPMI completo). Este meio é preparado na hora do uso e esterilizado por filtração em membranas de $0,22 \mathrm{~m} \mu$. 


\subsection{Linhagens tumorais animais.}

Foram utilizadas linhagens PC12 de feocromocitoma de glândula adrenal de rato e melanoma murino B16F10.

\subsection{Manutenção da linhagem celular.}

As linhagens celulares foram armazenadas em nitrogênio líquido $\left(-195^{\circ} \mathrm{C}\right) \mathrm{em}$ alíquotas de $1 \times 10^{6}$ células/ml em uma solução de congelamento. Para a realização dos experimentos, as células foram descongeladas e cultivadas em monocamada, em frascos de $25 \mathrm{~cm}^{2}$ com $10 \mathrm{ml}$ de meio de cultura RPMI 1640 suplementados com $10 \%$ de soro eqüino fetal e $5 \%$ de soro bovino fetal, incubadas em estufa a $37^{\circ} \mathrm{C}$, até atingirem o estado de confluência $\left(\sim 5 \times 10^{6}\right.$ células $)$, sendo subcultivadas a cada três dias.

\subsection{Tratamento das células com a LAAOBatrox.}

A proteína foi diluída em diversas concentrações a fim de se estabelecer a $\mathrm{LD}_{50}$ nas culturas das linhagens JURKAT, B16F10, PC12 e de células normais. As amostras foram diluídas em PBS 1X estéril e colocadas em cultura. Permaneceram em cultura por 24 horas.

\subsection{Análise da atividade antitumoral.}

Para o ensaio da atividade citotóxica as linhagens tumorais em crescimento logarítmico foram removidas dos frascos de cultura celular pela adição de $1 \mathrm{~mL}$ de Tripsina 0,5\%, em meio RPMI. Os frascos foram então mantidos sob agitação manual por aproximadamente 60 segundos. Em seguida, foram adicionados $10 \mathrm{~mL}$ de meio RPMI completo para neutralizar a tripsina, transferidas para tubos plásticos de 50mL, lavadas 3 vezes através da centrifugação a 4800 Xg / 10 minutos em meio completo, contadas em Câmara de Neubauer e ressuspensas à concentração final de $10^{6}$ células / mL em meio completo. As células foram então plaqueadas em placas de 96 poços nas concentrações apropriadas $\left(10^{5}\right.$ células/poço) e mantidas em estufa umidificada contendo $5 \%$ de $\mathrm{CO}_{2}$ e 
95\% de ar por 24 horas. Findo este período, as células tumorais e normais foram incubadas na presença de LAAO por 24 horas.

Para avaliar a atividade citotóxica da LAAO, utilizamos o método colorimétrico de citotoxicidade (Mosmann, 1983). Este método consiste em medir indiretamente a viabilidade celular pela atividade enzimática mitocondrial das células vivas. Quando as células estão vivas as desidrogenases mitocondriais são capazes de agir sobre substratos como o 3-(4,5-Dimetil tiazol 2-il) 2,5-Difenil Brometo de Tetrazolium (MTT) levando a redução desta molécula formando assim o Azul de Formazan. Portanto, quanto maior a viabilidade celular em uma determinada amostra, mais Azul de Formazan é formado. O Azul de Formazan é solubilizado com dodecilsulfato de sódio ou Isopropanol em meio ácido. A leitura da quantidade de Azul de formazan formado é medida através do espectrofotômetro em 540nm.

Deste modo, após a incubação de $24 \mathrm{~h}$ das linhagens tumorais com as diferentes concentrações de LAAOBatrox, foram adicionadas aos poços de cultivo celular, $10 \mu \mathrm{L}$ de MTT na concentração de $5 \mathrm{mg} / \mathrm{mL}$. A placa foi então incubada por mais 3 horas em estufa umidificada contendo $95 \%$ de ar e $5 \%$ de $\mathrm{CO}_{2}$ à $37^{\circ} \mathrm{C}$. Após este período, foram acrescentados $100 \mu \mathrm{L}$ de solução a $10 \%$ de dodecil sulfato de sódio/HCL 0,01N, para dissolver os sais de formazan. As placas de cultivo celular foram mantidas por uma noite a $37^{\circ} \mathrm{C}$ a temperatura ambiente. A avaliação de sais de formazan nas amostras foi medida em espectrofotômetro em 540nm. Todos os experimentos foram feitos em três repetições com triplicatas para cada concentração. A citotoxicidade sobre a linhagem tumoral, foi calculada conforme a seguinte fórmula:

(A) $\%$ de Crescimento $=[($ D.O Tumor + substância teste $)-($ D.O Basal MTT/ SDS $)] \times 100$ [(D.O Tumor + meio de cultura) - D.O Basal MTT/SDS]

$\%$ citotoxicidade da substância teste $=100$ - \% de crescimento celular (A) 


\subsection{Determinação do índice apoptótico com diferentes corantes}

As células cultivadas numa densidade de $1 \times 10^{6}$ células por garrafa de cultivo foram centrifugadas a $800 \mathrm{x}$ g por 5 minutos e o sobrenadante foi descartado deixando uma pequena quantidade de meio para ressuspender as células. Após este procedimento, foi preparada mistura de corantes contendo iodeto de propídeo, diacetato de fluoresceína em DMSO e Hoescht 33342. Em seguida, 100 $\mu \mathrm{L}$ da suspensão celular foram misturados com $2 \mu \mathrm{L}$ da mistura de corantes, incubando-se a $37^{\circ} \mathrm{C}$ por 5 minutos. Gotejou-se cerca de $15 \mu \mathrm{L}$ desta mistura sob lâmina e cobriu-se com lamínula. As lâminas foram imediatamente analisadas utilizando-se microscópio de fluorescência com filtro triplo (DAPI, propídeo e FITC). As células normais foram visualizadas com citoplasma verde com núcleo íntegro, as apoptóticas com o citoplasma verde e núcleo fragmentado (corpos apoptóticos corados em azul) e as necróticas em vermelho. O índice de células apoptóticas foi calculado de acordo com a seguinte fórmula:

$\%$ de células apoptóticas $=\underline{\text { número de células em apoptose } \mathrm{x} 100}$ número de células contadas

\subsection{Análise de efeitos apoptótico e necrótico por citometria de fluxo}

Neste estudo foi analisada a capacidade da LAAOBatrox de induzir apoptose pela marcação por anexina $\mathrm{V}$ em diferentes linhagens celulares tumoral e normal expostas a

\section{LAAOBatrox.}

As células Jurkat, B16F10, PC12 e células normais de sangue periférico $\left(1 \times 10^{6}\right)$ foram tratadas com LAAOBatrox em várias concentrações $(5,10,25$ e $50 \mu \mathrm{g} / \mathrm{mL})$ por 4 horas à $37^{\circ} \mathrm{C}$. Após lavagens com PBS, as células foram incubadas em $100 \mu \mathrm{L}$ de tampão HEPES (10mM HEPES, $\left.140 \mathrm{mM} \mathrm{NaCl}_{2}, 5 \mathrm{mM} \mathrm{CaCl}_{2}, \mathrm{pH} 7,4\right)$ contendo $2 \mu \mathrm{L}$ de Anexina-VFITC (marcador de apoptose - Roche Applied Science) e $20 \mu \mathrm{L}$ de uma solução de Iodeto

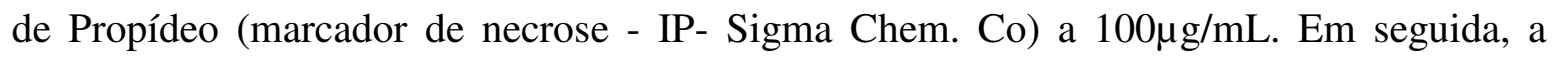


suspensão de células foi incubada por $15 \mathrm{~min}$ a $4^{\circ} \mathrm{C}$. Finalmente, foram adicionados $300 \mu \mathrm{L}$ de tampão HEPES a cada amostra-teste, e feita a análise dos níveis de exposição de fosfatidilserina nas superfícies celulares (marcação com anexina V e indicação de apoptose) e de marcação com IP (indicação de necrose), por citometria de fluxo (FACScanto-Becton \& de Dickinson Immunocytometry Systems (BDIS); San Jose, CA). As análises forma realizadas com auxílio do software (CBA - Becton \& Dickinson, San Jose, CA). A ciclofosfamida (CFA-200ug/mL) foi utilizada como referência para indução de apoptose (controle positivo).

\subsubsection{Análise Estatística}

A análise estatística utilizada para comparação entre os grupos controle e tratados foi a de variância variada (ANOVA) "one-way", seguido do pós-teste de Dunnet, ou teste t de Student não pareado, através do programa GraphPad Prism (versão 4 Prism, GraphPad, USA). 


\subsection{Isolamento de LAAO de B. atrox.}

A LAAO de B. atrox (LAAOBatrox) foi purificada em 3 etapas. A primeira consistiu em uma filtração em gel de Sephadex G-75 originando cinco picos principais, denominados BaP-I, BaPII, BaPIII, BaPIV e BaPV (Fig.5). As frações foram submetidas a ensaios de atividade de L-aminoácido oxidase para a detecção do pico ativo. A fração BaPI apresentou atividade L-aminoácido oxidase e foi concentrada em aparelho de ultrafiltração (AMICON) em membrana de 10.000 Da e submetida à cromatografia líquida de alta eficiência (CLAE) em coluna de troca iônica (Fig. 6). Nessa etapa cromatográfica foram obtidas 3 frações denominadas ES-I, ES-II e ES-III, sendo que a fração ES-III apresentou atividade sobre L-leucina. Em seguida, a fração ES-III foi concentrada em aparelho de ultra-filtração (AMICON) e submetida à cromatografia de afinidade em coluna de Lentil Lectina. Nessa etapa cromatográfica foram obtidas 2 frações L-I e L-II, sendo que a fração L-II demonstrou atividade sobre L-leucina (Fig. 7). Todas as etapas de purificação da LAAOBatrox foram monitoradas quanto à atividade sobre L-leucina, análises eletroforéticas (Figuras 8, 9 e 10) e espectrofotométricas em comprimento de onda de $280 \mathrm{~nm}$.

O controle do teste de atividade foi realizado com $20 \mu \mathrm{L}$ de amostra (LAAOBatrox) resultando em coloração amarela num tempo de 30 minutos, sendo que a reação é interrompida após 30 minutos com a adição de Ácido Cítrico 10\%, em seguida, realizou-se a leitura em espectrofotômetro no comprimento de onda de 490nm (Item 3.2.2). 


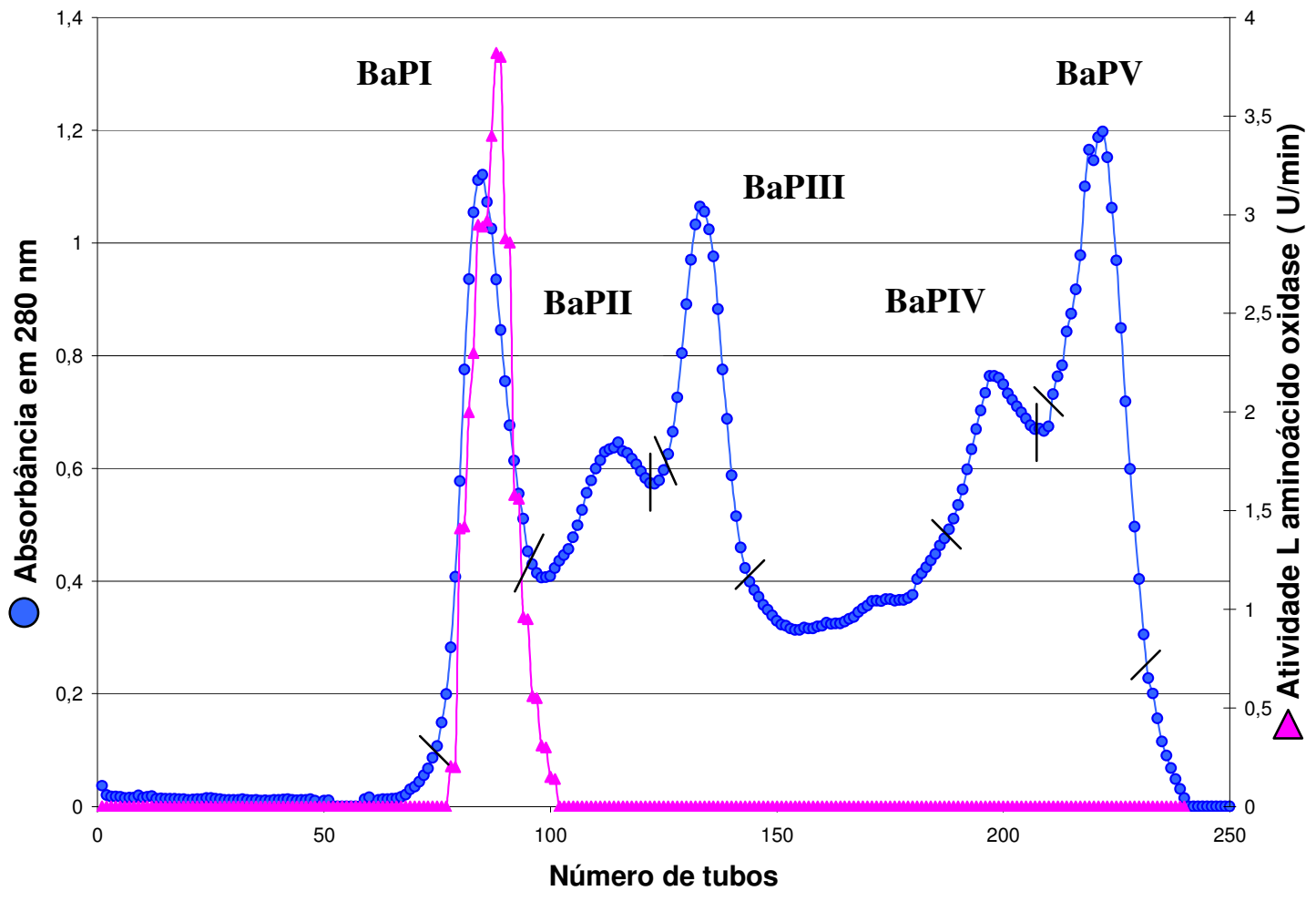

Figura 5: Filtração molecular em gel de Sephadex G-75 do veneno bruto de B.atrox. Amostra: 500mg do veneno de B. atrox dissolvido em AMBIC 0,05M, pH 8,0 (item 3.2.1.1) A coluna $(4,0 \times 90,0 \mathrm{~cm})$ foi previamente equilibrada com bicarbonato de amônio $0,05 \mathrm{M}, \mathrm{pH} 8,0$ e eluída em temperatura ambiente em um fluxo de $30 \mathrm{~mL} /$ hora com o mesmo tampão, coletando 5mL/tubo. Absorbância em 280nm (0-0). Atividade L-aminoácido oxidase $(\Delta)-500 \mu \mathrm{L}$ de tampão Tris- $\mathrm{HCl} 0,1 \mathrm{M}$, pH 7,2 contendo $5 \mu \mathrm{L}$ de o-fenilenediamina $(10 \mathrm{mg} / \mathrm{mL}$ de metanol) e $1 \mu \mathrm{L}$ de peroxidase $(1 \mathrm{mg} / \mathrm{mL})$ foram incubadas com $20 \mu \mathrm{L}$ de LAAO em cada tubo por 30 minutos a $25^{\circ} \mathrm{C}$. A reação foi bloqueada por adição de $500 \mu \mathrm{L}$ de ácido cítrico a $10 \%$ e a absorbância lida em 490nm. A atividade da LAAO foi expressa como $1 \mathrm{U}=1 \mathrm{nmol}$ de $\mathrm{H}_{2} \mathrm{O}_{2} /$ min. 


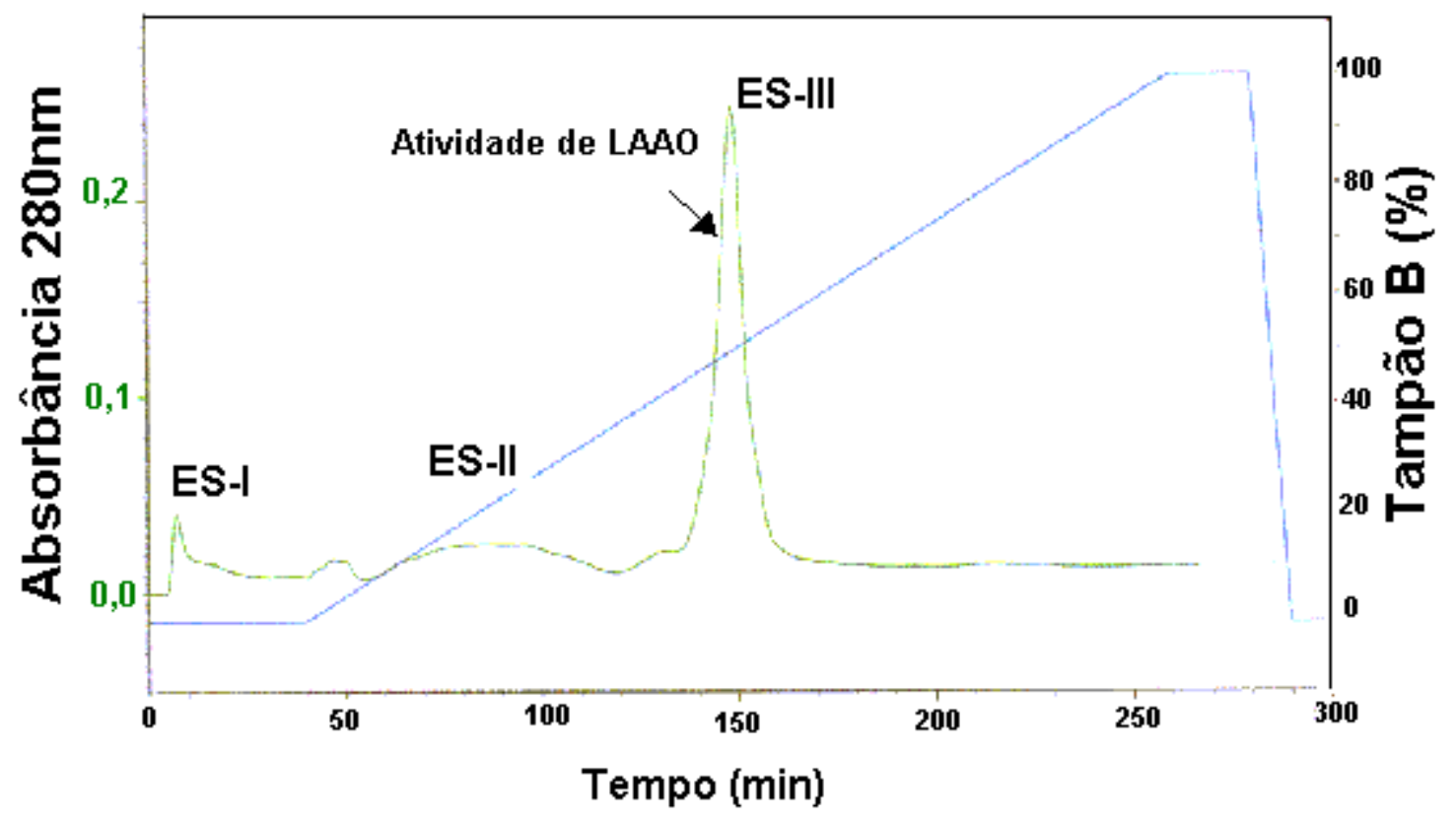

Figura 6 -: Purificação da fração BaPI por Cromatografia Líquida de Alta Eficiência, em coluna de troca iônica (Shodex ES-502N 7C - DEAE aniônica), com gradiente de concentração de bicarbonato de amônio (AMBIC) 0,05:0,5 M. A amostra (600 $\mu \mathrm{L}$ ) foi aplicada com o mesmo tampão permanecendo por 40 minutos, iniciando o gradiente linear de 0 a 100\% de B (AMBIC 0,5M) em 220 min mantendo-se por 20 min e voltando ao tampão inicial A (AMBIC 0,05M) em 20 min completando um total de 300 minutos, num fluxo de $0,4 \mathrm{~mL} / \mathrm{min}$ e a cromatografia foi monitorada em $280 \mathrm{~nm}$. Atividade Laminoácido oxidase foi determinada conforme descrito no item 3.2.2. 


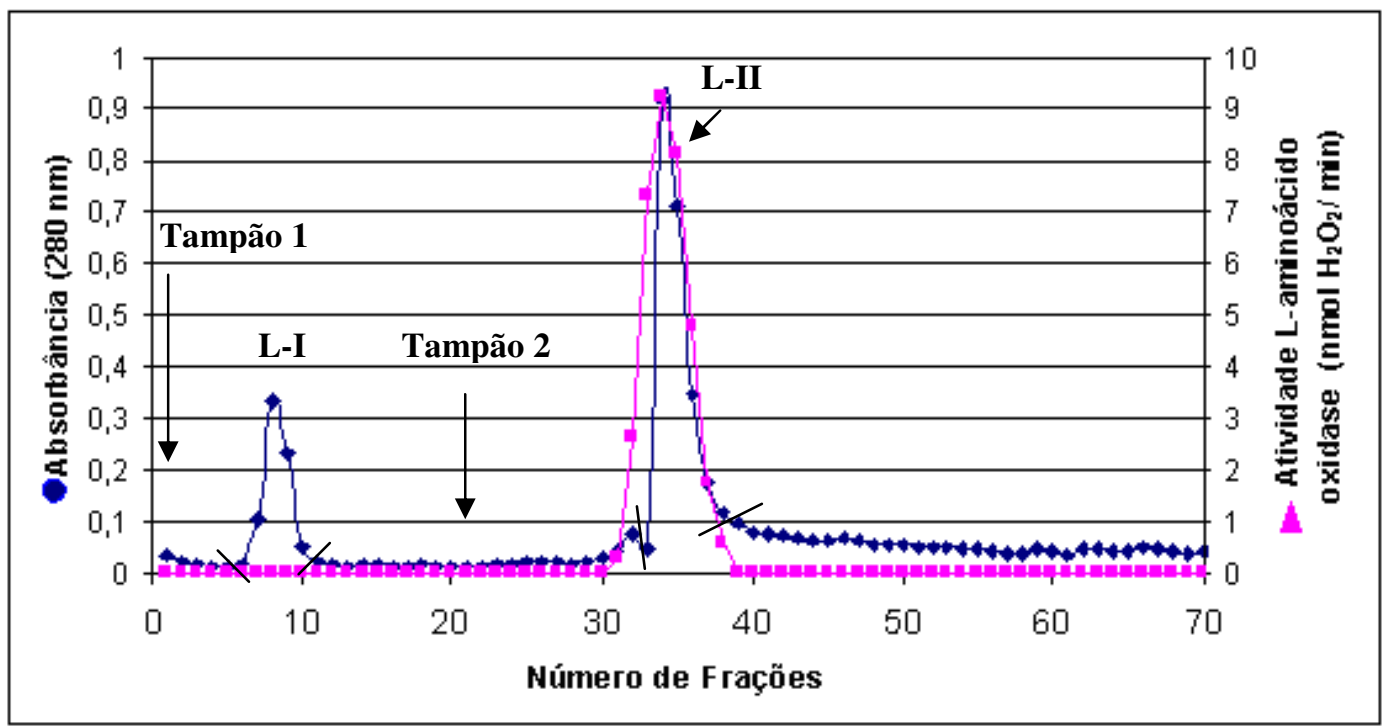

Figura 7: Cromatografia da fração ES-III em coluna de Lentil Lectina. Fluxo de $20 \mathrm{~mL}$ por hora, sendo coletados $3 \mathrm{~mL}$ por tubo. Foram aplicados $3 \mathrm{~mL}(2,0 \mathrm{mg} / \mathrm{mL})$ da fração ES-III concentrada. A coluna foi previamente equilibrada com tampão de ligação (Tubos 01 ao 20) correspondente a Tris- $\mathrm{HCl} 20 \mathrm{mM}, \mathrm{NaCl} 0,5 \mathrm{M}, \mathrm{MgCl}_{2} 1 \mathrm{mM}$ e $\mathrm{CaCl}_{2}$ $1 \mathrm{mM}, \mathrm{pH} 7,4$. Após eluição do primeiro pico (L-I) realizamos a troca de tampão (Tubo 21), para 0,1 a $0,5 \mathrm{M}$ de glicose em Tris- $\mathrm{HCl} 20 \mathrm{mM}$ e $0,5 \mathrm{NaCl}, \mathrm{pH} 7,4$ (Tubos 21 ao 70 ). A cromatografia foi monitorada em $280 \mathrm{~nm}$. Atividade L-aminoácido oxidase foi determinada conforme descrito no item 3.2.2. 


\subsection{Ensaio de Atividade Específica da LAAO.}

A Figura 8 representa a curva padrão de peróxido de hidrogênio utilizada para determinar a atividade específica da LAAO.

A análise comparativa da atividade específica do veneno com a LAAO purificada após cromatografia em Lentil Lectina apresentou uma afinidade 54 vezes maior que a do veneno bruto (Tabela 3 ).

A recuperação da LAAOBatrox após processo de purificação foi de 1,54\% (Tabela 3).

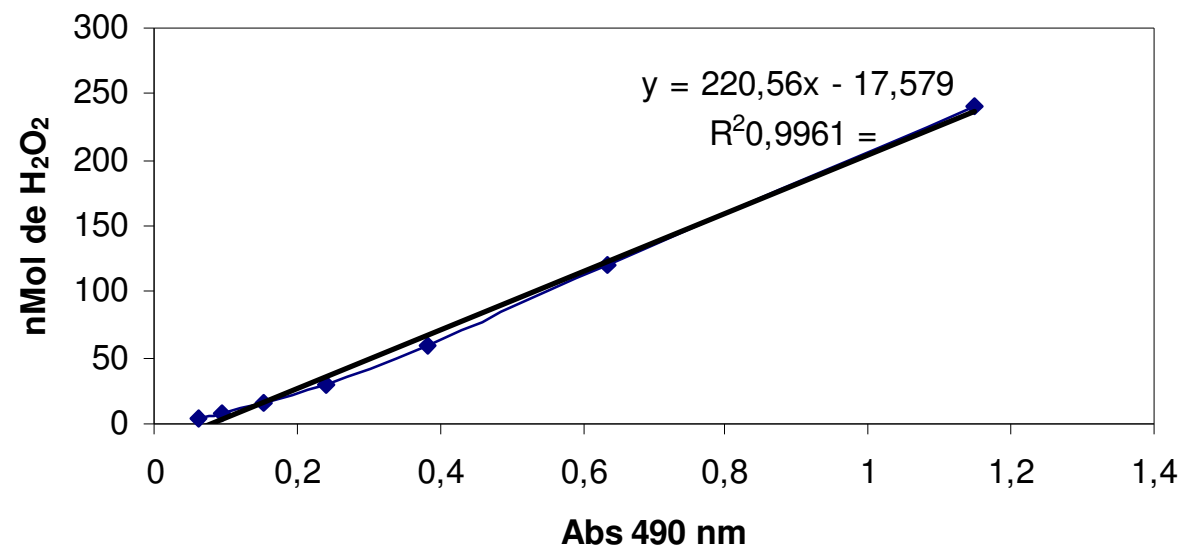

Figura 8: Uma curva padrão foi determinada a partir de diferentes concentrações de peróxido de hidrogênio $(3,75 ; 7,5 ; 15 ; 30 ; 60 ; 120$ e $240 \mathrm{nM}$ ). As concentrações de peróxido de hidrogênio foram obtidas após diluição em Tris- $\mathrm{HCl}, 0,1 \mathrm{M}$ pH 7,2 contendo $5 \mu \mathrm{L}$ de ODP $(10 \mathrm{mg} / \mathrm{mL}$ de metanol), $1 \mu \mathrm{L}$ de peroxidase $(1 \mathrm{mg} / \mathrm{mL})$ e incubado por 30 minutos a $25^{\circ} \mathrm{C}$. A reação foi parada pela adição de $500 \mu \mathrm{L}$ de ácido cítrico $10 \%(\mathrm{~m} / \mathrm{v})$ e a absorbância determinada em 490nm. 
Tabela 4. Análise Quantitativa das Etapas de Purificação da LAAOBatrox

\begin{tabular}{rcccc} 
& $\begin{array}{c}\text { Veneno } \\
\text { Bruto }\end{array}$ & $\begin{array}{c}\text { Sephadex } \\
\text { G-75 BaPI }\end{array}$ & $\begin{array}{c}\text { (DEAE-CLAE) } \\
\text { ES-III }\end{array}$ & $\begin{array}{c}\text { Lentil Lectina } \\
\text { L-II }\end{array}$ \\
\hline Proteínas totais $(m g)$ & 260 & 13,36 & 5,28 & 4,00 \\
Proteínas totais (\%) & 100 & 5,14 & 2,03 & 1,54 \\
Atividade LAAO (nmoles & 425,0 & 416,9 & 398,0 & 350,0 \\
$\left.\mathrm{H}_{2} \mathrm{O}_{2} / \mathrm{min}\right)$ & & & & \\
Atividade Específica $(\mathrm{U} / \mathrm{mg})$ & 1,63 & 31,60 & 75,37 & 87,5 \\
Recuperação Atividade\% & 100 & 98,1 & 93,8 & 82,5 \\
Purificação (número de vezes) & 1 & 19 & 46 & 54 \\
\hline
\end{tabular}




\subsection{Caracterização Bioquímica.}

\subsubsection{Eletroforese SDS-PAGE.}

As Figuras 9 e 10 representam o perfil protéico dos picos obtidos da filtração em Sephadex G-75 (Fig. 5), do ES-III da CLAE (Fig. 6) e da cromatografia em Lentil Lectina da enzima LAAO de B. atrox (Fig. 7), comparando com Padrão de Peso Molecular. Este resultado confirma a pureza da LAAO, pois apresenta uma única banda após as etapas de purificação realizadas.

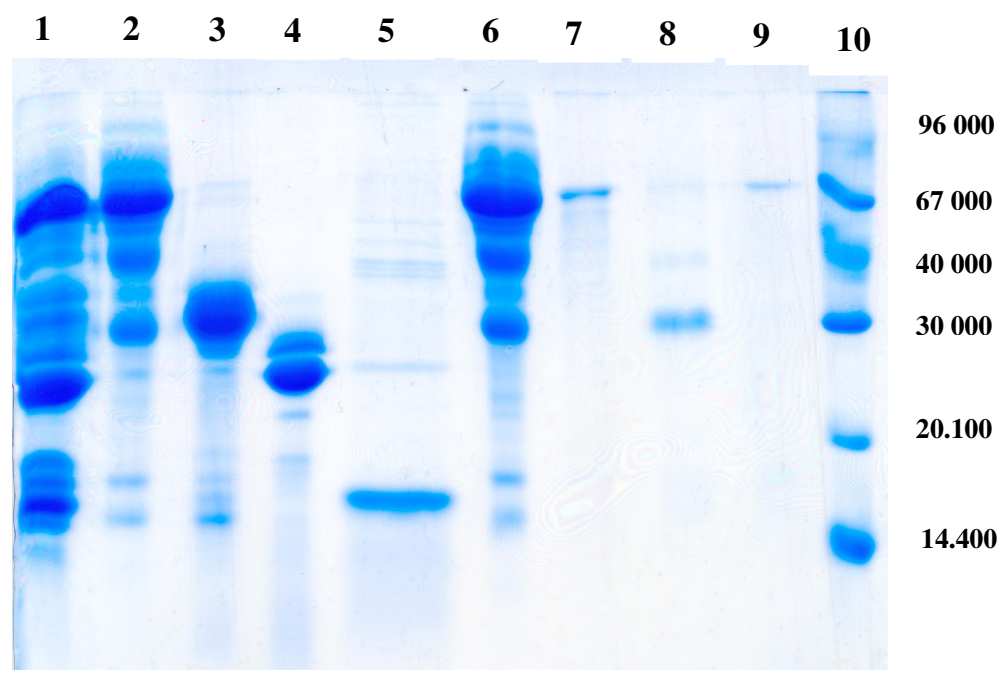

Figura 9: Eletroforese em Gel de Poliacrilamida a 12\%: 1 - Veneno Bruto (VB), 2 - BaPI, 3BaPII, 4 - BaPIII, 5 - BaPIV, 6 - BaPI, 7 - ES-III, 8 - L-I, 9 - L-II - LAAOBatrox, 10 - Padrão de Peso Molecular (PPM). Condições: $200 \mathrm{~V}$ (voltagem), $10 \mathrm{~mA}$ (amperagem) em 2h 50min. (tempo). Corada com Azul Coomassie G-250 0,2\% em $\mathrm{H}_{2} \mathrm{O} / \mathrm{MeOH}$ 1:1 (v/v) durante 15 min. O descoramento foi obtido com trocas sucessivas de solução de ácido acético glacial à 10\% (v/v). 


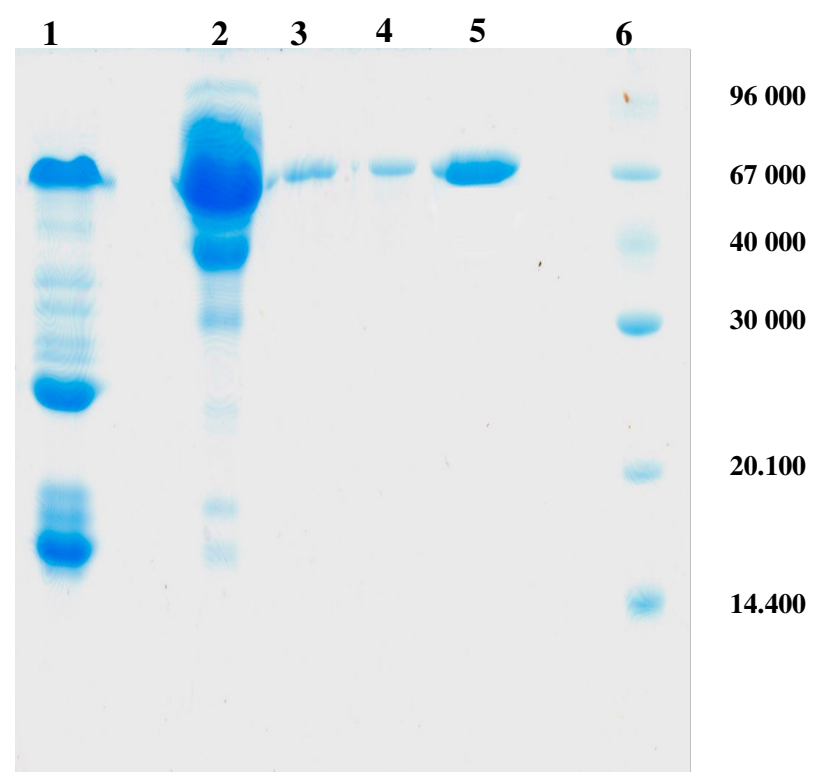

Figura 10: Eletroforese em Gel de Poliacrilamida a 12\%: 1 - Veneno Bruto (VB), 2 - BaPI -, 3, 4 e 5 - LAAO de B.atrox, 6 - Padrão de Peso Molecular (PPM) - (Fosforilase B 96.000 , Albumina 67.000, Ovoalbumina 43.000, Anidrase Carbônica 30.000, Inibidor de Tripsina de soja 20.100, Lactoalbumina 14.400). Condições: $200 \mathrm{~V}$ (voltagem), $10 \mathrm{~mA}$ (amperagem) em 2h 50min. (tempo). Corada com Coomassie G-250 0,2\% em $\mathrm{H}_{2} \mathrm{O} / \mathrm{MeOH}$ 1:1 (v/v) durante $15 \mathrm{~min}$. O descoramento foi obtido com trocas sucessivas de solução de ácido acético glacial à 10\% (v/v). 


\subsubsection{Determinação da Massa Molecular Relativa}

Em condições redutoras (SDS-PAGE) a LAAO purificada apresentou uma única banda com massa molecular relativa aparente de 67.000 (Figuras. 11A e B e 12).

(A)

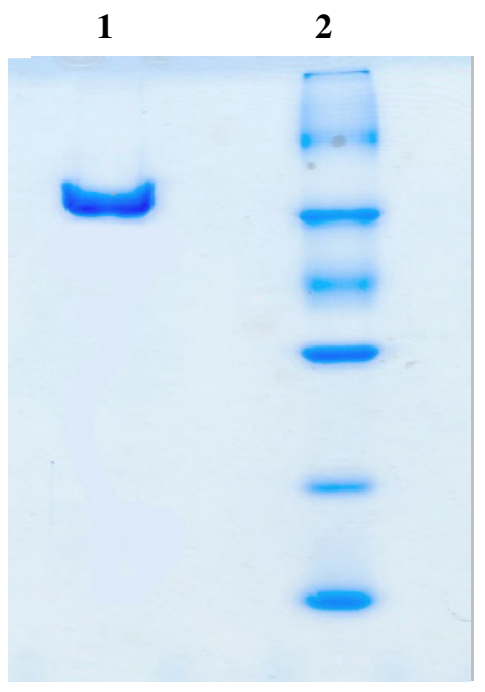

(B)

96000

67000

40000

30000

20.100

14.400
1

2

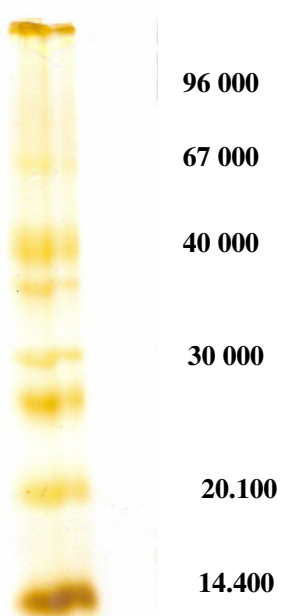

Figura 11: (A). Determinação da massa molecular relativa da LAAOBatrox. Eletroforese em Gel de Poliacrilamida a 12\%: 1 - LAAO de B. atrox, 2 - Padrão de Peso Molecular (PPM) - (Fosforilase B 96.000, Albumina 67.000, Ovoalbumina 43.000, Anidrase Carbônica 30.000, Inibidor de Tripsina de soja 20.100, Lactoalbumina 14.400), Condições: $200 \mathrm{~V}$ (voltagem), 10mA (amperagem) em 2h 50min. (tempo). Corada com Azul Coomassie G-250 0,2\% em $\mathrm{H}_{2} \mathrm{O} / \mathrm{MeOH} 1: 1$ (v/v) durante 15 min. O descoramento foi obtido com trocas sucessivas de solução de ácido acético glacial à $10 \%$ (v/v). (B). Determinação da massa molecular relativa da LAAOBatrox e confirmação de pureza dessa proteína. Eletroforese em Gel de Poliacrilamida a 12\%: 1 - LAAOBatrox, 2 - Padrão de Peso Molecular (PPM). Corada com solução de Nitrato de Prata 2,5\%. 


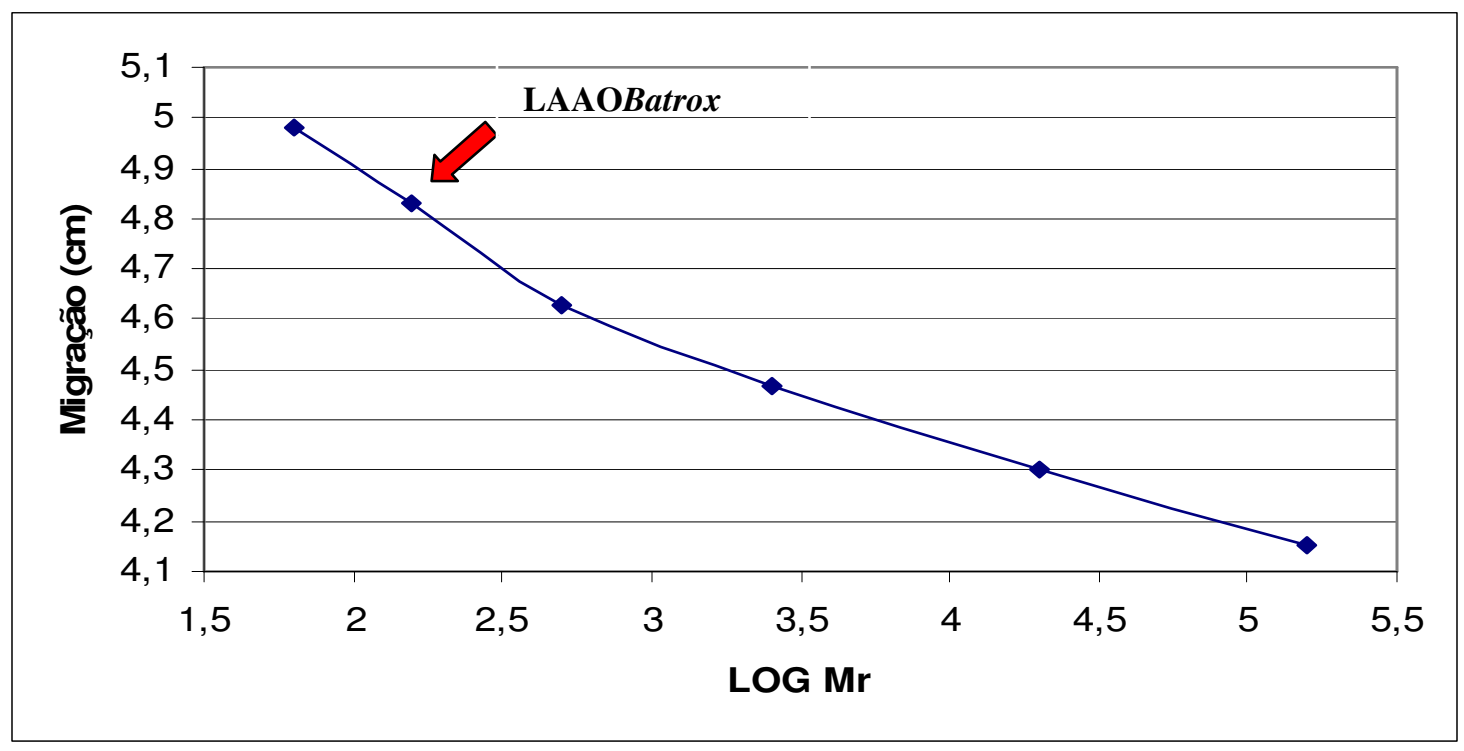

Figura 12: Determinação da Massa Molecular relativa de LAAOBatrox por SDS-PAGE. Eletroforese realizada em condições redutoras em gel de poliacrilamida 12\%, tampão Tris-glicina $0,01 \mathrm{M}$; pH 8,3 e SDS $0,1 \%$ por 150 minutos, $10 \mathrm{~mA}$ a $100 \mathrm{~V}$. Os valores foram expressos em migrações eletroforéticas $\mathrm{Rf}(\mathrm{cm})$ contra massa molecular de cada marcador. Padrão de massas moleculares relativas (Fosforilase B 96.000, Albumina 67.000, Ovoalbumina 43.000, Anidrase Carbônica 30.000, Inibidor de Tripsina de soja 20.100 Lactoalbumina 14.400). 


\subsubsection{Determinação do Ponto Isoelétrico}

O pI da LAAOBatrox foi determinado por focalização isoelétrica como mostra a Fig.13, apresentando um pI de 4,4.

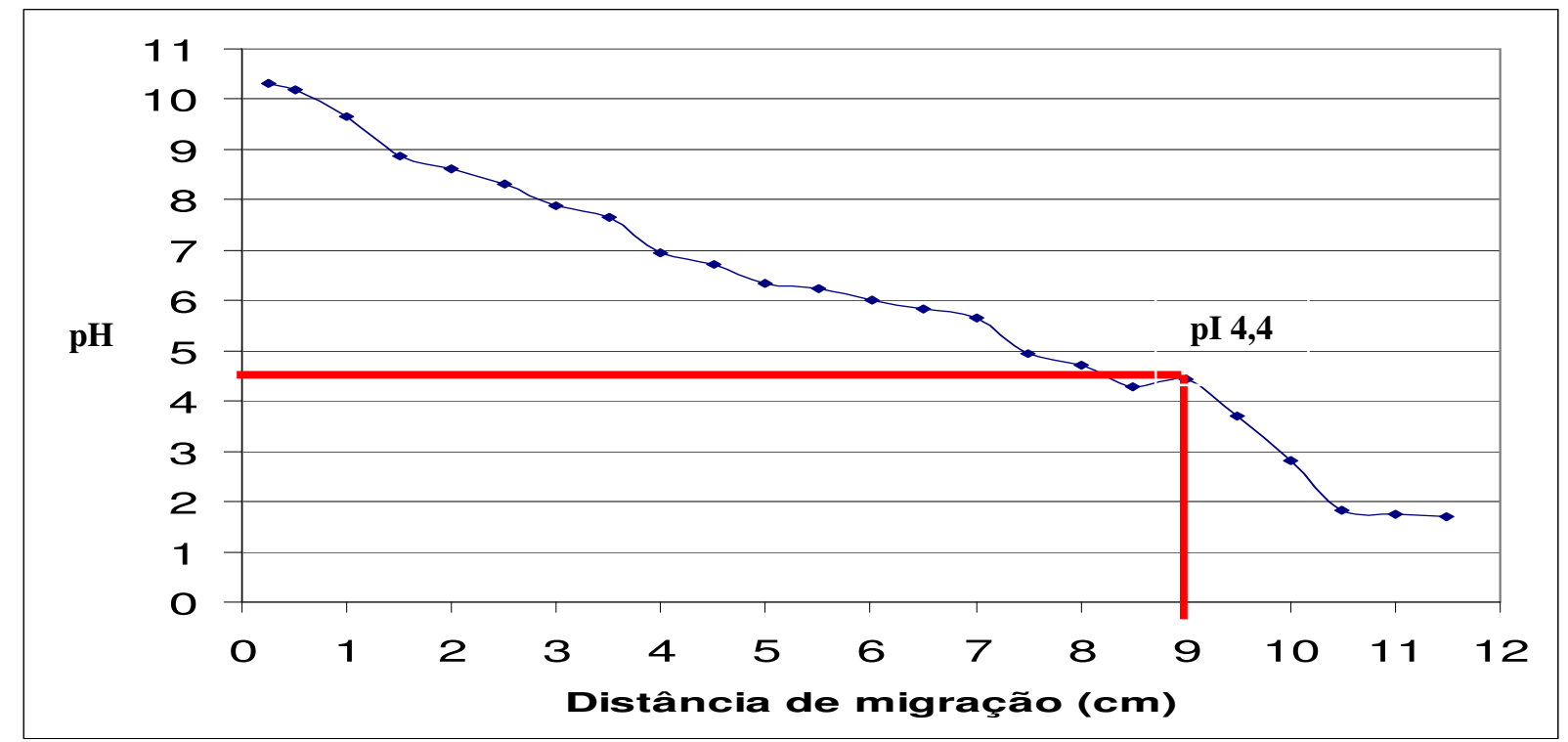

Figura 13: Determinação do Ponto Isoelétrico da LAAOBatrox. A - Eletrofocalização da LAAOB atrox em gel de poliacrilamida a $12 \%$. Uma pré-focalização foi realizada a $300 \mathrm{~V}$ e $20 \mathrm{~mA}$ por 30 minutos seguida por focalização a $300 \mathrm{~V}$ e $15-2 \mathrm{~mA}$ por 50 minutos, $800 \mathrm{~V}(4-2 \mathrm{~mA})$ por 60 minutos e finalmente a $1200 \mathrm{~V}(3-1 \mathrm{~mA})$ por 50 minutos. B - Gradiente de $\mathrm{pH}$ para focalização isoelétrica. 


\subsubsection{Composição em Aminoácido.}

A Tabela 5 mostra a composição em aminoácido da LAAOBatrox. A LAAO após composição em aminoácidos apresentou 588 resíduos apresentando alto conteúdo de Asx (ácido aspártico ou asparagina) Glx (ácido glutâmico ou glutamina), Lisina e Arginina.

Tabela 5. Composição em aminoácidos da LAAO de B. atrox.

\begin{aligned} & Asx 51 \\ & Glx 44 \\ & Ser 32 \\ & Gly 32 \\ & His 17 \\ & Arg 19 \\ & Thr 29 \\ & Ala 45 \\ & Pro 28 \\ & Tyr 14 \\ & Val 83 \\ & Met 16 \\ & 1/2 Cys 6 \\ & Ile 36 \\ & Leu 53 \\ & Phe 29 \\ & Lys 54 \\ & Trp nd \\ & \hline Total 588 resíduos \\ & \hline Peso Molecular 64.680 \\ & \hline\end{aligned}

Quantidades de 0,5 a $10 \mu \mathrm{g}$ da proteína foram hidrolisadas por 24 horas com $300 \mu \mathrm{L}$ de $\mathrm{HCl} 6 \mathrm{~N}$ a vácuo com fluxo de $\mathrm{N}_{2}$. O hidrolisado foi submetido a derivatização com $20 \mu \mathrm{L}$ do reagente de derivatização (metanol/ $\mathrm{H}_{2} \mathrm{O} /$ Trietilamina/PITC (7:1:1:1:) por 20 minutos à temperatura ambiente. Após retirar o excesso de reagente, a amostra foi aplicada a uma coluna de fase reversa acoplada a um cromatógrafo líquido de alta pressão e um contador. A eluição dos PTC-aminoácidos foi realizada em um gradiente de $10 \%$ a $5 \%$ de B (acetronitrila $60 \%$ durante 28 minutos com fluxo de 1,0mL/min). 


\subsubsection{Deglicosilação.}

Após deglicosilação com uso de PGNase-F o conteúdo de açúcar foi de aproximadamente $12 \%$ do seu peso.

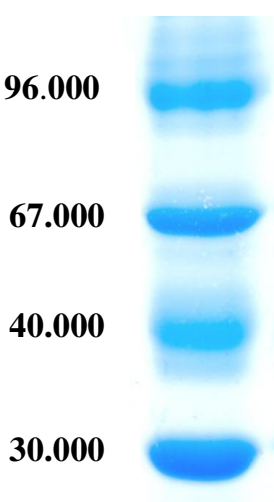

Figura 14: Determinação do conteúdo de açúcar após tratamento com PGNase. LAAO tratada com PGNase e submetida à eletroforese SDS-PAGE 12\% e LAAOBatrox sem tratamento com PGNase submetida à eletroforese SDS-PAGE 12\%. Padrão de Peso Molecular (PPM) - (Fosforilase B 96.000, Albumina 67.000, Ovoalbumina 43.000, Anidrase Carbônica 30.000, Inibidor de Tripsina de soja $20.100 \mathrm{kDa}$, Lactoalbumina $14.400 \mathrm{kDa}$ ), Condições: $200 \mathrm{~V}$ (voltagem), 10mA (amperagem) em 2h 50min. (tempo). Corada com Azul Coomassie G-250 0,2\% em $\mathrm{H}_{2} \mathrm{O} / \mathrm{MeOH}$ 1:1 (v/v) durante $15 \mathrm{~min}$. O descoramento foi obtido com trocas sucessivas de solução de ácido acético glacial à $10 \%$ (v/v). 


\subsubsection{Sequenciamento da LAAOBatrox em comparação com outras LAAOs de} venenos de serpentes.

A Figura 15 representa o espectro de massa dos peptídeos obtidos pela hidrólise enzimática da LAAO com tripsina e a sequiência dos peptídeos trípticos foi deduzida da série de fragmentos de íons b e y produzidos pela espectrometria de massa por dissociação induzida por colisão (CID-MS/MS). A Figura 16 representa o espectro de massa dos íons 569,6 $\left[\mathrm{M}+2 \mathrm{H}^{+}\right]$, indicando alta homologia dos peptídeos internos de LAAO de Bothrops moojeni com os da LAAO de Bothrops atrox.

A Tabela 6 representa a comparação da sequiência dos peptídios trípticos internos com a seqüência conhecida de LAAOs de outros venenos no banco de dado BLASP, confirmando forte similaridade desta enzima com LAAOs isoladas dos venenos de Bothrops moojeni e Bothrops jararacussu. A Tabela 6 compara a região N-terminal da LAAO de Bothrops atrox com as seqüências de aminoácidos de outras LAAOs derivadas de venenos de serpentes. 


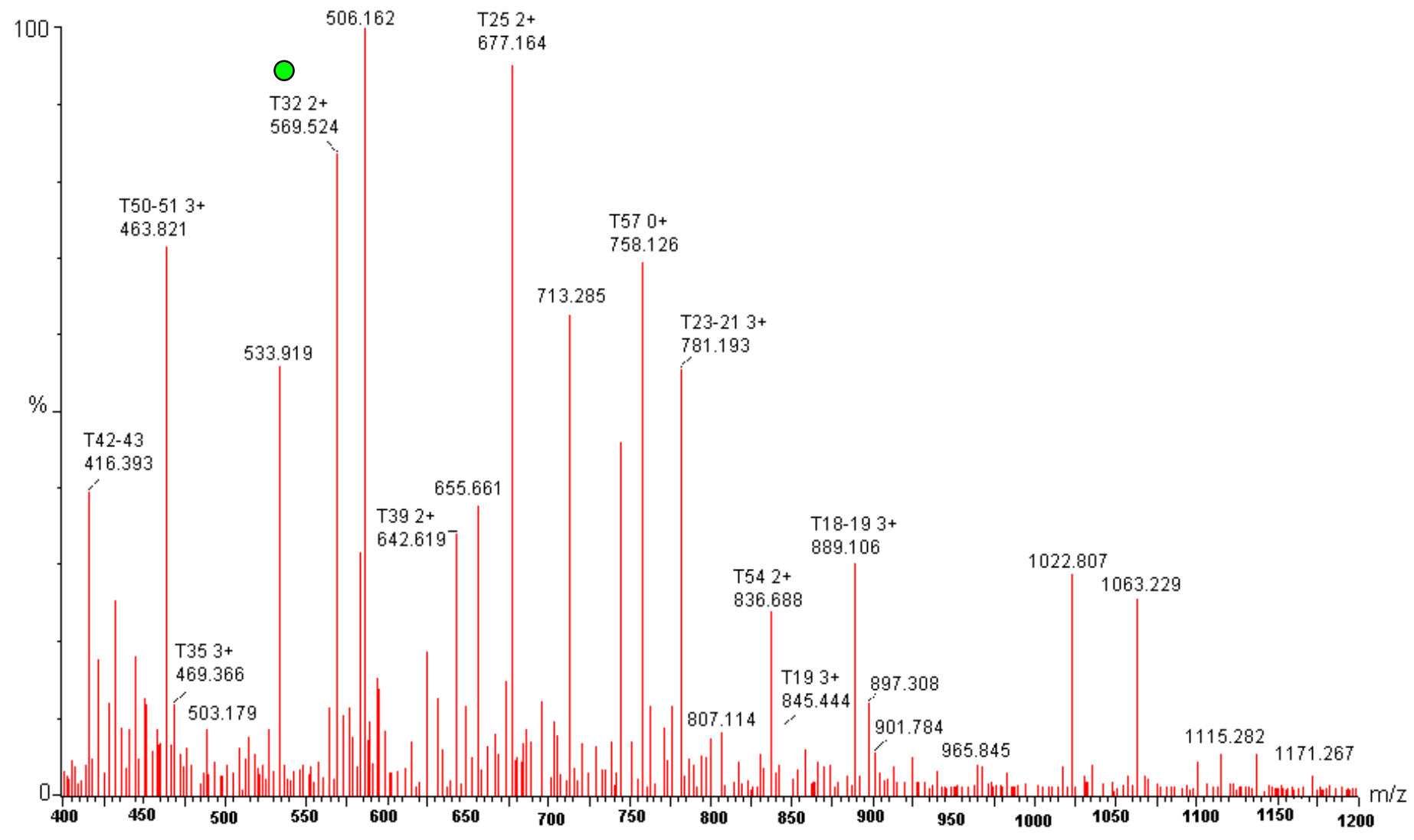

Figura 15: Espectro de massa dos peptídeos tripsínicos obtidos por electrospraytriple-quadruple-MS de LAAOBatrox. 
L-amino oxidase Bothrops atrox in situ tryp dig, poros, $30 \mathrm{ul} 60 \% \mathrm{MeOH}, 5 \% \mathrm{Formic}$ ac. nflw

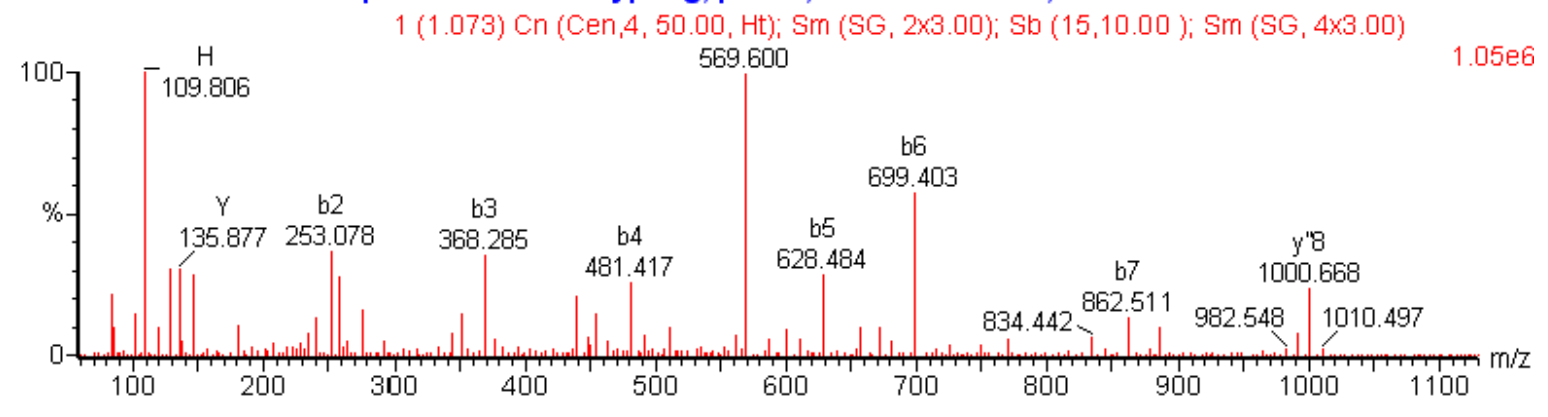

L-amino acid oxidase [fragment] Bothrops moojeni

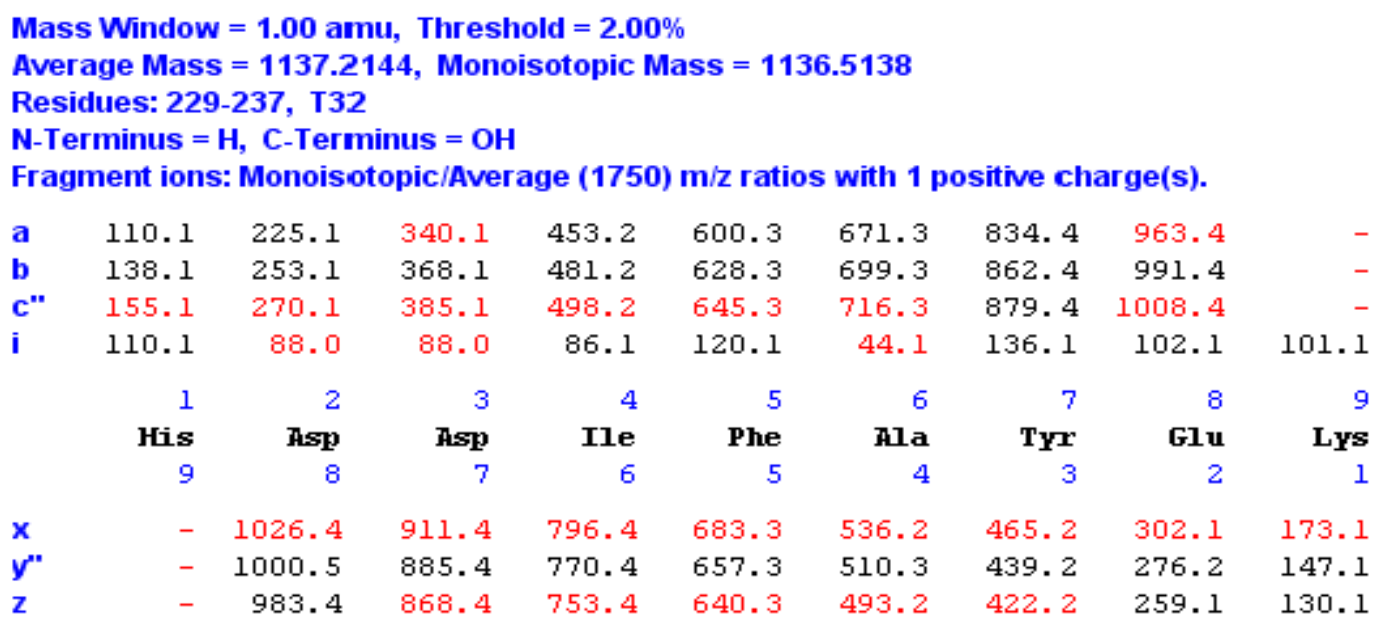

Figura 16: Espectro de Massa CID-MS/MS dos íons 569,6 $\left[\mathrm{M}+2 \mathrm{H}^{+}\right]$referente ao íon destaque da Figura 15. Indica alta homologia com seqüência interna de peptídeo de LAAO de Bothrops moojeni. 
Tabela 6. Alinhamento das seqüências parciais determinadas de fragmentos peptídicos trípticos de LAAO B. atrox.

\begin{tabular}{|c|c|c|c|c|}
\hline $\begin{array}{c}\text { Nome do Peptídeo } \\
\text { (número de } \\
\text { acesso) }\end{array}$ & Espécie & Observação & $\begin{array}{l}\text { Seqüiência } \\
\left(M+2 H^{+}\right)\end{array}$ & $\begin{array}{c}\% \\
\text { Homologia }\end{array}$ \\
\hline
\end{tabular}

\begin{tabular}{llll} 
LAAO & B. atrox & HDDIFAYEK & \\
AAR31983-1 & B. moojeni & $229-------237$ & 100 \\
AAR31182-1 & B. jararacussu & $236-------244$ & 100 \\
AAR20248-1 & Gloydirus halys & $241-------249$ & 100 \\
AAQ16181-1 & Trimerisurus stejnegeri & $241-------249$ & 100 \\
BAB69450-1 & Agkistrodon blomhoffi & $241-------249$ & 100 \\
Sp/P81382 & Calloselasma rhodostoma & $241--------249$ & 100 \\
50513732 & Agkistrodon halys & $223-------231$ & 100 \\
\hline
\end{tabular}

\begin{tabular}{|c|c|c|c|c|}
\hline LAAO & B. atrox & 11654416 & IKFEPPLPPK & \\
\hline AAR31183-1 & B. moojeni & & 308--------317 & 100 \\
\hline AAR31182-1 & B. jararacussu & & 315--------324 & 100 \\
\hline AAR20248-1 & Gloydirus halys & & 320--------329 & 100 \\
\hline AAD45200-1 & Crotalus atrox & & 320--------329 & 100 \\
\hline AAC32267-1 & Crotalus adamanteus & & 320--------329 & 100 \\
\hline BAB69450-1 & Agkistrodon blomhoffi & & 320---------329 & 100 \\
\hline 50513732 & Agkistrodon halys & & 302---------311 & 100 \\
\hline AAQ16182-1 & Trimerisurus stejnegeri & & 320--------327 & 100 \\
\hline AAJ89681-1 & Notechis scutellatus & & 323--------330 & 100 \\
\hline AAY89680-1 & Oxyuramus scutellatus & & 323--------330 & 100 \\
\hline
\end{tabular}
LAAO
B. atrox
13524643

SAGQLYEESLQK

\begin{tabular}{ll} 
AAR31183-1 & B. moojeni \\
AAR31182-1 & B. jararacussu \\
\hline
\end{tabular}

158---------------169

100

AAR31182-1

B. jararacussu

$165---------------176$

100

\begin{tabular}{|c|c|c|c|c|}
\hline LAAO & B. atrox & 13885008 & KFWEDDGIHGGK & \\
\hline AAC3267-1 & Crotalus adamantus & & 352---------------363 & 100 \\
\hline AAR31183-1 & B. moojeni & & 340---------------351 & 100 \\
\hline AAR31182-1 & B. jararacussu & & 347----------------358 & 100 \\
\hline P81382 & Calloselasma rhodostoma & & 352---------------363 & 100 \\
\hline
\end{tabular}

\begin{tabular}{llll} 
LAAO & B. atrox & 22715148 & IYFAGETAQAHGWIDSTIK \\
P81382 & Calloselasma rhodostoma & $470------------------------489$ & 95 \\
AAR31183 & B. moojeni & $458---------------------472$ & 95 \\
AAD45200 & Crotalus atrox & $470---------------------489$ & 90 \\
AAC32267-1 & Crotalus adamanteus & $470---------------------489$ & 90 \\
AAR31182 & B. jararacussu & $465-----------------------484$ & 90 \\
\hline
\end{tabular}

Resíduos de aminoácidos idênticos aos de LAAO de B. atrox são indicados por pontos.

A seqüência dos peptídeos trípticos foram determinadas por MS/MS. 
Tabela 7: Alinhamento da região N-terminal da LAAOBatrox com LAAOs isoladas de outros venenos de serpentes.

\begin{tabular}{|c|c|c|}
\hline Proteína & Espécie & Seqüência N-terminal \\
\hline LAAOBatrox & B. atrox & ADDN-NPLEE-NIRRDD \\
\hline BpirLAAO & B. pirajai & ADDK-NPLEE-FRETNY \\
\hline BmooLAAO & B. moojeni & ADDR-NPLEECFRETDY \\
\hline BjussuLAAO & B. jararacussu & ADDR-NPLEECFRETDY \\
\hline Apoxin & Crotalus atrox & AHDR-NPLEECFRETDY \\
\hline LAAO & Agkistrodom halys & ANDR-NPLEECFRETDY \\
\hline LAAO & Calloselasma & ADDR-NPLAECFOENDY \\
\hline Comparação do seqüenciamento N-terminal de LAAOBatrox com outras LAAOs isoladas \\
\hline de B. pirajai, B., moojeni, B. jararacussu, Crotalus atrox, A. halys e Calloselasma . Os \\
\hline resíduos conservados na seqüência são marcados com asteriscos.
\end{tabular}




\subsubsection{Ensaio de Especificidade de substrato.}

A atividade de L-aminoácido oxidase foi testada usando diferentes aminoácidos como substrato (Fig.17). Foi detectada alta atividade para aminoácidos hidrofóbicos L-Met e L-Leu. A LAAO apresentou baixa atividade catalítica para L-Cis, L-Iso, L-Phe, L-Tyr e L-Trp. Para outros aminoácidos não apresentou atividade catalítica.

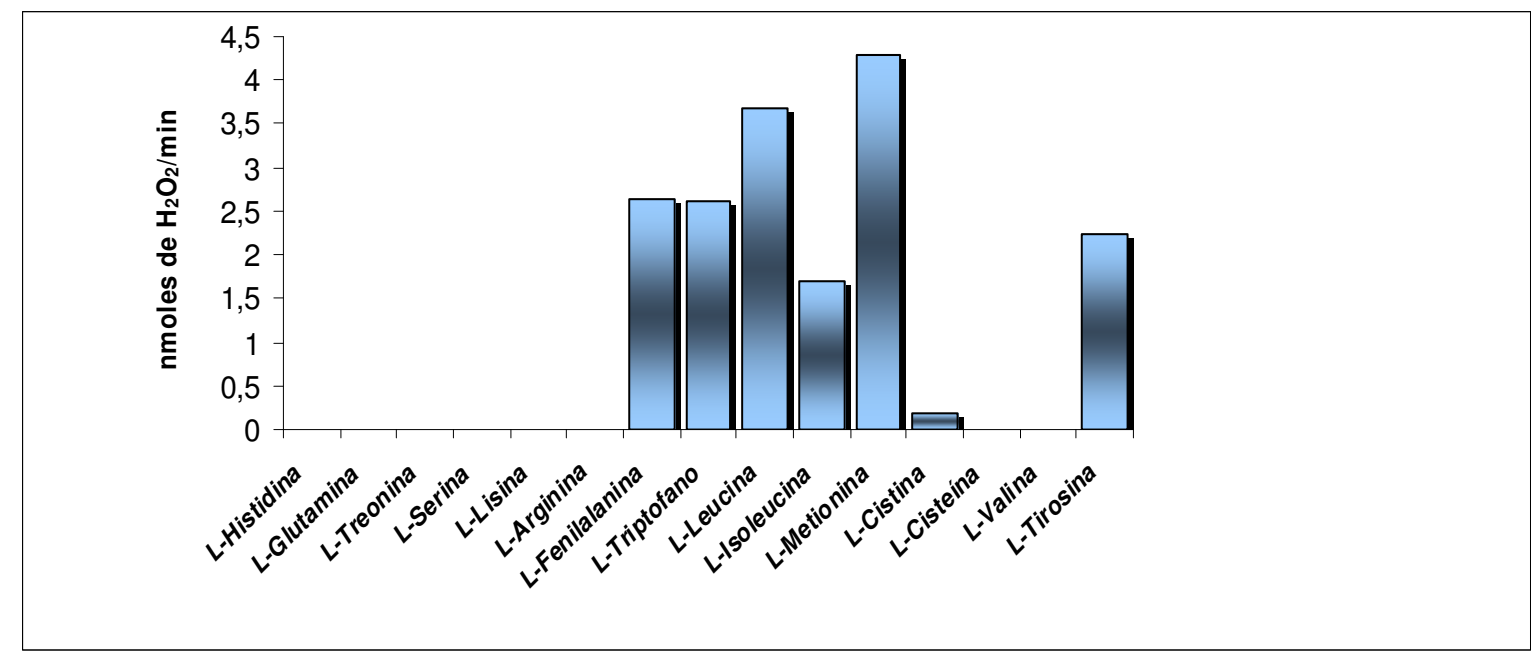

Figura 17: Ensaio de especificidade de substrato. $2 \mathrm{nM}$ de diferentes aminoácidos foram suspensos em $500 \mu \mathrm{L}$ de tampão Tris-HCl $0,1 \mathrm{M}, \mathrm{pH} 7,2$ contendo $5 \mu \mathrm{L}$ de o-fenilenediamina $(10 \mathrm{mg} / \mathrm{mL}$ de metanol) e $1 \mu \mathrm{L}$ de peroxidase $(1 \mathrm{mg} / \mathrm{mL})$ ei incubados com $2 \mu \mathrm{g}$ de LAAO por 30 minutos a $25^{\circ} \mathrm{C}$. A reação foi bloqueada por adição de $500 \mu \mathrm{L}$ de ácido cítrico a 10\% e a absorbância lida em 490nm. 


\subsection{Caracterização Funcional.}

\subsubsection{Indução de Edema.}

As Figuras 18 A e B representam a porcentagem de edema verificada após a aplicação por via i.d., na pata direita traseira de LAAO (Figura 18 A) e análise comparativa induzida pelo veneno bruto de B.atrox e a LAAOBatrox (Figura 18 B).

O edema induzido pela LAAOBatrox $(100 \mu \mathrm{g} / \mathrm{animal})$ é significativo no período de 0,5 a 4 horas em relação ao controle de PBS, permanecendo com nível médio de $40 \%$ de edema. Após 12 horas da administração da LAAOBatrox o edema volta ao nível basal. Comparativamente ao veneno bruto, a LAAOBatrox é menos edematogênica e retorna ao nível basal em 12 horas da sua administração enquanto que, o edema induzido pelo veneno bruto, não retorna ao nível basal mesmo após 72 horas da sua administração. Até 24 horas após a administração do veneno bruto de B. atrox o edema permanece em torno de $80 \%$. 
A)

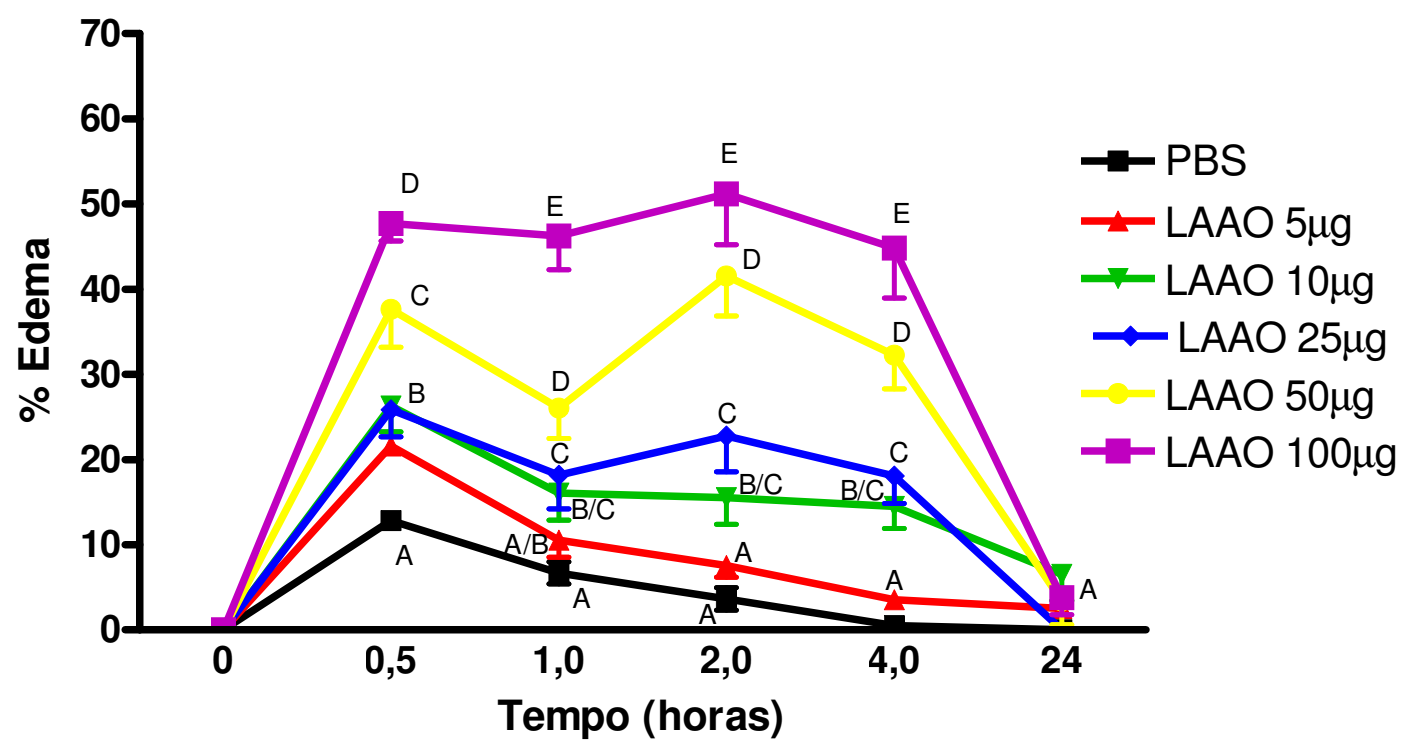

B)

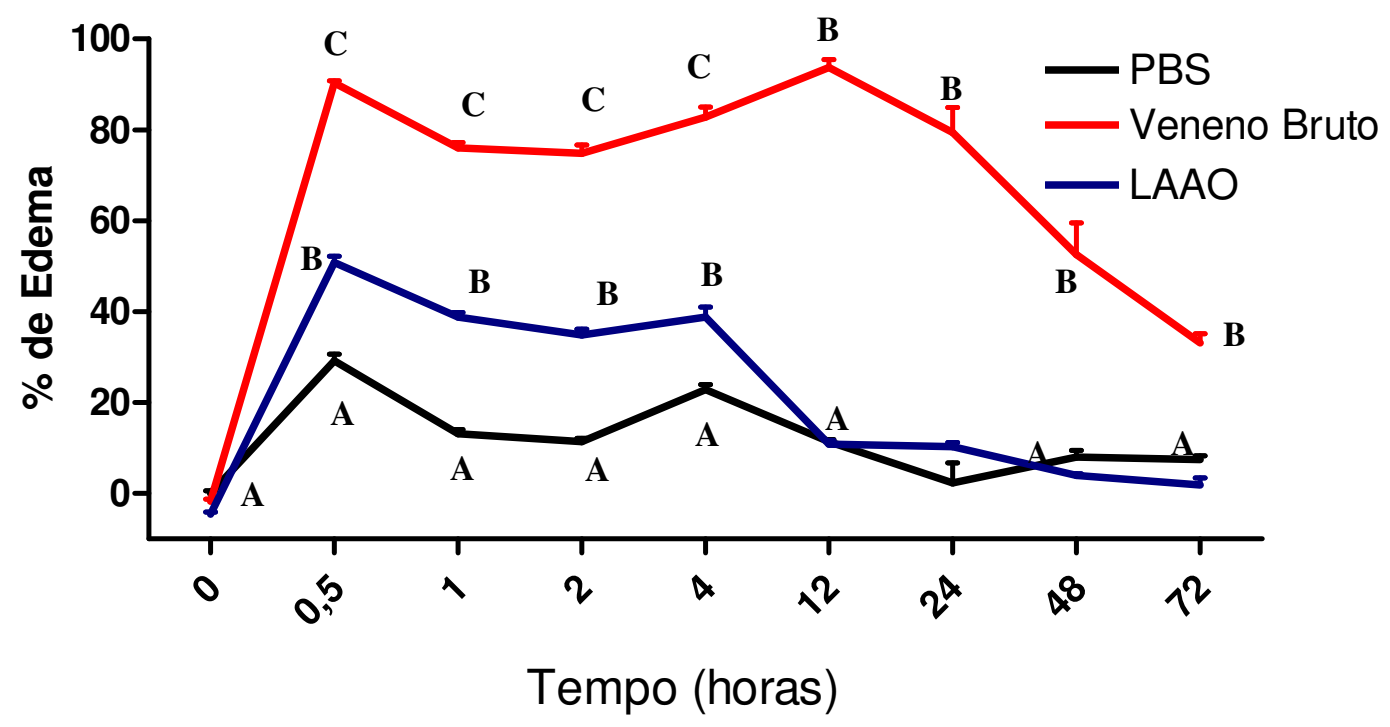

Figura 18: Indução de edema em pata traseira direita. A - Diferentes concentrações de LAAO $(5,10,25,50$ e $100 \mu \mathrm{g})$. B -Análise comparativa do edema induzido pelo veneno bruto de B.atrox e LAAOBatrox. PBS 50 $\mu \mathrm{L} /$ animal, usado como controle

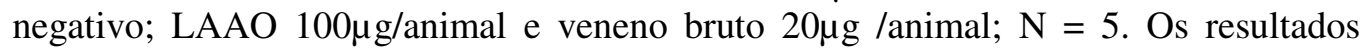
representam a média \pm DP. Valores estatísticos analisados conforme cada tempo. Foram atribuídas letras para representar diferenças estatisticamente significativas $(P<$ $0,05)$. 


\subsubsection{Atividade Hemorrágica.}

As Figuras 19 e 20 mostram a hemorragia induzida pela LAAO de B. atrox, verificada após a aplicação por via i.d. na região dorsal dos animais.

Os grupos tratados com $50 \mu \mathrm{g}$ da mencionada toxina não apresentaram hemorragia. A toxina não apresentou atividade hemorrágica quando comparada ao grupo controle do veneno bruto de $B$. atrox (VB) e o pico BaPI proveniente da filtração em gel de Sephadex G-75 (Figs. 19 e 20).

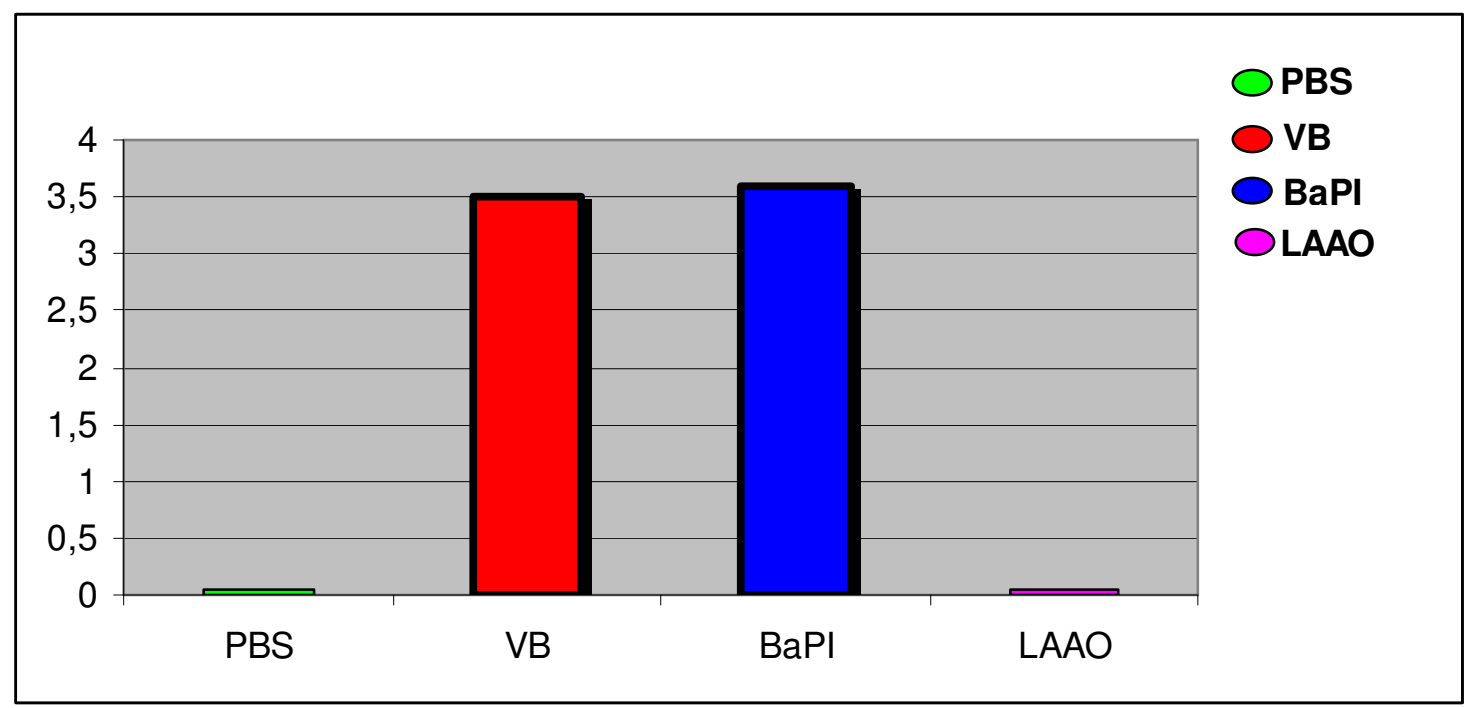

Figura 19: Indução da hemorragia em camundongos pela LAAO de $B$. atrox. Tratamentos:

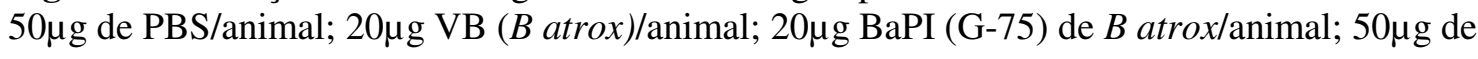
LAAO de $B$ atrox/animal; $\mathrm{n}=5$. Os resultados representam a média $\pm \mathrm{DP}$. 

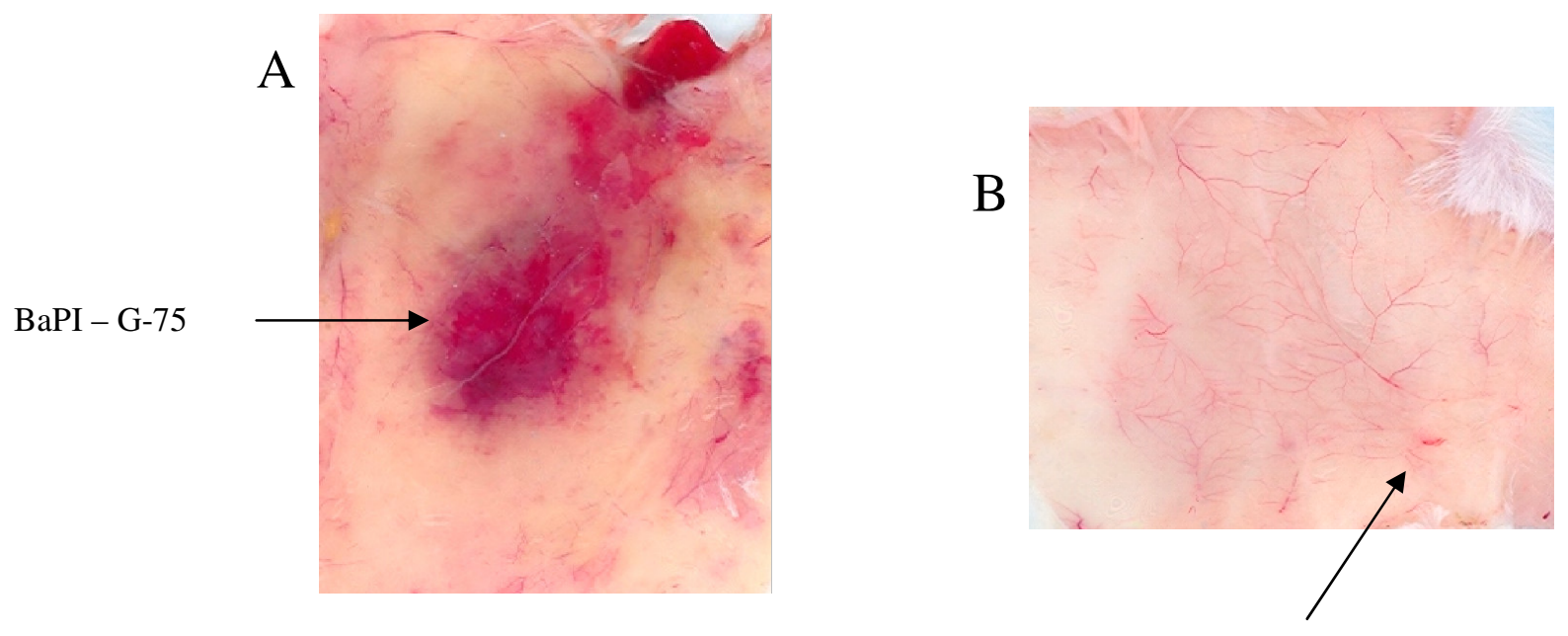

LAAOBatrox $(50 \mu \mathrm{g})$

Figura: 20: Indução da hemorragia em camundongos pela LAAO de B. atrox. A) Atividade hemorrágica induzida por BaPI; B) Atividade hemorrágica induzida por LAAO de B. atrox.

\subsubsection{Atividade Coagulante.}

A LAAOBatrox apresentou atividade coagulante sobre o plasma. A DCM foi de 3,8 $\mu$ g. Como controle do experimento utilizamos $25 \mu \mathrm{L}$ da solução de $\mathrm{CaCl}_{2}(0,25 \mathrm{mM})$, onde o plasma coagulou em 3 minutos. 


\subsubsection{Atividade de Agregação Plaquetária.}

As Figuras 21 e 22 demonstram o perfil de agregação plaquetária induzido por LAAOBatrox em plasma de coelho.

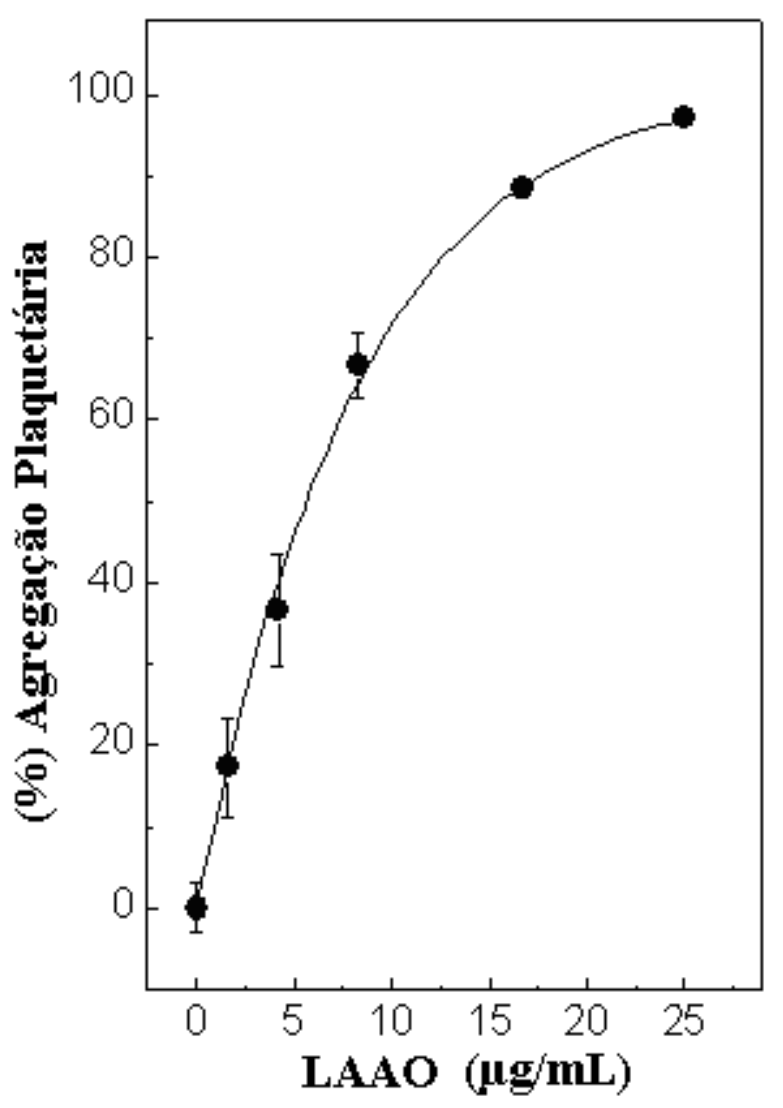

Figura 21: Efeito da LAAOBatrox sobre agregação plaquetária. Plaquetas de coelhos lavadas (3-4 $\mathrm{X} 10^{5}$ cells $/ \mu \mathrm{L}$ ) foram misturadas com diferentes concentrações de LAAOBatrox à temperatura de $37^{\circ} \mathrm{C}$. A agregação plaquetária máxima, que atingiu o efeito de $100 \%$, foi obtida com colágeno (5 $\mu \mathrm{g} / \mathrm{mL}$ ) e comparada com valores obtidos com LAAOBatrox. O valor de agregação em $0 \%$ foi registrado na presença de plaquetas lavadas isoladas de coelho ou após a adição de tampão Tyrode. Os resultados são expressos com média e desvio padrão de dois experimentos independentes $(\mathrm{n}=4)$. 




Figura 22: Efeito da Catalase na indução de Agregação Plaquetária por LAAOBatrox. Plaquetas lavadas de coelhos (3-4 x 105 células $/ \mu \mathrm{L})$ foram incubadas a $37^{\circ} \mathrm{C}$ por 2 minutos com diferentes concentrações de catalase $(80-500 \mu \mathrm{g} / \mathrm{mL})$. Em seguida, LAAOBatrox foi adicionada para observação do efeito de agregação.100\% de agregação plaquetária foi obtido com uma concentração supramáxima de LAAOBatrox $(8 \mu \mathrm{g} / \mathrm{mL})$ na ausência de catalase. 


\subsubsection{Atividade Antitumoral.}

\subsubsection{Ensaio de atividade antitumoral.}

Para a análise da atividade antitumoral foram utilizadas as linhagens celulares Jurkat, B16F10, PC12 e mononucleares do sangue periférico normais tratadas ou não com LAAO em várias concentrações $(5 ; 10 ; 25$ e $50 \mathrm{ug} / \mathrm{mL})$. As culturas não tratadas foram utilizadas como controle negativo e como controle positivo utilizamos culturas tratadas com ciclofosfamida $(200 \mathrm{ug} / \mathrm{mL})$.

A LAAOBatrox em $50 \mu \mathrm{g} / \mathrm{mL}$ induziu uma atividade citotóxica de $70 \%$ sobre a

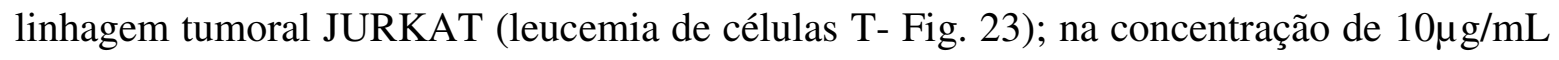
o efeito citotóxico foi de $60 \%$ sobre linhagens de células tumorais B16 F10 (melanoma de células de camundongo) (Fig. 24).

Para a linhagem PC12, as células tiveram uma resposta dose dependente. Quando utilizamos a concentração de $25 \mu \mathrm{g} / \mathrm{mL}$ observamos uma citotoxicidade de aproximadamente $70 \%$ em relação ao controle negativo (células não tratadas com LAAO) (Fig. 25).

Quando $10 \mu \mathrm{g} / \mathrm{mL}$ de LAAOBatrox foi incubada com células normais (células mononucleares de sangue periférico) (Fig. 26) observou-se insignificante atividade citotóxica.

Como complemento do ensaio de citotoxicidade foi avaliado o índice apoptótico nas células tratadas com LAAOBatrox (Fig. 27). As células PC12 quando tratadas com a concentração de $25 \mu \mathrm{g} / \mathrm{mL}$ apresentaram o maior número de células mortas por apoptose em relação ao controle negativo (cultura de células não tratadas com LAAO).

A Figura 28 mostra a análise morfológica das células das linhagens anteriormente citadas tratadas com LAAOBatrox e verificada por microscopia de fluorescência. As Figuras. 29, 30, 31 e 32 referem-se à análise de indução de apoptose por citometria de fluxo nas linhagens expostas ao tratamento com LAAOBatrox. Observa-se, para células normais,

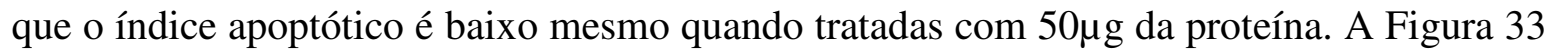
expõe uma análise comparativa da indução de apoptose por citometria de fluxo nas diferentes linhagens expostas ao tratamento com LAAOBatrox. O destaque se dá às células 


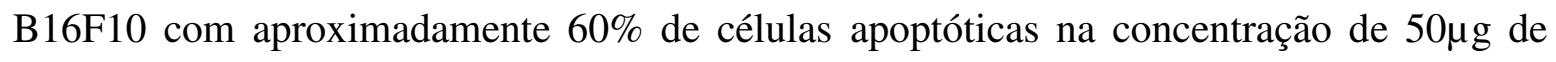
proteína, bem como em seguida, as células PC12 com aproximadamente 30\% de apoptose nessa mesma concentração.

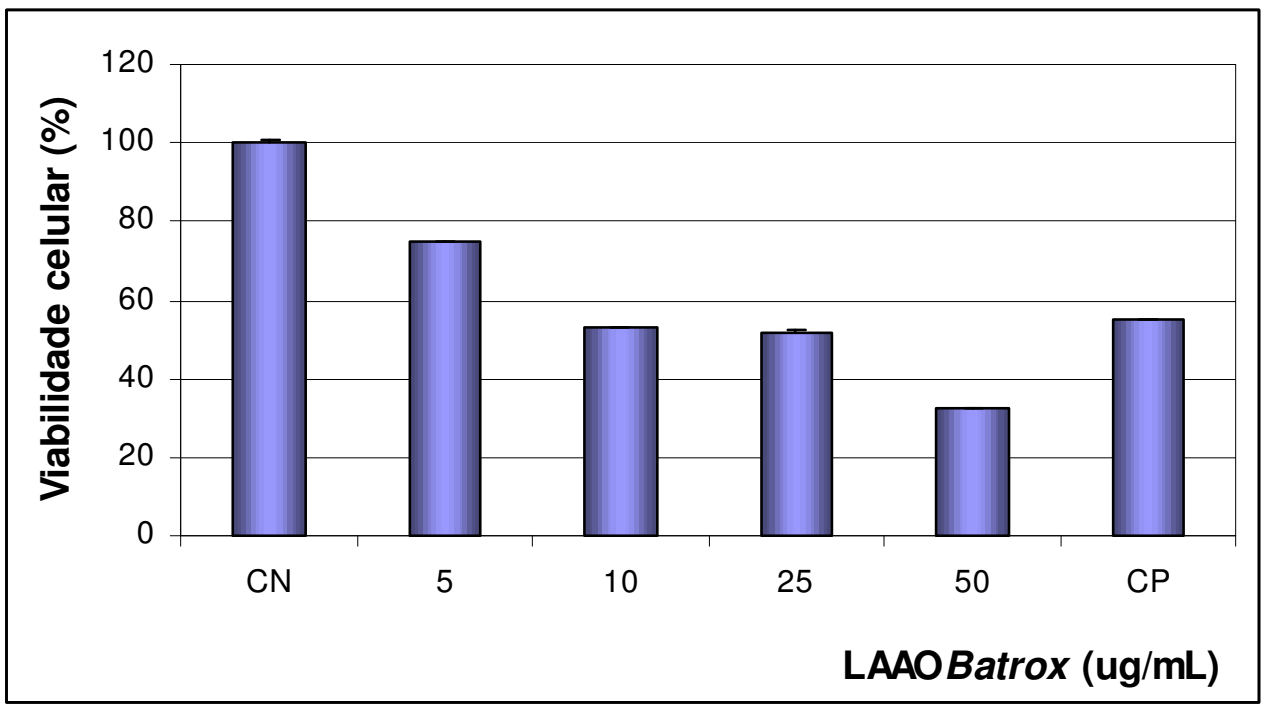

Figura 23: Atividade antitumoral pelo ensaio de MTT em células da linhagem JURKAT tratadas com LAAOBatrox. Os experimentos foram realizados em triplicata para cada concentração testada. Dados agrupados de 3 experimentos independentes (Média e Desvio Padrão). CN: Controle negativo. CP: Controle positivo 


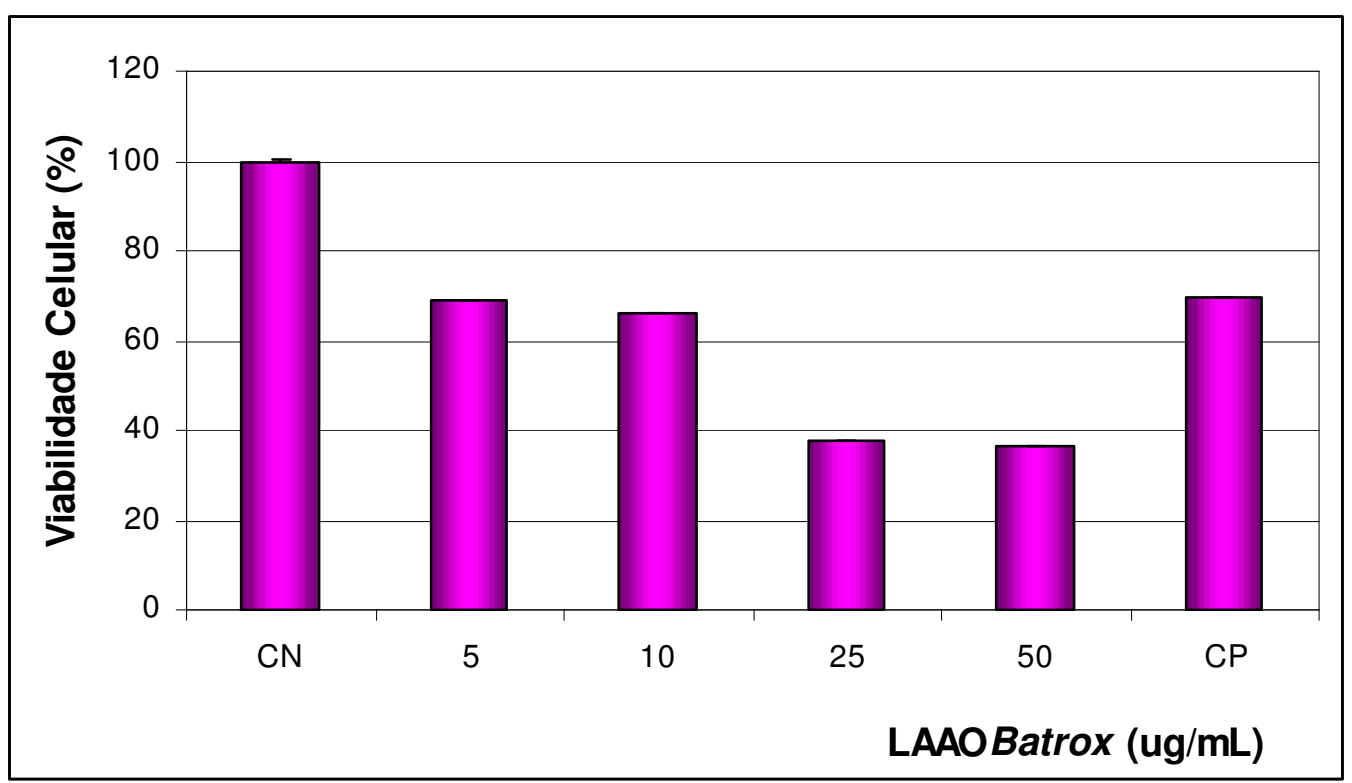

Figura 24: Atividade antitumoral pelo ensaio de MTT em células da linhagem B16F10 tratadas com LAAOBatrox. Os experimentos foram realizados em triplicata para cada concentração testada. Dados agrupados de 3 experimentos independentes (Média e Desvio Padrão). CN: Controle negativo. CP: Controle positivo 


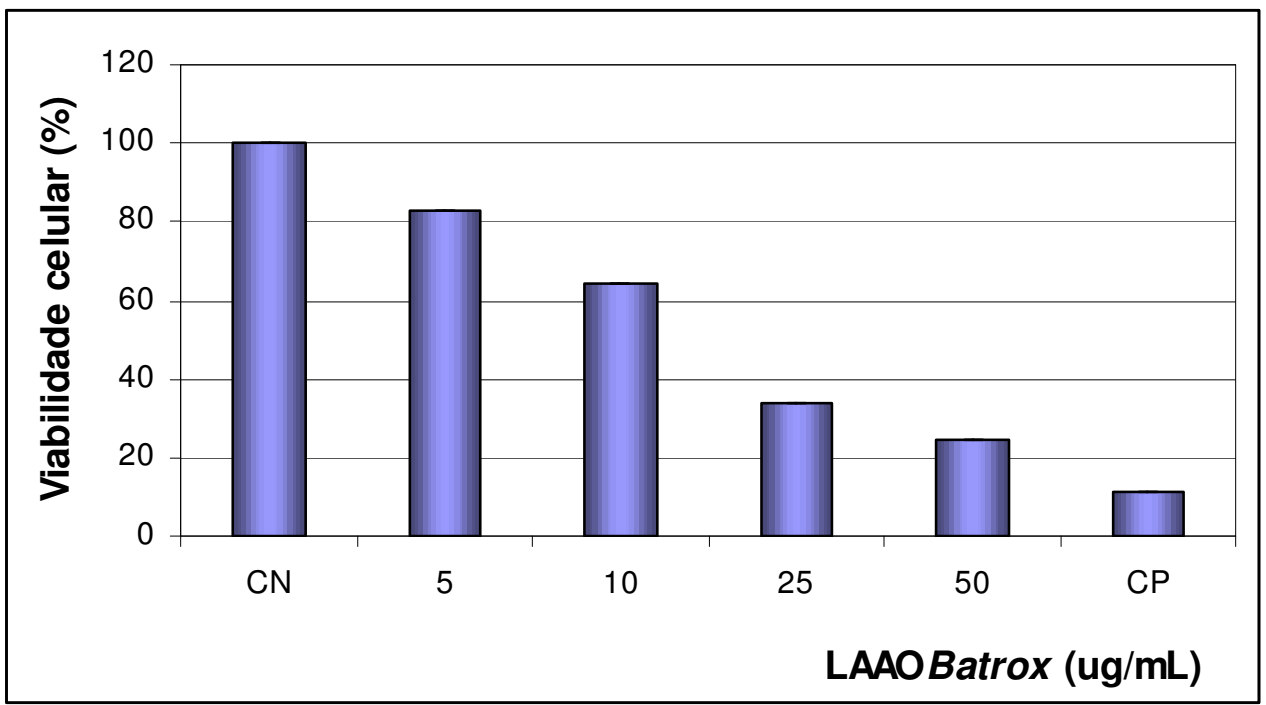

Figura 25: Atividade antitumoral pelo ensaio do MTT em células da linhagem PC12 tratadas com LAAOBatrox. Os experimentos foram realizados em triplicata para cada concentração testada. Dados agrupados de 3 experimentos independentes (Média e Desvio Padrão). CN: Controle negativo. CP: Controle positivo 


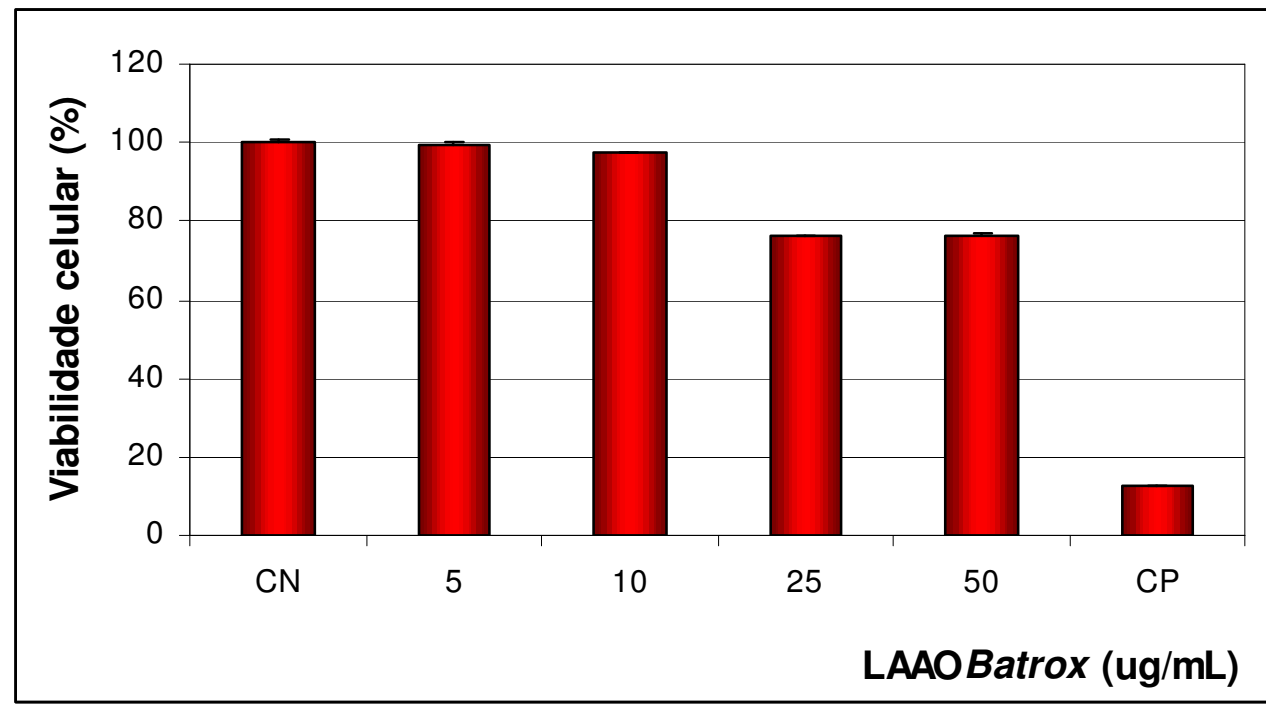

Figura 26: Atividade antitumoral em células mononucleares de sangue periférico humano expostas a LAAOBatrox. Os experimentos foram realizados em triplicata para cada concentração testada. Dados agrupados de 3 experimentos independentes (Média e Desvio Padrão). CN: Controle negativo. CP: Controle positivo 


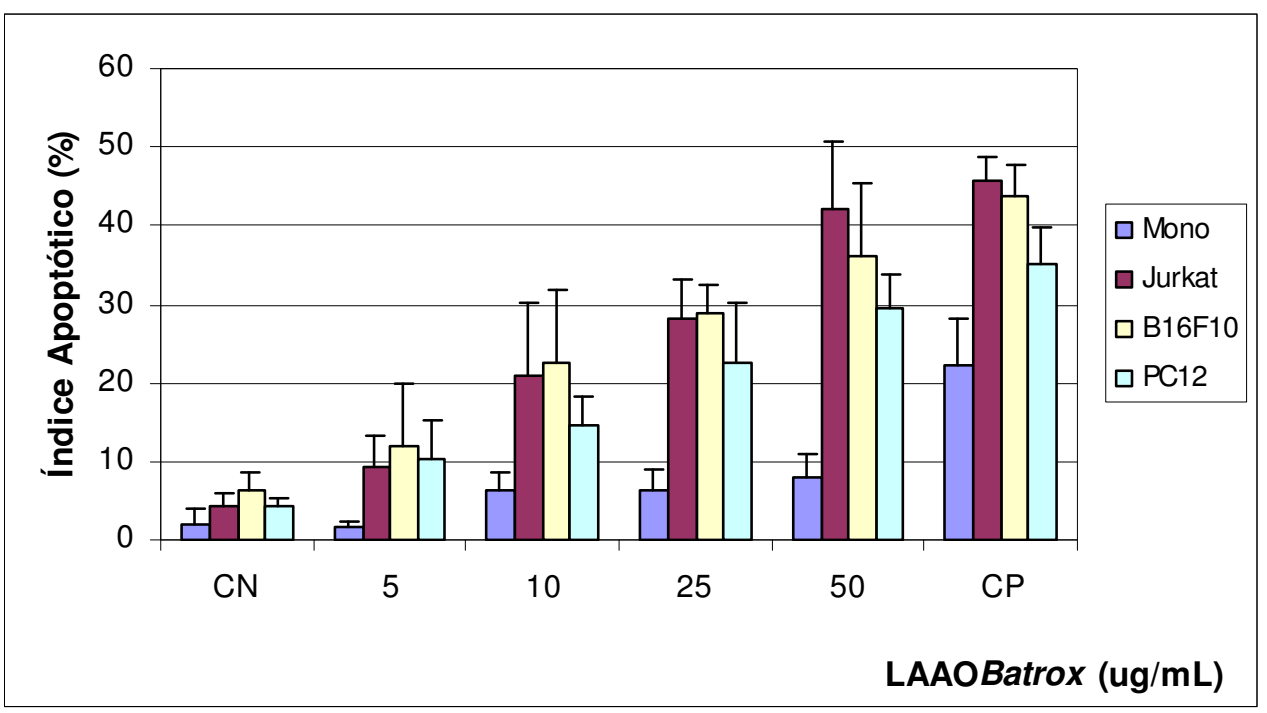

Figura 27: Análise do índice apoptótico por microscopia de fluorescência. Tratamento com LAAO em diferentes concentrações e diferentes linhagens. CN: Controle negativo. CP: Controle positivo
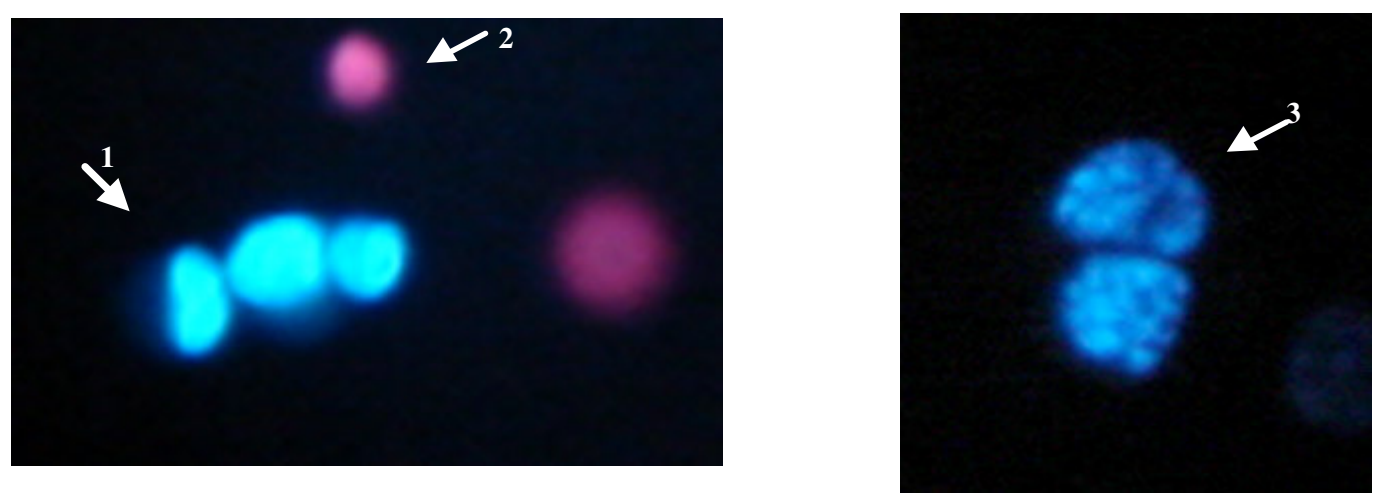

Figura 28: Análise de núcleos apoptóticos por microscopia de fluorescência. A seta 1 indica uma célula normal; a seta 2 indica uma célula em necrose; a seta 3 indica duas células em apoptose. 


\subsubsection{Análise do efeito apoptótico por citometria de fluxo.}

\subsection{Nível de apoptose induzido pela LAAO.}

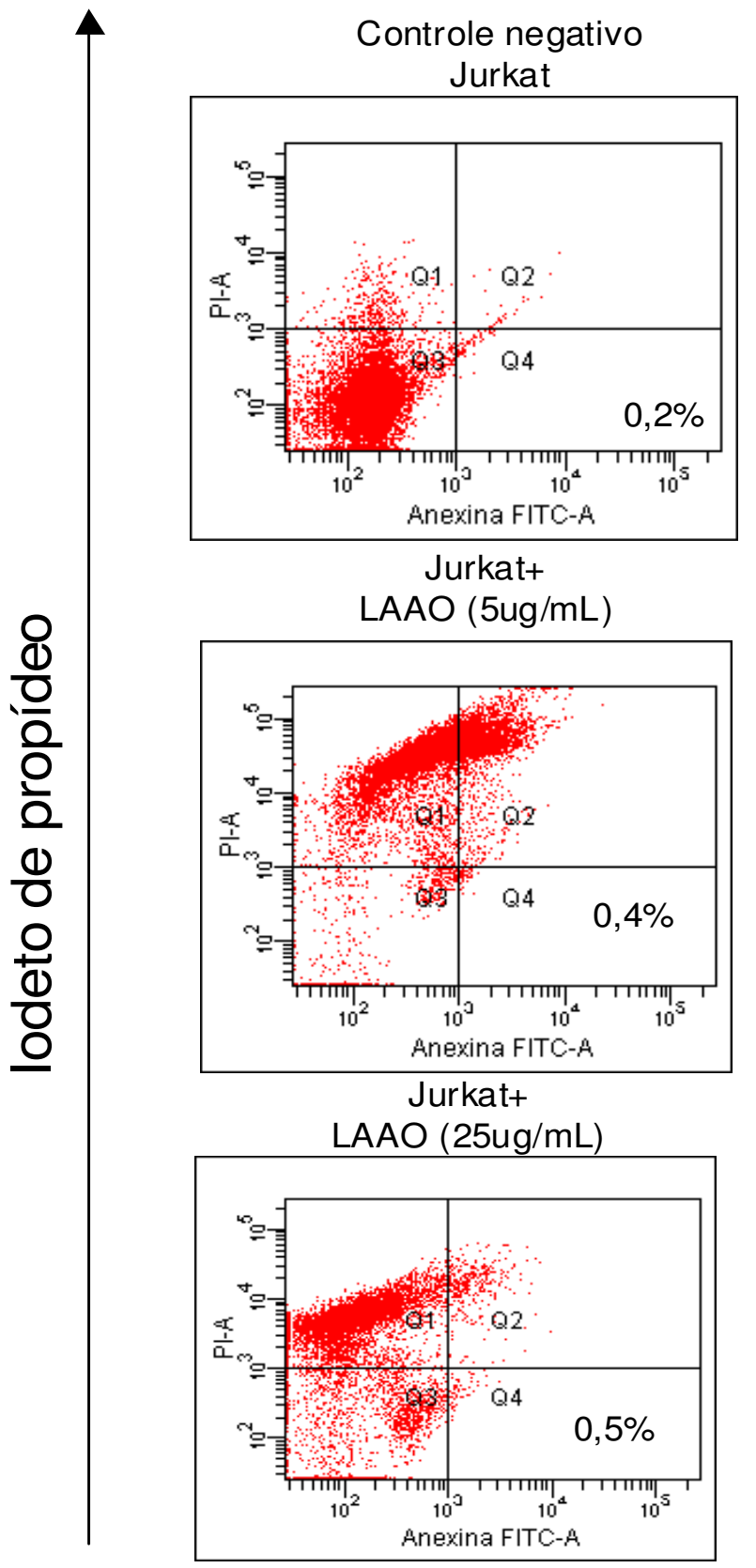

Jurkat+

CFA (200ug/mL)

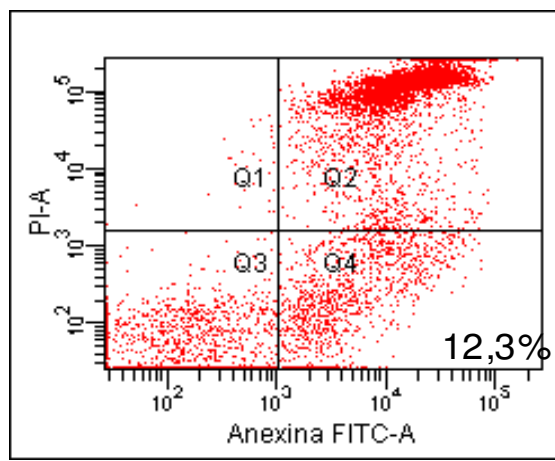

Jurkat+

LAAO (10ug/mL)

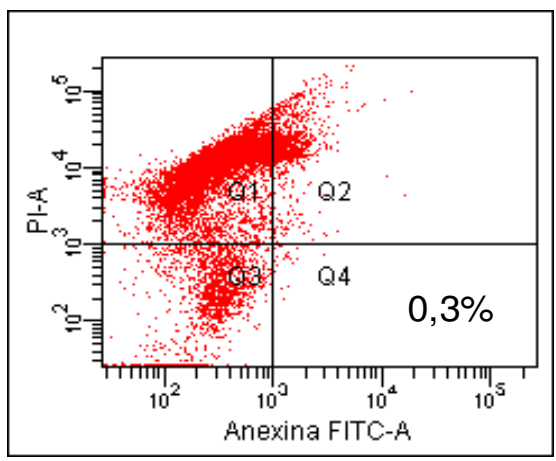

Jurkat+ LAAO (50ug/mL)

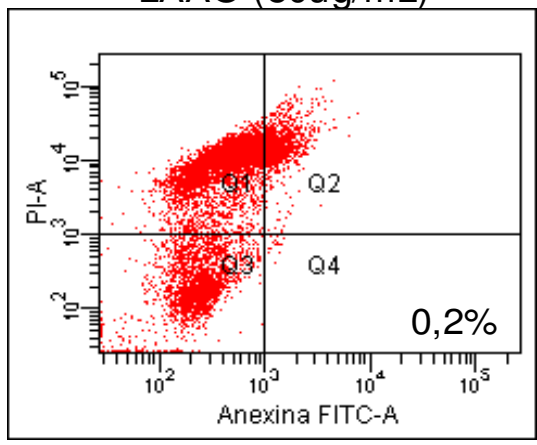

\section{Anexina}

Figura 29: Análise de indução de apoptose por citometria de fluxo em células da linhagem Jurkat expostas ao tratamento com LAAOBatrox em diferentes concentrações $(0 ; 5 ; 10 ; 25$ e $50 \mathrm{ug} / \mathrm{mL})$. A ciclofosfamida (CFA200ug/mL) foi utilizada como referência para indução de apoptose (controle positivo) e as células nãotratadas como controle negativo. As amostras foram analisadas por citometria de fluxo e os quadrantes são indicados por: Q1 - anexina-V negativa e IP (iodeto de propídeo) positivo; Q2 - anexina-V positiva e IP positivo; Q3 - anexina-V negativa e IP negativo; Q4 - anexina-V e IP negativo. A porcentagem de células em apoptose está indicada no quadrante 4. 




Figura 30: Análise de indução de apoptose por citometria de fluxo em células da linhagem B16F10 expostas ao tratamento com LAAOBatrox em diferentes concentrações $(0 ; 5 ; 10 ; 25$ e $50 \mathrm{ug} / \mathrm{mL})$. A ciclofosfamida (CFA-200ug/mL) foi utilizada como referência para indução de apoptose (controle positivo) e as células nãotratadas como controle negativo. As amostras foram analisadas por citometria de fluxo e os quadrantes são indicados por: Q1 - anexina-V negativa e IP (iodeto de propídeo) positivo; Q2 - anexina-V positiva e IP positivo; Q3 - anexina-V negativa e IP negativo; Q4 - anexina-V e IP negativo. A porcentagem de células em apoptose está indicada no quadrante 4. 


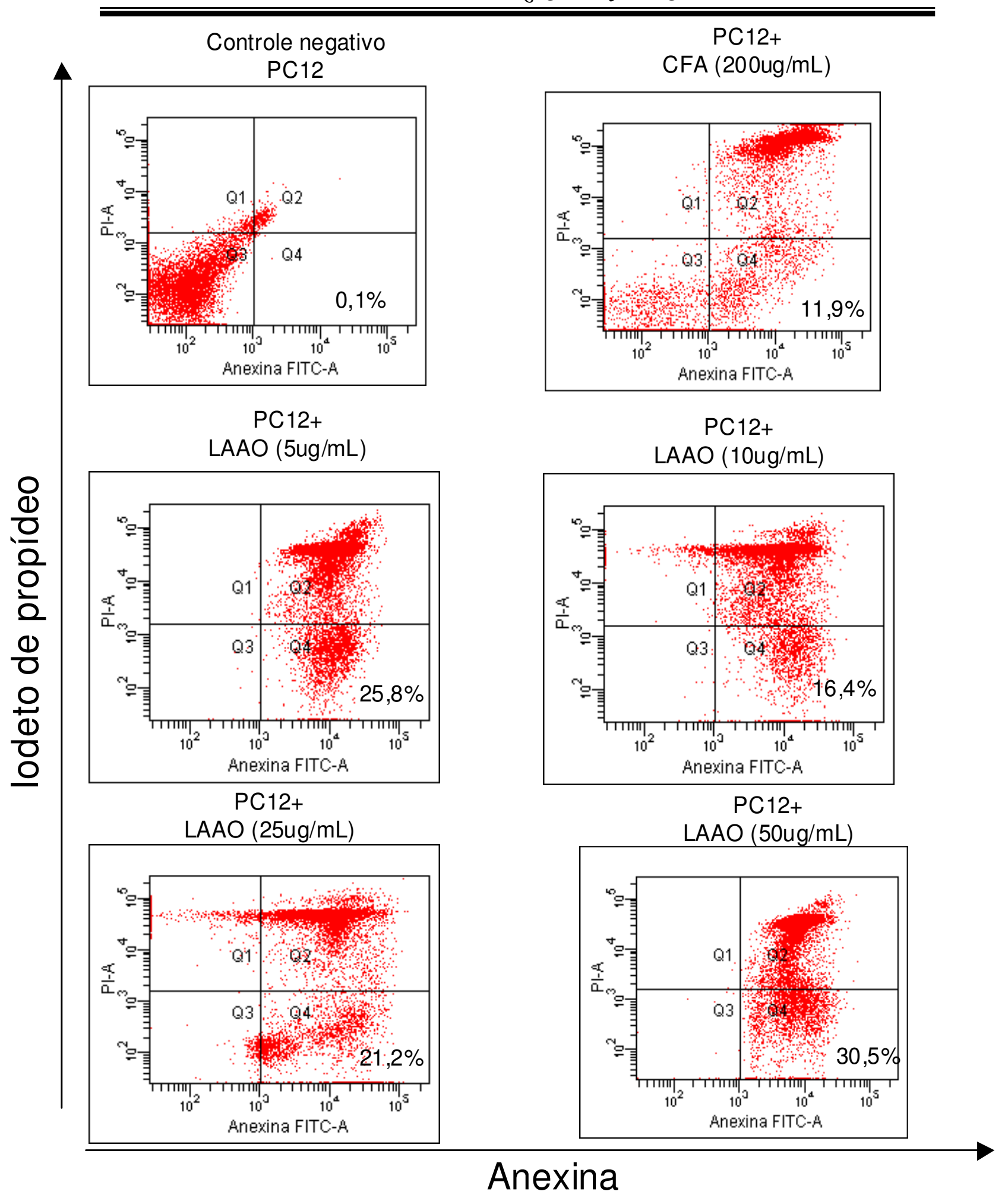

Figura 31: Análise de indução de apoptose por citometria de fluxo em células da linhagem PC12 expostas ao tratamento com LAAOBatrox em diferentes concentrações $(0 ; 5 ; 10 ; 25$ e $50 \mathrm{ug} / \mathrm{mL})$. A ciclofosfamida (CFA200ug/mL) foi utilizada como referência para indução de apoptose (controle positivo) e as células nãotratadas como controle negativo. As amostras form analisadas por citometria de fluxo e os quadrantes são indicados por: Q1 - anexina-V negativa e IP (iodeto de propídeo) positivo; Q2 - anexina-V positiva e IP positivo; Q3 - anexina-V negativa e IP negativo; Q4 - anexina-V e IP negativo. A porcentagem de céluals em apoptose está indicada no quadrante 4. 


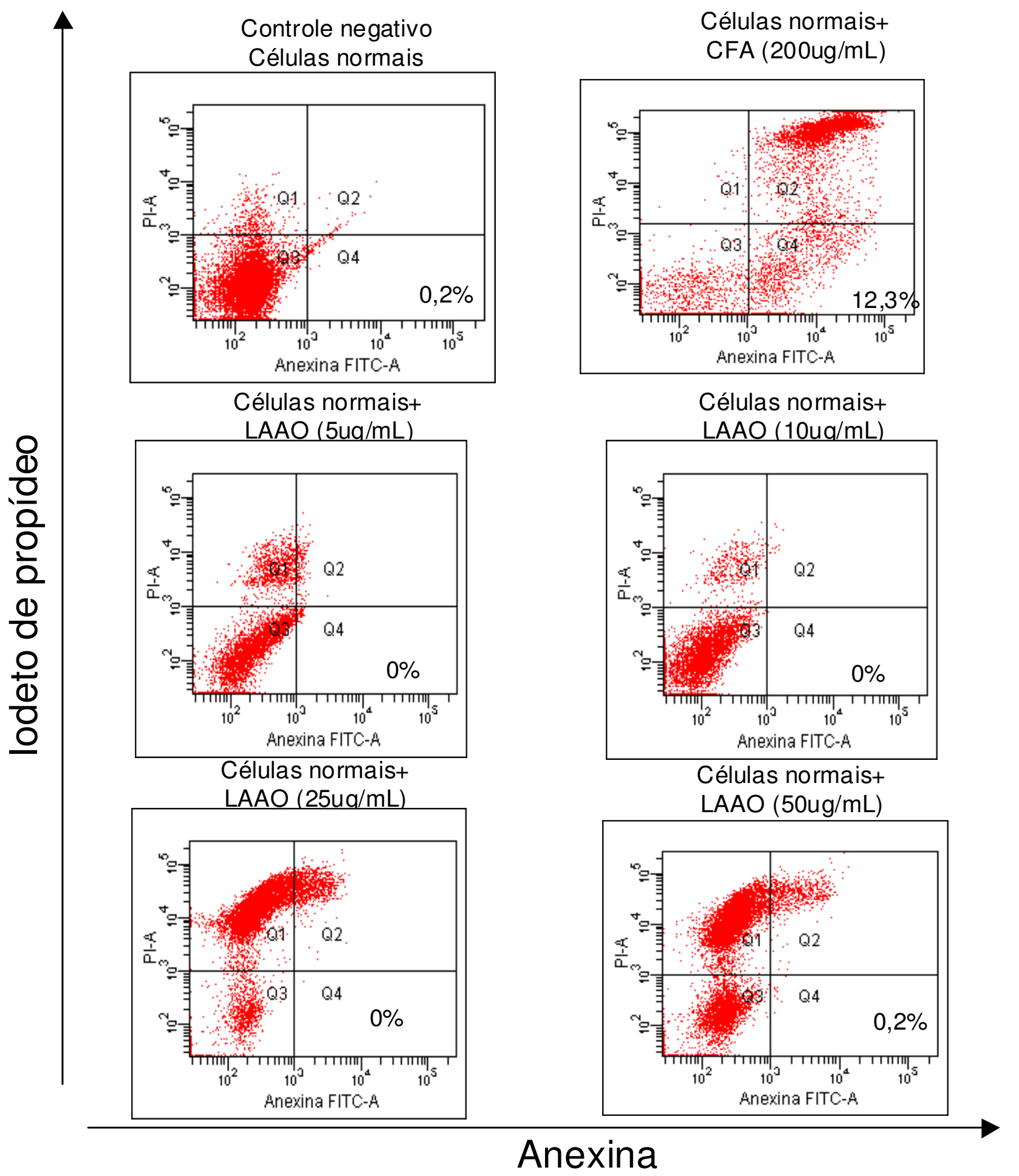

Figura 32: Análise de indução de apoptose por citometria de fluxo em células da linhagem de células mononucleares do sangue periférico normais expostas ao tratamento com LAAOBatrox em diferentes concentrações $(0 ; 5 ; 10 ; 25$ e $50 \mathrm{ug} / \mathrm{mL})$. A ciclofosfamida $(C F A-200 \mathrm{ug} / \mathrm{mL})$ foi utilizada como referência para indução de apoptose (controle positivo) e as células não-tratadas como controle negativo. As amostras form analisadas por citometria de fluxo e os quadrantes são indicados por: Q1 - anexina-V negativa e IP (iodeto de propídeo) positivo; Q2 - anexina-V positiva e IP positivo; Q3 - anexina-V negativa e IP negativo; Q4 - anexina-V e IP negativo. A porcentagem de células em apoptose está indicada no quadrante 4. 


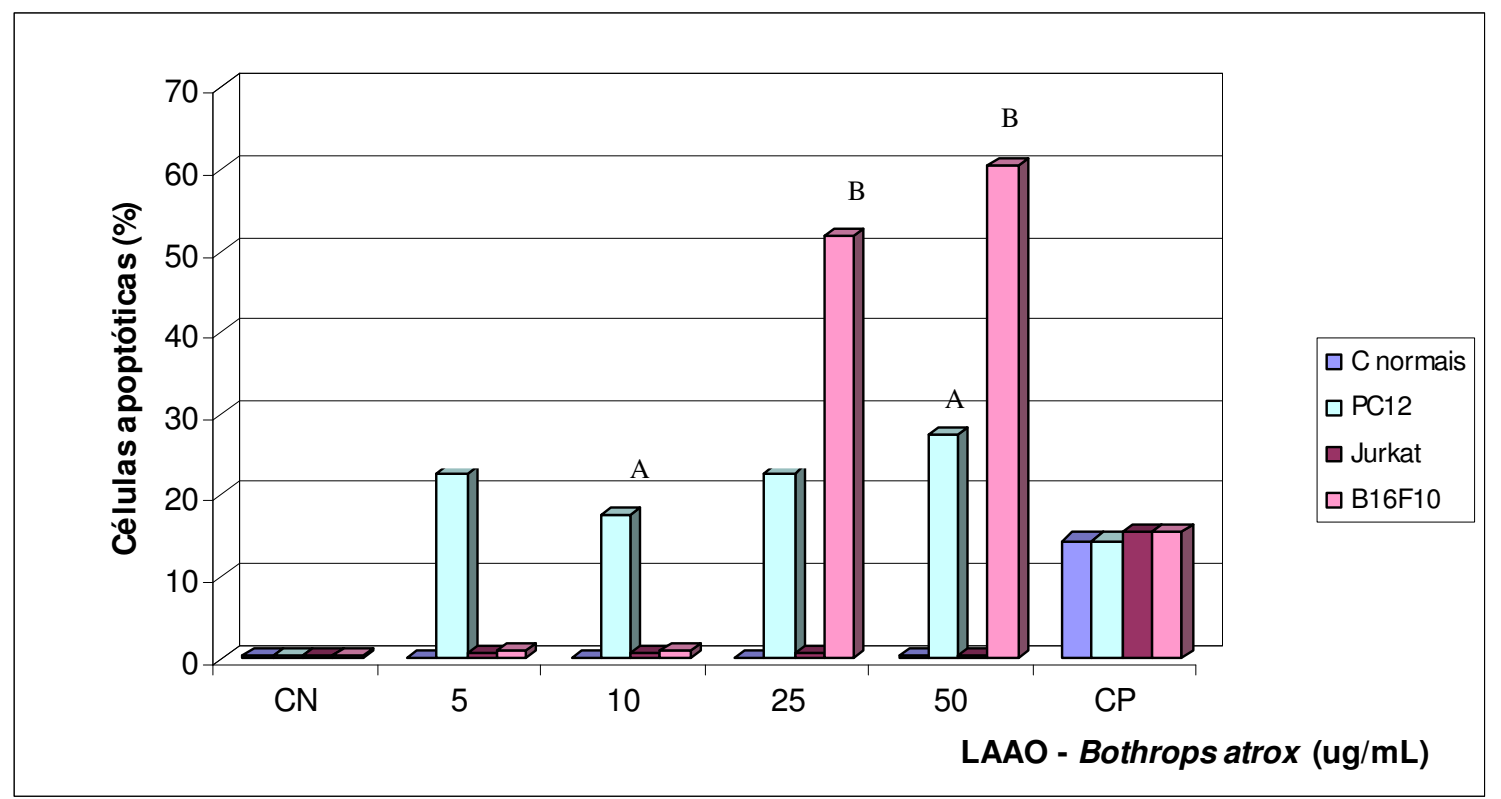

Figura 33: Análise comparativa da indução de apoptose por citometria de fluxo nas diferentes linhagens celulares expostas ao tratamento com LAAOBatrox. $\mathrm{CN}=$ controle negativo (células não-tratadas); $\mathrm{CP}=$ controle positivo (ciclofosfamida-200ug $/ \mathrm{mL}$ ). (A) estatisticamente significativo em relação ao controle negativo $(P \leq 0,05)$; (B) estatisticamente significativo em relação ao controle negativo $(P \leq 0,05)$. 
A diversidade de flora e fauna no Brasil e suas diferenças climáticas e geográficas estimulam novos pesquisadores em busca de novos fármacos, principalmente substâncias bioativas extraídas de plantas e animais. Estima-se que 60\% das drogas anti-tumorais e antiinfecciosas que se encontram no mercado, ou estão em estudos na fase clínica, são de origem natural.

O uso de produtos naturais com propriedades terapêuticas é tão antigo quanto à própria civilização humana e, por um longo tempo, minerais, produtos de plantas e animais, foram as principais origens de medicamentos (De Pasquale, 1984).

As toxinas animais também ganharam seu espaço no mercado farmacêutico, assim como os vegetais que exercem diversas ações, inclusive antiofídicas. O homem aprendeu, com a evolução da ciência, que a diferença entre um medicamento e o veneno está na administração correta da dose, portanto, os estudos químicos, bioquímicos, farmacológicos, fisiológicos e tóxicos de determinados compostos como proteínas, enzimas e peptídeos estão sendo realizados de forma cada vez mais específica, a fim de se encontrar nas próprias toxinas animais, substâncias que possam agir de forma benéfica ao homem.

As pesquisas e experimentos com venenos de serpentes em geral não são simples de serem realizadas pois requerem um conhecimento teórico aprofundado para o início dos experimentos, tanto conhecimento do veneno a ser escolhido como da toxina ou proteína em estudo como dos meios cromatográficos necessários para o isolamento e purificação das mesmas.

A escolha do veneno de B. atrox (originária do Pará) foi devido a sua maior atividade L-aminoácido oxidase, superada apenas pelo veneno de B. moojeni que foi isolada e caracterizada (Tempone et al., 2001).

Verifica-se na Tabela 8 a atividade L-aminoácido oxidase de venenos de serpentes, incluindo variação de gênero. 


\section{Tabela 8 Atividade L-Aminoácido Oxidase de Venenos de Serpentes}

Serpentes

\section{Gênero: Crotalus}

Crotalus durissus terrificus

Crotalus durissus terrificus (região

ibitiuva)

Crotalus durissus collilineatus

Crotalus durissus cascavella

\section{$U / m g$}

85,2

-----

52,0

28,2

\section{Gênero Bothrops}

B. alternatus

B. moojeni

B. atrox (região Pará)

B. $\operatorname{atrox}($ região Macapá)

B. atrox (região Belém)

B. jararacussu

B. jararaca

B. pirajai
94,7

235,3

165,7

38,7

11,38

66,76

71,20

113,50

O processo de isolamento da LAAO de B. atrox consiste de filtração de exclusão molecular em Sephadex G-75, eluída em AMBIC 0,05M pH 8,0 (Fig. 5). O tampão apresenta condições favoráveis de $\mathrm{pH}$, o qual não interfere na atividade das enzimas que geralmente perdem parte de sua atividade em $\mathrm{pHs}$ ácidos, como as metaloproteinases (Mazzi et al., 2004). Outra vantagem, é que o tampão possui características químicas que o torna mais volátil, não necessitando, portanto, de exaustivos processos de diálise, conferindo rapidez no processo de isolamento e conservando maior atividade de outras classes de enzimas, podendo ser utilizadas em estudos posteriores. Nessa etapa cromatográfica, onde as proteínas foram separadas de alto e baixo peso molecular, foram obtidas 5 frações, em seguida, a primeira fração (BaPI) foi submetida a Cromatografia Líquida de Alta Eficiência em coluna de troca aniônica (DEAE) com gradiente AMBIC 0,05 a 0,5 M, controlando-se atentamente o pH (Fig. 6). Das três frações obtidas nesse processo a fração ES-III apresentou atividade sobre L-Leucina. Uma última etapa de purificação fez-se necessário devido à presença de uma metaloproteinase que eluiu juntamente com o pico ES-III da cromatografia de troca iônica (Fig. 6). Esses resultados 
foram confirmados pela atividade hemorrágica apresentada por essa fração e que na presença de EDTA não desenvolve nenhum halo hemorrágico. O EDTA é um inibidor de metaloproteinase.

Devido a esses fatos utilizamos, então, uma cromatografia de afinidade em Lentil Lectina sendo que a fração L-II apresentou atividade sobre L-Leucina (Fig. 7) enquanto que a fração L-I apresentou atividade hemorrágica e um Rf maior em SDS-PAGE (Fig. 9). Souza et al. (1999) descreveram o isolamento e caracterização estrutural de uma LAAO de Agkistrodom contortrix laticinctus que apresentou atividade hemorrágica.

A recuperação da atividade da proteína isolada foi consideravelmente alta, 82,5\%, com um valor de 54 vezes maior que a atividade específica do veneno. A recuperação em termos de proteínas totais foi de $1,54 \%$ do veneno de B. atrox (Tabela 4). LAAOs obtidas de outros venenos apresentam de 1 a 9\% de recuperação de proteínas totais (Tan; Ponnudurai, 1991; Ali et al., 2000) exceto para o veneno de Calosellasma rhodostoma que é de 30\% (Ponnudurai; Chung; Tan, 1994).

LAAOs de venenos de serpentes são glicoproteínas ligadas ao FAD, homodiméricas com massa molecular ao redor de 110 - $150 \mathrm{kDa}$ quando medidas por filtração em gel, em condições não redutoras e a massa molecular detectada ao redor de 50 - $70 \mathrm{kDa}$ ocorre quando são analisadas por SDS-PAGE em condições redutoras. LAAOs isoladas de venenos de víboras apresentam uma massa molecular ao redor de $58 \mathrm{kDa}$, como no caso da víbora de Eristocophis macmahoni - 58,7 kDa (Ali et al., 2000) e a de víbora berus berus 57,7 kDa (Samel et al., 2006).

Abe et al. (1998) isolaram e caracterizaram uma LAAO de Trimeresurus flavoviridis com massa molecular de $55 \mathrm{kDa}$. Do gênero Agkistrodom, duas LAAOs foram isoladas e caracterizadas com massa molecular de $60 \mathrm{kDa}$, a LAAO de Agkistrodom contortrix laticinctus (Mr 60.000) (Souza et al., 1999) e Agkistrodom halys blomhoffi (Takatsuka et al., 2001). LAAOs isoladas de Crotalus apresentam massa molecular ao redor de $60 \mathrm{kDa}$ como por exemplo C. adamanteus - 58,7kDa (Raibecas; Massey, 1998); C. atrox - 55 kDa (Torii; Naito; Tsuruo, 1997) e, como exceção, a LAAO isolada de Crotalus durissus cascavella - $68 \mathrm{kDa}$ (Toyama et al., 2006). A massa molecular relativa (Mr) das LAAOs isoladas de C. rhodostoma (Ponnudurai; Chung; Tan, 1994), B. alternatus 
(Stábeli et al., 2004), B. pirajai (Izidoro et al., 2006) é de 66.000. Tempone et al. (2001) isolaram e caracterizaram uma LAAO de B. moojeni com $\mathrm{Mr}$ de 69.000.

A massa molecular relativa da LAAO de B. atrox é de 67.000 (Fig. 12) o que demonstra proximidade com as massas moleculares de outras LAAOs discutidas anteriormente.

A análise do seqüenciamento N-terminal da LAAOBatrox foi realizada após a realização de SDS-PAGE 12\% seguida de transferência para membrana de PVDF pelo método de "Western Blotting". A seqüência N-terminal foi ADDN-NPLEE-NIRRDD (Tabela 7) que apresenta homologia com a sequiência de outros L-aminoácidos (Tabela 6) de outras serpentes.

LAAOs de veneno de serpentes (SV LAAOs) apresentam ponto isoelétrico entre 4,4 (LAAOs de A. contortrix lacticinctus ; C. rhodostoma) a 8,12 (LAAOs de Naja naja kaauthia), ( Tan; Swaminathan, 1992). A LAAO de B. atrox apresentou pI de 4,4 (Fig. 13). Um único tipo de veneno pode conter mais de um tipo de LAAO (Stiles; Sexton; Weintein, 1991). Essas podem ser ácidas, básicas ou neutras, as quais são semelhantes às fosfolipases $\mathrm{A}_{2}$ de venenos. Não se sabe se essa diferença de carga reflete em diferentes propriedades farmacológicas como no caso das três fosfolipases $\left(\mathrm{PLA}_{2}\right)$ do veneno de Agkistrodom halys palla, onde a $\mathrm{PLA}_{2}$ ácida apresenta atividade antiplaquetária, a $\mathrm{PLA}_{2}$ neutra é uma neurotoxina e a básica é hemolítica (Du et al., 1998).

A LAAO de Bothrops alternatus apresentou 15\% de conteúdo de açúcar após deglicosilação. Já, a LAAOBatrox após deglicosilação com uso de PGNase-F, apresentou o conteúdo de açúcar de aproximadamente $12 \%$ do seu peso.

Resultados obtidos com a composição em aminoácidos contribuíram para confirmar o caráter ácido da LAAO de B. atrox que apresentou grande quantidade de aminoácidos ácidos (ácido glutâmico e ácido aspártico) como mostra a Tabela 5.

Antes de 1990, LAAOs de venenos de serpentes foram muito usadas para identificação de isômeros ópticos de aminoácidos e para preparação de $\alpha$-cetoácidos (Tan, 1998). Usualmente, a atividade de oxidação é determinada usando L-Leu como substrato e, no caso de venenos Viperídeos, aminoácidos hidrofóbicos (incluindo L-Leu) são os melhores substratos para LAAOs. O substrato específico para LAAOs de venenos de $B$. 
alternatus, B. pirajai, Vipera berus berus são os aminoácidos hidrofóbicos (L-Phe > L-Met $>$ L-Leu > L-Ile).

No caso da LAAO de Agkistrodom contortrix laticinctus os substratos específicos são os aminoácidos hidrofóbicos (L-Ile $>$ L-Phe $>$ L-Met $>$ L-Val > L-Leu). O substrato específico para LAAO de B. atrox são os aminoácidos hidrofóbicos L-Met > L-Leu (Fig. 17).

A LAAO isolada do veneno de Ophiophagus hannah tem como substrato específico a L-Lys que é praticamente não oxidada pela maioria dos venenos Viperídeos (Tan; Saifuddin, 1991). As diferenças catalíticas das LAAOs podem ser explicadas pela presença de cadeias laterais diferentes ao redor do sítio responsável pela especificidade de substrato da enzima.

Proteínas de venenos de serpentes do gênero Bothrops afetam a hemostasia de diferentes formas, promovendo a hemorragia, hemólise e outros efeitos sobre a circulação e sistema nervoso (Matsui; Fujimura; Titani, 2000). Os componentes de venenos mais comuns são metaloproteinases, serinoproteases, fosfolipases $\mathrm{A}_{2}$ e miotoxinas. Por outro lado, L-aminoácido oxidases são igualmente expressas em venenos de serpentes e catalisam a deaminação oxidativa de L-aminoácidos, produzindo $\alpha$-cetoácidos, peróxido de hidrogênio e amônia.

Nos últimos anos, LAAOs de venenos de serpentes tornaram-se objetos de estudos farmacológicos apresentando indução de apoptose, citotoxicidade, agregação plaquetária e outros efeitos fisiológicos. Sugere-se que alguns desses efeitos sejam medidos pelo peróxido de hidrogênio que é liberado no processo de oxidação. Muitas vezes os efeitos não podem ser atribuídos ao $\mathrm{H}_{2} \mathrm{O}_{2}$ e são provavelmente causados pela interação com receptores (Zhang et al., 2003).

Ticli et al. (2006) demonstraram que a LAAO de B. jararacussu em altas concentrações $(100 \mu \mathrm{g}$ de LAAO / animal) promove a indução de edema, sendo que o pico mais elevado ocorre em 4 horas. A LAAO de B. atrox apresenta atividade edematogênica

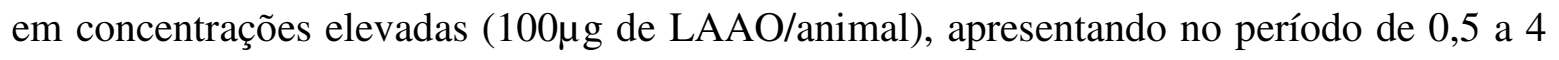
horas uma porcentagem de $40 \%$ de edema.

Ali et al. (2000) demonstraram que a LAAO isolada do veneno de Eristocophis macmahami (víbora) induz edema apresentando uma dose edematogênica mínima de 
4,8 $\mu \mathrm{g} / \mathrm{mL}$. Em dose de $10 \mu \mathrm{g}$ o efeito persiste por mais de 24 horas. Estudos preliminares com indução de edema por veneno de serpentes revelam que sua ação é devido a ação direta de toxinas (proteases, fosfolipases e miotoxinas) que são mediadas através da liberação de histamina, 5-hidroxitriptamina, prostaglandinas, serotoninas e cinina (Ali et al., 1999).

Tan e Choy (1994) demonstraram que a indução de edema pela LAAO não foi inibida por difenildramina (droga anti-histamínica) entretanto, a pré-administração de glutationa inibiu a indução de edema, sugerindo o envolvimento do peróxido de hidrogênio na indução de edema produzido por L-aminoácido oxidase.

A LAAO obtida após as três etapas de purificação não apresentou atividade

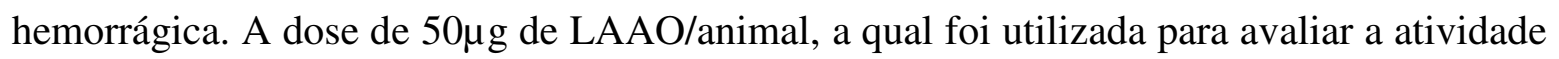
hemorrágica, corresponde a 10 vezes a DHM (Dose Hemorrágica Mínima) do veneno de $B$. atrox (Figura 19 e 20).

A fração BaPI originada da filtração do veneno bruto em Sephadex G-75 (Fig. 20) apresentou atividade hemorrágica similar à do veneno de B. atrox, demonstrando assim, ser a responsável pela atividade hemorrágica do mesmo (Figura 20-A e B). Souza et al. (1999) descreveram o isolamento e a caracterização de uma LAAO de A. contortrix laticinctus que apresenta atividade hemorrágica. A fração BaPI apresenta as enzimas proteolíticas (serinoproteases e metaloproteinases) responsáveis pelo desequilíbrio homeostático causado após o acidente ofídico.

A concentração de LAAO de B. atrox para coagular o plasma em 1 minuto foi de $3,8 \mu \mathrm{g} / \mu \mathrm{L}$, o que corresponde a dose coagulante mínima (DCM).

Até o momento, apenas a LAAO isolada do veneno de B. jararacussu (Ticli et al., 2006) apresentou efeito coagulante com uma DCM de $0,5 \mu \mathrm{g} / \mu \mathrm{L}$. Alguns testes podem ser referidos como falso positivos, onde, ao invés de coagulação tem-se agregação plaquetária pois o plasma utilizado pode ser PRP. Para melhor elucidação dessa atividade, faz-se necessário o uso de PPP e conseqüente uso de catalase para verificação da via responsável pela mesma.

Os efeitos de LAAO na agregação plaquetária são controversos. Nathan et al. (1982) descreveram uma LAAO de Echis colorata que inibe agregação plaquetária induzida por 
ADP. Takatsuka et al. (2001) também reportaram que LAAO de A. halys blomhoffi inibiu agregação plaquetária induzida por um agonista e por estresse.

Ali et al. (2000) demonstraram que LAAO de Eristocophis macmahoni induz agregação plaquetária humana $\left(\mathrm{ED}_{50} 33 \mu \mathrm{g} / \mathrm{mL}\right)$ e Li et al. (1994) também caracterizaram uma LAAO de $O$. hannah que induz agregação plaquetária em plasma rico em plaquetas.

Em alguns estudos, a catalase e EDTA bloquearam completamente a agregação plaquetária induzida pela enzima. Alguns resultados apresentados por Du e Clemetson (2002) sugerem que LAAO induz agregação plaquetária através da formação de $\mathrm{H}_{2} \mathrm{O}_{2}$ e subsequente síntese de tromboxano $\mathrm{A} 2$ requerente de $\mathrm{Ca}^{2+}$ mas independente da liberação de ADP.

Segundo Pignatelli et al. (1998), o $\mathrm{H}_{2} \mathrm{O}_{2}$ é produzido pelas plaquetas estimuladas por colágeno e age como mensageiro pela ativação do metabolismo do ácido aracdônico e via das fosfolipases $C$. Ainda não está claro as funções de $\mathrm{H}_{2} \mathrm{O}_{2}$ na agregação plaquetária induzida por LAAO.

Os resultados obtidos na indução de agregação plaquetária induzida por LAAOBatrox (Fig. 21) foi dose dependente, onde essa proteína apresentou quase 100\% de agregação plaquetária. Visando verificar a participação do $\mathrm{H}_{2} \mathrm{O}_{2}$ formado na agregação plaquetária utilizamos um experimento com plaquetas tratadas com catalase (Fig. 22), seguida da adição de LAAO. A agregação foi inibida conforme o aumento da concentração desse agente na reação.

Em adição às funções mencionadas aqui, todas as LAAOs de venenos de serpentes estudadas induzem apoptose.

Apoptose é uma forma regulada e controlada de morte celular que tem papel importante no controle e desenvolvimento do organismo. É caracterizada por alterações morfológicas e bioquímicas severas tais como condensação nuclear e clivagem da cromatina ou fragmentos oligonucleossomal. Em contraste, necrose representa a forma de morte acidental da célula resultando em lise celular, extravasamento do conteúdo intracelular ao redor do tecido e inflamação. Experimentos realizados em culturas de células mostraram que a exposição a pré-oxidantes pode causar apoptose ou necrose dependendo da sua dose e duração da exposição (Samel et al., 2006). 
Samel et al. (2006) descreveram uma LAAO de Vipera berus berus que, em baixas concentrações e pouco tempo de incubação, em células K562 (Leucemia Mielóide Crônica Humana) não induziu apoptose. No entanto, após 24 horas de incubação, ocorreu indução de apoptose e inibição da mesma quando incubada com catalase, indicando a função do peróxido de hidrogênio no processo. Torii; Naito; Tsuruo (1997) descreveram uma LAAO de Crotalus atrox que induziu apoptose em células endoteliais de veia umbilical humana, bem como em alguns tipos de células tumorais.

LAAO do veneno de Agkistrodom contortrix laticintus (ACL LAO) em $25 \mu \mathrm{g} / \mathrm{mL}$ causou fragmentação de DNA em células HL-60, que foi detectada após 24 horas de tratamento com a enzima, sugerindo indução de apoptose por essa enzima. Em baixas concentrações ACL LAO não induziu apoptose em células HL-60 mesmo após 24 horas de incubação (Souza et al., 1999).

A LAAOBatrox induziu efeito citotóxico sobre a linhagem tumoral JURKAT (Leucemia de Células T); B16F10 (Melanoma de Células de Camundongo) e PC12 (Célula Tumoral - feocromocitoma de glândula adrenal de rato) e não apresentou efeito citotóxico quando incubada com células normais, nas mesmas concentrações (Figuras 23, 24, 25, e 26).

Em todas as concentrações de LAAO utilizadas na linhagem PC12 ocorreu maior número de mortes por apoptose que por necrose (Figura 25). Assim também podemos afirmar para as células B16F10, onde as células apresentaram 70\% de morte por apoptose ocorrendo pouca necrose (Figuras 24 e 27). A Figura 28 indica a análise de núcleos apoptóticos por microscopia de fluorescência, onde são indicadas células normais, células em necrose e células em apoptose.

No estudo de apoptose por citometria de fluxo foi analisada a capacidade da LAAOBatrox de induzir apoptose pela marcação por anexina $\mathrm{V}$ em diferentes linhagens celulares tumoral e normal. A Figura 32 mostra que a LAAOBatrox não induziu apoptose de modo significativo em células normais quando comparado às demais linhagens testadas (Figs. 29, 30 e 31).

Num estudo envolvendo Calloselasma rhodostoma, Moustafa et al. (2006) evidenciaram regiões susceptíveis a ação do peróxido de hidrogênio que funcionam como via de entrada de $\mathrm{O}_{2}$ durante a reação oxidativa. Em uma segunda região separada do canal 
de $\mathrm{O}_{2}$ proposto no $\mathrm{N}$-terminal (resíduos de 8-16) na proteína, podem ter um papel na liberação de $\mathrm{H}_{2} \mathrm{O}_{2}$. Interessantemente, a porção final do canal poderia dirigir o produto do $\mathrm{H}_{2} \mathrm{O}_{2}$ para a superfície exterior da proteína, próxima as glicanas, considerando a enzima como âncora na célula hospedeira. Esta localização do canal poderia explicar a capacidade da enzima localizar $\mathrm{H}_{2} \mathrm{O}_{2}$ nas células alvo e assim induzir efeito apoptótico.

Sun et al. (2003) observaram que OHAP-1, uma LAAO de Trimeresurus flavoridis, apresentou um efeito apoptótico em células de glioma humano RBR 17T, U251 e C6 de ratos. Estes efeitos, segundo os autores, poderiam ser mediados pela promoção de geração de ROS intracelular e expressão da proteína p53 em células de glioma, sugerindo OHAP-1 como um potencial candidato a terapia clínica antitumoral.

Com base nos resultados obtidos até aqui, podemos considerar as LAAOs dos venenos de serpentes, em particular a LAAOBatrox, enzimas multifuncionais que podem servir de ferramentas para o estudo do mecanismo dos acidentes ofídicos e, devido ao seu potencial biotecnológico, servirem como modelo para agentes terapêuticos. 
O presente trabalho teve com objetivo isolar e caracterizar bioquímica e funcionalmente a L-aminoácido oxidase do veneno de Bothrops atrox. Os resultados obtidos nas condições experimentais utilizadas nos permitiram concluir que:

- $\quad$ Por meio de processos simples de separação tais como filtração utilizando gel de Sephadex, cromatografia de troca iônica e afinidade, foi possível isolar a LAAO do veneno de B. atrox (LAAOBatrox) com alto grau de pureza e com recuperação em termos de proteínas totais de 1,54\%, atividade específica de 87,5\%, correspondendo a 54 vezes à atividade do veneno bruto de B. atrox.

- A LAAO de B. atrox é uma glicoproteína de cadeia única com massa molecular de 67 kDa, pI 4,4 e 12\% de conteúdo de açúcar.

- $\quad$ Após composição em aminoácidos, a LAAO apresentou 588 resíduos e grande quantidade de aminoácidos Asx (Ácido aspártico ou asparagina) e Glx (Ácido glutâmico ou glutamina).

- $\quad$ O seqüenciamento de peptídeos trípticos internos da LAAO de B. atrox revela $100 \%$ de homologia com as LAAOs dos venenos de B. moojeni e $B$. jararacussu bem como o seqüenciamento N-terminal revelou semelhança com outras LAAOs de outros venenos de serpentes.

- $\quad$ A LAAO de B. atrox apresentou especificidade de substrato para L-Met e LLeu.

- A LAAO de B. atrox apresenta moderada atividade edematogênica em relação ao veneno bruto e coagulante. Não induz atividade hemorrágica.

- $\quad \mathrm{Na}$ concentração de $25 \mu \mathrm{g} / \mathrm{mL}$ a LAAOBatrox induziu agregação plaquetária em plasma de coelhos em aproximadamente $100 \%$.

- Apresenta efeito citotóxico sobre diferentes linhagens tumorais (JURKAT, B16F10 e PC12), não apresentando efeito citotóxico sobre células normais (Células mononucleares de sangue periférico).

Devido ao seu amplo espectro de ação, a LAAOBatrox é uma molécula modelo para estudo do mecanismo de ação e sua participação no acidente ofídico, bem como na busca de características estruturais responsáveis pela ação antitumoral desta proteína que possa contribuir para a síntese de um novo modelo de fármaco. 
ABE, Y.; SHIMOYAMA, Y.; MUNAKATA, H.; ITO, J.; NAGATA, N.; OHTSUKI, K. Characterization of an apoptosis-inducing factor in Habu snake venom as a glycyrrhizin (GL)-binding protein potently inhibited by GL in vitro. Biol. Pharm. Bull., v.21, p.924927, 1998.

AIRD, S.D., Ophidian envenomation strategies and the role of ourines. Toxicon, v.40, p. 335- 393, 2002.

AHN, M.Y.; LEE, B.M.; KIM, Y.S. Characterization and cytotoxicit of L-amino acid oxidase from the venom of king cobra (Ophiphagus hannah). Int. J. Biochem. Cell biol., v.29, p.911-919, 1997.

ALI, S.A.; STOEVA, S.; ABBASE, A.; ALAN, J. M.; KAYED, R.; FAIGLE, M.; NEUMEISTER, B.; VOELTER, W. Isolation, Structural and a Functional Characterization of an apoptosis Inducing L-amino acid oxidase from Leaf-nosed Viper (Eristocophis macmahoni) Snake Venom. Arch. Bioch and Biophisycs, vol. 384, n 2, p 216-226, 2000.

AMARAL, A. Serpentes do Brasil: iconografia colorida. $2^{\text {a }}$ ed., Ed. Melhoramentos, São Paulo, 1977.

ARAKI, S.; ISHIDA, T.; YAMAMOTO, T.; KAJI, K.; HAYASHI, H. Inductions of apoptosis by hemorrhagic snake venom in vascular endothelial cells. Biochemical and Biophisical Research Communication. v. 190, p. 148 - 153, 1993.

ASSAKURA, M. T., REICHL, A. P., ASPERTI, M. C., MANDELBAUM, F. R., Isolation of the major proteolytic enzyme from the venom of the snake Bothrops moojeni (caissaca). Toxicon v 23, p. 691-706, 1985.

BJARNASSON, J. B., FOX, J. W. Hemorrhagic metalloproteinases from snake venos. Pharmacol. Ther. v 62, p. 325-372, 1994.

BARRAVIEIRA, B. Venenos Animais: uma visão integrada. Rio de Janeiro, EPUB, cap.63 p.97-105, 1994.

BRAUD, S.; BON, C.; WISNER, A. Snake venom acting on hemostasis. Biochimie v. 82, p. 851-859, 2000.

CARDOSO, J.L.C., et al., Animais Peçonhentos no Brasil: Biologia, Clínica e Terapêutica dos Acidentes, São Paulo: SARVIER, 2003.

COLES, C.J.; EDMONDSON, D.E.; SINGER, T.P. Reversible in activation of L-amino acid oxidase. Properties of the three conformational forms. J. Biol. Chem. v.252, p.80358039, 1977.

COOPER, A.J.L., PINTO, J.T. Aminotransferase, L-amino acid oxidase and $\beta$-lyase reactions involving L-cysteine S-conjugates found in allium extracts. Revelance to biological activity? Biochemical Pharmacology, v.69, p.209-220, 2005. 
COSTA, E. P., SANTOS, M.F. Jararhagin, a snake venom metalloproteinase-disintegrin, stomulates epithelial cell migration in na vitro restitution model. Toxicon, Vol.44, p. 861870, 2004.

CURTI, B.; MASSEY, V.; ZMUDKA, M. Inactivation of snake venom L-amino acid oxidase by freezing. Journal of Biological Chemistry. v. 243, p. 2306-2314, 1968.

CURTI, B.; RONCHI, S.; SIMONETTA, P.M. D- and L-amino acid oxidases. In: Mueller, F. Chemistry and Biochemistry of Flavoenzyme, v.3, Ed. CRC Press, Boca Roton, p.6994, 1992.

DE PASQUALE, A. Pharmacognosy: the oldest modern science. J. Ethnopharmacol. v. 11, p. 1 $-16,1984$.

DU, X.Y.,CLEMETSON,K.J. Snake venom L-amino acid oxidases. Toxicon, v.40, p. 659665,2002 .

DU, X. Y.; ZHANG, X. Y.; WV, X. F.; RUAN, K. C.; ZHOU, Y. C. Advances in the study of phospholipases A2 from Agkistrodon halys pallas J. Toxicol - Toxin Rev. v. 17, p. $17-22,1998$.

FERREIRA, M. L., MOURA-DASILVA, A. M., FRANCA, F. O., CARDOSO, J. L., MOTA, I. Toxic activities of venoms from nine Bothrops species and their correlation with lethality and necrosis. Toxicon v 30 p. $1603-1608,1992$.

FERREIRA, S.H. Angiotensin Converting Enzyme: History and Relevance. Sem. Perinatology. v. 24 (1), p. 7-10, 2000.

FRISCHAUF, A. M.; ECKSTEIN, F. Purification of a phosphodiesterase from Bothrops atrox by affinity chromatography. Eur J. Biochem. v. 32, p. 479-85, 1973.

GARTNER, T. K.; STOCKER, K.; WILLIAMS, D. C. Thrombolectin: a lectin isolated from Bothrops atrox venom. FEBS Lett. v. 117, p. 13-6, 1980.

GEWITZ, H. S.; PIEFKE, J.; LANGOWSKA, K.; VENNESLAND, B.; The formation of hydrogen cyanide from histidine in the presence of amino acid oxidase and peroxidase. Biochemtry and Biophisical Acta. v. 611, p. 11-26, 1980.

GUÉRCIO, R. A. P., SHEVCHENKO, A., SHEVCHENKO, A., LOPEZ-LOZANO, J. L., PAHA, J., SOUSA, M. V., RICART, C. A. O. Ontogenetic variation inthe venos proteome of the Amazonian snaki Bothrops atrox. Proteome Science 4:11, 2006.

GUTIERREZ, J.M.; CHAVES, F.;Proteolytic, hemorrhagic and myonecrotic effects of the venoms of Costa Rican snakes from the genera Bothrops, Crotalus and Lachesis. Toxicon V. 18 P. $315-321,1980$. 
GUTIERREZ, J. M., ROMERO, M., NUNEZ, J., CHAVES, F., BORKOW, G., MICHEL OVADIA. Skeletal Muscle Necrosis and Regeneration after Injection of BaH1, a Hemorrhagic Metalloproteinase Isolated from the Venom of the snake Bothrops asper (Terciopelo). Experimental and Molecular Pathology. V 62, p. 28-41, 1995.

HOFMANN, H., BON, C. Blood coagulation induced by the venom of Bothrops atrox. 2.Identification, purification and properties of two factor $\mathrm{X}$ activators. Biochemistry. $\mathrm{V}$ 26, p. $780-787,1987$.

HOMSI-BRANDEBURGO, M.I.; BORGES, M.H.; SOARES, A.S.; RODRIGUES, V. de M.; IZIDORO, LF.M.. Ação antipeçonha do extrato vegetal de Casearia sylvestris. Biotecnologia-Ciência e Desenvolvimento, v. 1, p.28-30, 1988.

IZIDORO, L. F. M.; RIBEIRO, M. C.; SOUZA, G. R. L.; SANT'ANA, C. D.; HAMAGUCHI, A.; HOMSI-BRANDEBURGO, I.; GOULART, L. R; BELEBONI, R. O.; NOMIZO, A.; SAMPAIO, S. V.; SOARES, A. M.; RODRIGUES, V. M. Biochemical and Functional Characterization of na L-amino acid oxidase isolated from Bothrops pirajai snake venom. Bioorg. Méd. Chem. in press, 2006.

KINI, R.M. Excitement ahead: structure, function and mechanism of snake venom phospholipase $\mathrm{A}_{2}$ enzymes. Toxicon v. 42, p. 827-840, 2003.

KINI. R. M.; EVANS, H. J. Effects os snake venom proteins on blood platelets. Toxicon v. 28, p. 1387-1422, 1990.

KIRBY, E. P.; NIEWIAROWSKI, S.; STOCKER, K.; KETTNER, C.; SHAW, E.; BRUDZYNSKI, T. M. Thrombocytin, a serine protease from Bothrops atrox venom 1. Purificatio and characterization of the enzyme. Biochemistry. v.18, p. 3564-70, 1979.

KOMMOJU, P. R.; MACHEROUX, P.; GHISLA, S. Molecular cloning, expression and purification of L-amino acid oxidase from the Malayan pit viper Calloselasma rhodostoma. Protein Expression and Purification. Article in press (2007).

KONDO, H.; KONDO, S.; IKEZAWA, H.; MURATA, R.; OHSAKA, A. Studies on the quantitative method for the determination of hemorrhagic activity of Habu snake venom. Jpn. J. Med. Sci. Biol., v.13, p.43-51, 1960.

LAEMMLI, U.K. Cleavage of structural proteins during the assembly of the head of bacteriophage $\mathrm{T}_{4}$. Nature 227, p. 680-685, 1970.

LEVY, L. Carrageenan paw edema in the mouse. Life Sci. v. 8 p. 601-606, 1969.

LI, Z. Y.; YU, T. F.; LIAN, E. C. Purification and characterization of L-amino acid oxidase from King cobra (Ophiophagus Hannah) venom and its effects on human platelet aggregation. Toxicon. v. 32, p. 1348-58, 1994. 
LOMONTE, B., GUTIERRZ, J. M. A new muscle damaging toxin myotoxin II, from the venom of the snake Bothrops asper (terciopelo). Toxicon v. 27 p. $725-733,1989$.

LU, Q., NAVDAEV, A., CLEMETSON, J. M., CLEMETSON, K, J. Snake venom C-type lectins interacting with platelet receptors. Structure-function relationships and effects on haemostasis. Toxicon v. 451089 - 1098, 2005.

MATSUI, T. FUJIMURA,; Y.; TITANI, K. Biochem Biophys Acta. v 1477, p. 146 - 156, 2000.

MAZZI, M. V., MARCUSSI, S., CARlOS, G.B., STÁBELI, R. G., FRANCO, J.J., TICLI, F. K., CINTRA, A.C.O., FRANÇA, S.C., SOARES, A. M., SAMPAIO, S.V. A new hemorrhagic metalloprotease from Bothrops jararacussu snake venom: isolation and biochemical characterization. Toxicon v. 44 p. 215 - 223, 2004.

MORA, R.; VALVERDE, B.; DÍAZ, C.; LOMONTE, B.; GUTIÉRREZ, J.M., A Lys49 phospholipase $\mathrm{A}_{2}$ homologue from Bothrops asper snake venom induces proliferation, apoptosis and necrosis in a lymphoblastoid cell line Toxicon, v. 45, p. $651-660,2005$.

MOSMANN, T. Rapid colorimetric assay for cellular growth and survival: application to proliferation and cytotoxicity assays., J.Imm. Methods, v.65, p. 55-63, 1983.

MOUSTAFA, I.M.; FOSTER, S.; LYUBIMOV, A.Y.; VRIELINK, A. Crystal structure of LAAO from Calloselasma rhodostoma with an L-phenylalanine substrate: insights into structure and mechanism., J. Mol. Biol, v.364, p. 991-1002, 2006.

NATHAN, I., DVILANSKY, A., YIRMIYAHU, T., AHARON, M., LIVNE, A. Impairment of a platelet aggregation by Echis colorata venom mediated by L-amino acid oxidase or $\mathrm{H}_{2} \mathrm{O}_{2}$. Thromb. Haemost. v 48, p. 277 - 282, 1982.

PANTIGOSO, C.; ESCOBAR, E.; MALAGA, O.; YARLEQUE, A. Isolation and some properties of the proteinase atroxin from the venos of the snake B.atrox.Acta Cient Venez. v.47, p. 67-73, 1996.

PESSATTI, M.; FONTANA, J.D.; FURTADO, M.F.; GUIMARÃES, M.F.; ZANETTE, L.R.; COSTA, W.T.; BARON, M. Screening of Bothrops snake venom for L-amino acid oxidase activity. Appl. Biochem. Biotechnol., v.51/52, p.197-210, 1995.

PIGNATElli, P., PUlCinelli, F.M., LENTI, L., GAZZANIGA, P.P., VIOLI, F. Hydrogen peroxide is involved in collagen-induced platelet activation. Blood. v.91, p. 484490, 1998.

PONNUDURAI, G.; CHUNG, M.C.; TAN, T.H. Purification and properties of the Lamino acid oxidase from Malayan pit viper (Calloselasma rhodostoma) venom. Arch. Biochem. Biophys., v.313, p.373-378, 1994. 
QUEIROZ, L.S., PETTA, C. A. Histophatological changes caused by venom of urutu snake (Bothrops alternatus) in mouse skeletal muscle. Rev. Inst. Med. Trop. Sao Paulo. v 26, p. 247- 253, 1984.

RAIBEKAS, A. A.; MASSEY, V. Primary structure of the snake venom L-amino acid oxidase shows high homology with the mouse B cell interleukin 4 - induced Fig 1 portein. Biochem. Biophys. Res. Commun. v. 248, p. 476 - 478, 1998.

RIBEIRO, L. A.; de CAMPOS, V. A.; ALBUQUERQUE, Mde J.; TAKAOKA, N.Y.; Snake bites in the state of São Paulo, Brazil. Rev Assoc Med Brás. v. 39, p. 4 - 7, 1993.

ROCHA E SILVA M.; BERALDO W.T.; ROSENFELD, G. Bradykinin, a hypotensive and smooth muscle stimulating factor released from plasma globulin by snake venoms and by trypsin. Am. J. Physiol. v. 156, p. 261-273, 1949.

RODRIGUES, F. G.; PETRETSKI, J. H.; KANASHIRO, M. M.; LEMOR, L.; DA SILVA, W. D.; KIPINS, T.L. The complement system is involved in acute inflammation but not in the hemorrhage produced by a $B$. atrox snake venom low molecular mass proteinase. Mol Immunol. v. 40, p. 1149-56, 2004.

ROSENFELD, G. Symptomatology, pathology and treatment of snake bites in South America. In: Venomous Animals and their Venoms. v.2, Ed. W. Burcherl and E. Bucley, New York, p.345, 1971.

SAMEL, M., VIJA, H., RONNHOLM, G., SIIGUR, J., KALKKINEN, N., SIIGUR, E. Isolation and characterization of an apoptotic and platelet aggregation inhibiting L-amino acid oxidase from Vipera berus berus (common viper) venom. Biochimica et Biophisica Acta 1764, 707 - 714, 2006.

SELISTRE, H.S.; GIGLIO, J.R.; HAMSI-BRANDEBURGO, M.I. Atividade anticoagulante de toxinas de venenos de Bothrops insularis e B. jararacussu. M. Inst. Butantan v. 52, p.73-74, 1990.

SOUZA, D.H.; EUGENIO, L.M.; FLETCHER, J.E.; JIANG, M.S.; GARRATT, R.C.; OLIVA, G.; SELISTRE-DE-ARAUJO, H.S. Isolation and structural characterization of a cytotoxic L-amino acid oxidase from Agkistrodon contortrix laticinctus snake venom: preliminary crystallographic data. Arch. Biochem. Biophys. v.368, p.285-290, 1999.

STÁBELI, R.G., MARCUSSI, S.;CARLOS, G.B.; PIETRO, R. C. L. R.; SELISTREARAÚJO, H. S.; GIGLIO, J. R.;.OLIVEIRA, E. B.; SOARES, A. M. Platelet aggregation and antibacterial effects of na L-amino acid oxidase purified from Bothrops alternatus snake venom. Bioorganical Medicinal Chemistry. V.12, p.2881-2886, 2004.

STABELI , R.G.; MAGAMLÃES, L.M.P.; SELISTRE-ARAÚJO, H.S.; SOARES, A.M.; OLIVEIRA, E.B. Antibodies to a fragment of the Bothrops moojeni L-amino acid oxidase cross-react with snake venoms components unrelated to the parent protein. Toxicon. in press, 2005. 
STILES, B. G.; SEXTON, F. W.; WEINTEIN, S. A.; Antibacterial effect of different snake venoms: purification and characterization of antibacterial protein from pseudochis asutralis (Australian king or mulga snake) venom. Toxicon v. 29, p. 1129 - 1141, 1991.

STOCKER, K; BARLOW, G. H. The coagulant enzyme from Bothrops atrox venom (batroxobin). Methods Enzymol v. 45, p. 214-23, 1976.

SUHR, S.M.; KIM, D.S. Comparison of the apoptotic pathways induced by L-amino acid oxidase and hydrogen peroxide. J. Biochem. v.125, p.305-309, 1999.

SUN, L.K.; YOSHII, Y.; HYODO, A.; TSURUSHIMA, H.; SAITO, A.; HARAKUNI, T.; LI, Y.P.; KARIYA, K.; NOZAKI, M.; MORINE, N. Apoptotic effect in the glioma cells induced by specific protein extracted from Okinawa Habu (Trimeresurus flavoviridis) venom in relation to oxidative stress. Toxicol. In Vitro v. 17, p. 169-77, 2003.

TAKATSUKA, H.; SAKURAI, Y.; YOSHIOKA, A.; KOKUBO, T.; USAMI, Y.; SUZUKI, M.; MATSUI, T.; TITANI, K.; YAGI, H.; MATSUMOTO, M.; FUJIMUKA, Y. Molecular characterization of L-amino acid oxidase from Agkistrodon halys blomhoffii with special reference to platelet aggregation. Biochem. Biophys Acta v. 1544, p. $267-$ $277,2001$.

TAN, N. H.; L-amino acid oxidases and lactate dehydrogenase, In: G.S. Bailey (ed) Enzynmes from snake venom, Atakem Inc, Fort Collins, C.O. p. 579 - 598, 1998.

TAN. N. H.; PONNUDURAI, G. A comparative study of the biological properties of some snake venoms. Compo. Biochem. Physiol. B. v. 99, p. 351 - 354, 1991.

TAN, N.H.; SAIFUDDIN, M.N. Isolation and characterization of na unusual form of Lamino acid oxidase from King cobra (Ophiophagus hannah) venom. Biochem. Int. v.19, p.937-944, 1989.

TAN, N.H.; SAIFUDDIN, M.N Substrate specificity of king cobra (Ophiophagus hannah) venom L-amino acid oxidase. Biochem. Int. v. 23. p. 323 - 327, 1991.

TAN, N.H.; SWAMINATHAN, S. Purification and properties of the L-amino acid oxidase from monocellate cobra (Naja naja kaouthia) venom. Int. J. Biochem. v.24, p.967-973, 1992.

TEMPONE, A.G.; ANDRADE Jr., H.F.; SPENCER, P.J.; LOURENÇO, C.O.; ROGERO, J.R.; NASCIMENTO, N. Bothrops moojeni venom kills Leishmania spp. With hydrogen peroxide generated by its L-amino acid oxidase. Biochem. Biophys. Res. Commun. v.280, p.620-624, 2001.

TICLI, F. K.; SOARES, A. M.; FRANCO, J. J.; SAMPAIO, S. V.; Caracterização Estrutural e Funcional da L-aminoácido oxidase do veneno de Bothrops jararacussu e avaliação da ação antitumoral, antiparasitária e bactericida. (Tese de doutorado), 2006. 
TORII, S.; NAITO, M.; TSURUO, T. Apoxin I, a novel apoptosis-inducing factor with Lamino acid oxidase activity purified from Western diamondback rattlesnake venom. J. Biol. Chem. v.272, p.9539-9542, 1997.

TORII, S.; YAMANE, K.; MASHIMA, T.; HAGA, N.; YAMAMOTO, K.; FOX, J. W.; NAITO, M.; TSURUO, T. Molecular cloning and functional análisis of apoxin I, a snake venom-derived apoptosis inducing factor L-amino acid oxidase activity. Biochemitry. v.12, p. 3197-205, 2000.

TOYAMA, M. H., TOYAMA, D. O., PASSERO, L. F. D., LAURENTI, M. D., CORBETT, C. E., TOMOKANE, T. Y., FONSECA, F. V., ANTUNES, E., JOAZEIRO, P. P., BERIAM, L. O. S., MARTINS, M. A. C., MONTEIRO, H. S. A., FONTELLES, M. C. Isolation of a new L-amino acid oxidase from Crotalus durissus cascavella venom Toxicon v. 47 p. 47-57, 2006.

VESTERBERG, O. Isoletric focusing of proteins in polyacrylamide gels. Biochem. Biophys Acta 257, p. 11-13, 1972.

ZHANG, Y, I.; WANG, J. H.; LEE, W. H.; WANG, Q. LIV, H.; ZHENG Y. T. ZHANG, Y. Molecular Characterization of Trimeresurus stejnegeri venom L-amino acid oxidase with potential anti-HIV activity. Biochem. Biophys. Res. Commun. v. 309, p. 598 - 604, 2003.

WILLIAMS, K.R. \& STONE, K.L. Enzymatic cleavage and HPLC peptide mapping of proteins. Mol Biotechnol. New Haven, v. 8, p.155-167, 1997.

WORLD HEALTH ORGANIZATION (1981) Progress in Characterization of Venoms and Standartization of Antivenoms. Geneva: World Health Organization. 